\title{
ECONOMICS
}

\section{Understanding International Price and Consumption Disparities}

by

\section{Long Hai Vo}

Economics Department, Business School, The University of Western Australia

Research Center in Business, Economics and Resources, HCMC Open University

Faculty of Banking, Finance and Business Administration, Quy Nhon University 


\title{
Understanding International Price and Consumption Disparities *
}

\author{
Long Hai $\mathrm{Vo}^{\dagger}$ \\ Economics Department, Business School, The University of Western Australia \\ Research Center in Business, Economics and Resources, HCMC Open University \\ Faculty of Banking, Finance and Business Administration, Quy Nhon University
}

\begin{abstract}
This study proposes a new measure of the tradability of $120+$ commodities based on price dispersion. This approach is used to construct price indices of tradables and non-tradables for $150+$ countries. The expenditure share of tradables is lower for richer countries, while the relative price of non-tradables, which plays an important role in the determination of real exchange rates, is higher. Secondly, a common-factor approach (based on principal components) is introduced to compress the large volume of information on prices and quantities consumed globally. We find that cross-commodity correlations are higher for prices than for consumption. In addition, income is responsible for $98 \%$ of the variation in the first principal component of consumption but explains only $24 \%$ of the first price component. This suggests consumption are driven primarily by domestic factors, while prices are determined by factors outside the country, along the lines of the Purchasing Power Parity theory.
\end{abstract}

JEL classifications: F40, E01, C43

Keywords: Economic measurement; Price and consumption; Principal component analysis; Tradability

\footnotetext{
*Acknowledgements: This paper is based on part of the author's Ph.D thesis at the University of Western Australia (UWA) (Vo, 2020), where he received financial support from an Australian Government Research Training Program Scholarship. Comments by Simon Chang, Chia-lin Chang, Ken Clements, Indrajit Coomaraswamy, Yihui Lan, James Lothian, Ranjan Ray, Jeffrey Sheen, Duc Vo and participants at the $3^{\text {rd }}$ Vietnam Business and Economics Research Conference at HCMC Open University, the $12^{\text {th }}$ International Research Conference at the Central Bank of Sri Lanka and various seminars at UWA help improve the paper. For provision of unpublished data, I thank the ICP administrators at the World Bank. All errors remain with the author.

${ }^{\dagger}$ Contact: Economics Department, Business School, UWA. 35 Stirling Highway, Crawley, WA 6009, Australia. Email: long.vo@uwa.edu.au.
} 


\section{INTRODUCTION}

It is an empirical regularity that due to productivity differentials, the price of services is systematically higher in developed countries than in less developed ones, while the price of tradable goods tends to be equalised internationally via arbitrage. However, various market frictions and barriers to trades stand in the way of complete equalisation of the prices of tradables, leading to cross-country price volatility. Recently, a growing body of literature has focused on examining this type of volatility (Feenstra et al., 2015; Inklaar and Rao, 2017), as well as the co-movement of prices across countries (de Nicola et al., 2016; Bunn et al., 2017). The main objective of this paper is to study, through a unified framework, these two aspects of international pricing patterns, i.e., cross-country dispersion in prices and price co-movements among commodities and commodity groups.

Our contributions to the literature are three-fold. First, we propose a new index that measures the degree of commodity tradability on the basis of price dispersion, which is strictly free of the unit of measurement effects. Second, based on this index, we are able to identify the composition of two important baskets of goods: Tradables and non-tradables. This leads to novel unit-free price and volume indices of these goods, which facilitates a re-examination of the classic productivity bias hypothesis as a prominent currency-value determinant. Third, by employing principal component analyses (hereafter, PCA) as an alternative to conventional index-number theory, we document strong co-movement of various elements of consumption which can be efficiently summarised by a common factor that is highly correlated with income. The corresponding common price factor captures a high proportion of the co-movement among prices, but shows a much weaker association with domestic income. Unlike the typical outcomes of PCA, these two factors have a clear economic interpretation. In particular, the price factor represents global forces such as trade and exchange-rate effects (consistent with the PPP theory). On the other hand, consumption is strongly influenced by local forces such as an income effect.

The remaining of this paper is structured as follows: Section 2 surveys the related literature. This is followed by Section 3 which discusses the dispersion of commodity prices and construct tradability indices. Section 4 illustrates the usefulness of these indices in explaining the productivity-bias theory of real-exchange-rate determination. Section 5 examines crosscountry drivers of prices and consumption using principal component analyses. Section 6 provides concluding comments. 


\section{RELATED LITERATURE}

If, when converted to a common currency, the price of a product is equal in two countries, a complete pass-though means domestic-currency prices will respond one-for-one to exchangerate changes, and the currency neutralises changes in prices in one country vis-à-vis another. This constitutes the fundamental basis of the concept of the "law of one price" (LOP) which is facilitated by arbitrage - the process of buying in the country in which the product is cheap and selling it where it is expensive. When prices are not equalised, prima facie, there is a deadweight efficiency loss that could be eliminated by transferring the product from the low-cost location to where it is more highly valued. ${ }^{1}$

When transportation costs are prohibitive, the goods and services are not traded internationally, that is, they become non-traded. Anderson and van Wincoop (2004) estimate that the total trade cost for a rich country to be approximated by a 170-percent ad-valorem tax. This encompasses both domestic (retail and wholesale distribution) and international (transport and border-related trade barriers) costs of about 55 percent and 74 percent, respectively. The authors draw upon a mixture of literature that employs direct and indirect (inferences from trade volumes and prices) measures to determine trade costs. However, they emphasise the incompleteness and sparseness of data available across countries. According to these authors, policies that directly affect trade, such as tariffs and quotas, are less important for trade costs than other policies such as those associated with transport infrastructure, property rights, regulation and language. Thus, in developing countries, where economic and institutional infrastructure can be lacking, trade costs are much higher. Trade costs also vary substantially across products.

An early explanation as to why relative prices of non-tradables co-vary positively with the level of development is offered by the Harrod-Balassa-Samuelson hypothesis (Harrod, 1939; Balassa, 1964; Samuelson, 1964) (hereafter, HBS) which attributes this phenomenon to the cross-country productivity gap in tradable sectors, which is wider than that in non-tradable sectors. ${ }^{2}$ Suppose that a country experiences productivity growth in its traded goods sector and the law of one price holds among traded goods only. Higher productivity in the traded goods sector means that these firms expand, add to their workforce, and in the process, pay higher

\footnotetext{
${ }^{1}$ The aggregated version of LOP is purchasing power parity (PPP), according to which the value of the country's currency equals the ratio of some macroeconomic index of prices at home to that abroad. For a recent review of LOP and its relation to PPP, see Marsh et al. (2012). For reviews of the PPP theory, see, among many others, Frenkel (1978), Dornbusch (1988), Rogoff (1996), Taylor and Taylor (2004) and Manzur (2008).

${ }^{2}$ Productivity differences might be a result of more productive firms (which focus on producing tradables) crowding out less productive firms (Bergin et al., 2006). They could also, according to Buera et al. (2011), be a result of misallocation of productive resources due to financial frictions. Sposi (2015) examines an exogenous source for this gap, namely, specialisation in the production of goods with high trade barriers: Because tradables can be intermediate inputs for other goods, this specialisation increases the measured productivity difference.
} 
wages. Higher wages are just matched by productivity, so nothing happens to the domestic price of traded goods, which is linked to the world price. Suppose also that the traded goods sector acts as the wage-leader, and so producers of non-traded goods have to match the higher wages paid by firms in the tradables sector. Assuming that productivity remains unchanged in non-tradables, the higherwages that producers of non-tradables must pay lead to higher overall costs, which have to be passed onto consumers in the formof higher prices of non-tradables. Because the prices of traded goods are unchanged while non-tradable prices rise, the end result is that higher productivity leads to a higher overall price level. As nothing happens to traded goods prices, there is no change in the exchange rate (again, this is assumed). A higher price level at home with a constant nominal rate means that a naïve application of PPP based on price levels would lead to the conclusion that the currency of the high-productivity country is overvalued (Lothian and Taylor, 2008).

Productivity bias is not the only source of price dispersion, however, nor are price differentials exclusive to non-tradable items. In fact, there is an accumulation of evidence which highlights the higher prices of tradable consumption goods in richer countries, as shown by Alessandria and Kaboski (2011) and Simonovska (2015). Simonovska (2015) argues that nonhomothetic preferences lead to high cross-country variation of price elasticities of demand for identical items. When trade barriers exist, monopolistic firms exert their pricing power to charge systematically higher mark-ups to more affluent consumers, who are less responsive to changes in the prices of tradables. Variable mark-ups, therefore, can also be a contributing factor to the seeming failure of the LOP in its absolute form (see also Froot and Rogoff, 1995; Crucini and Yilmazkuday, 2014). A further qualification to the HBS effect is recently identified by Hassan (2016), who documents a negative price-income relationship for low-income countries. As agriculture is a predominantly non-traded sector and as it represents a large share of expenditure in these countries, productivity growth in this sector could decrease (rather than increase) the overall price level, therefore inducing a "natural" real exchange-rate depreciation at the initial stages of the development path.

In broader terms, the relationship between exchange rates and prices is also crucial for regional economic comparisons and by extension, the evaluation of the United Nations' most important sustainable development goal, namely, poverty eradication. In part, at least, the measurement of poverty at the national level involves GDP per capita. These GDPs must obviously be expressed in terms of the same currency if they are to be compared with each other. But what set of exchange rates should be used for this purpose? International agencies tend to use some form of equilibrium exchange rates, typically based on a form of PPP. However, 
this approach to poverty measurement ignores differences in intra-national poverty, which can be substantial in some large, diverse countries. To deal with this issue, new demand system approaches to calculating intra-national PPPs based on reference utility in one region, have been proposed by Majumder et al. (2015), Rao et al. (2010) and Ray (2017, 2018), among others. Majumder et al. (2015) report substantial regional differences in PPPs in the cases of India and Vietnam. Relatedly, intra-national PPPs are important in policies designed to mitigate regional imbalances and resource misallocations, as pointed out by Chaudhuri and Sheen (2004). These authors study the Australia's states and territories, and find that when the exchange rate is flexible and inflation is not controlled, intra-national PPP does not hold.

Finally, there exist three studies that are closer to ours, which utilise PCA to construct indices that help solve a number of dimensionality issues in cross-country economic measurement. First, Oulton (2008) shows how to estimate a system of almost-ideal demand equations for 70 commodities, by compressing the price-elasticity parameter space from 70 to 6 (corresponding to the first 6 principal components) for each equation. These estimates enable the construction of a true cost-of-living index (Konüs, 1939) that is free from the classical path-dependence bias (Hulten, 1973). Second, Cuthbert (2009) examines and compares the properties of price and consumption indices derived from PCA, and finds that the underlying traits of data from the International Comparison Program, in particular the large negative price elasticities of demand, are useful for sorting countries into groups represented by consumption behaviour. Third, Ponomareva et al. (2019) shows that the first principal component of a panel of 15 exchange-rate series is strongly related to a time-varying set of economic fundamentals commonly used for exchange-rate modelling.

\section{Tradability and PRICE dispersion}

In this section, we examine the disparities of cross-country commodity prices adjusted for exchange-rate differentials. In logarithmic form, the deviation from the Law of One Price (LOP) parity is $k_{i, c}=\log p_{i, c}-\log p_{i}^{*}-\log S_{c}$, where $S_{c}$ denotes the market exchange rate between country c's currency and a reference currency $d, p_{i, c}$ is the price in c of commodity $i$, and $\mathrm{p}_{\mathrm{i}}^{*}$ is its price in $\mathrm{d}$. For example, the International Comparison Program (ICP) chooses the USD as the reference currency and normalises unit prices on the basis that U.S prices for all items are \$1 (Cuthbert, 2009).

An alternative specification is to treat all countries symmetrically, as proposed by Betts and Kehoe (2017), and construct deviations for all possible country pairs for each item as:

$$
k_{c, d}=\log p_{c}-\log p_{d}-\log S_{c}-\log S_{d}(c, d=1 \ldots C ; c<d),
$$


where the subscripts $\mathrm{c}$ and $\mathrm{d}$ refer to the country pair, and $\mathrm{C}$ denotes the total number of countries. $S_{c}$ and $S_{d}$ refer to the local currency unit (LCU) costs of $\$ 1$ in c and d, respectively. The absolute LOP then implies that $\mathrm{k}_{\mathrm{c}, \mathrm{d}}=0(\forall \mathrm{c}, \mathrm{d})$, while positive (negative) values indicate over-valuation (under-valuation) of $\mathrm{c}$ with respect to $\mathrm{d}$, for the commodity in consideration. A reasonable criterion for LOP to hold, in relative terms, is that the distribution of $\mathrm{k}_{\mathrm{c}, \mathrm{d}}$ tightly centers around zero. The lower the standard deviation, the stronger the degree to which crosscountry prices coincide, and it can be inferred that the commodity is more tradable. This approach is also supported by earlier empirical work that suggests the degree of international commodity arbitrage should be higher for tradables than nontradables (e.g., Goldstein and Officer, 1979). ${ }^{3}$

This approach is illustrated using the 12 broad household consumption categories published by the ICP for 155 countries (World Bank, 2013b). ${ }^{4}$ This leads to a total of $(155 \times 154) / 2=$ 11, 935 unique bilateral relationships. Results are presented in Table 3.1 where items are ranked according to increasing dispersion of prices [given in column (8)]. Items which contains a high proportion of non-tradable inputs, such as "Education", "Housing and Utilities" and "Health" exhibit higher deviations from LOP, as expected. Note also the relative importance of these three categories - on average, they account for about one quarter of total consumption, as seen from column (3). On the basis of standard deviation of $\mathrm{k}_{\mathrm{c}, \mathrm{d}}$, "Transport" is the most tradable, while "Education" is the least tradable.

As described in Section 2, the HBS hypothesis is contingent upon the tradable/nontradable dichotomy. A simple approach to the tradable and non-tradable identification is to rely on the extent to which a good is actually traded on the basis of our measure of price dispersion. This approach will be followed later in the paper. ${ }^{5}$ Figure 3.1 summarises the dispersion of $\mathrm{k}_{\mathrm{c}, \mathrm{d}}(\mathrm{c}>\mathrm{d})$ for 125 items at the disaggregated basic heading level, with a selection of item names displayed. It can be seen that the arrangement of the items in terms of price dispersion is in broad agreement with that of Table 3.1. For example, items exhibiting a large dispersion of deviations, such as "Medical services" or "Housing rents" imply that they have a substantial non-traded component, while items in the categories of communication equipment or food can be considered as more tradable. Interestingly, while many transportation services

\footnotetext{
${ }^{3}$ The tradable/nontradable dichotomy is a central element in a vast literature, with relevance for, among other themes, the determination of inflation in open economies (Cross and Laidler, 1976), the effects of exchange-rate valuation (Dornbusch, 1973; Salter, 1959), and the estimation of international trade flows (Murray and Ginman, 1976). In Section 4.1, we cover related implications for the productivity bias in the PPP theory of exchange rates.

${ }^{4}$ Details regarding the source, the construction, and adjustments of these data can be found in Appendix A1.

${ }^{5}$ It is important to emphasise that we are using consumer prices that almost always contain certain non-tradable components, such as local distribution margins. However, the importance of traded goods has risen since 1990s (Fieleke, 1995; Frankel et al., 2012).
} 
Table 3.1: Price Dispersion, 12 Consumption Categories, 155 Countries

\begin{tabular}{|c|c|c|c|c|c|c|c|}
\hline \multirow[b]{2}{*}{$\begin{array}{c}\text { Category Name } \\
\text { (1) }\end{array}$} & \multirow[b]{2}{*}{$\begin{array}{c}\text { Share of } \\
\text { GDP (\%) } \\
(2)\end{array}$} & \multirow[b]{2}{*}{$\begin{array}{c}\text { Share of } \\
\text { consumption (\%) } \\
\text { (3) }\end{array}$} & \multicolumn{5}{|c|}{ LOP deviation } \\
\hline & & & $\begin{array}{l}\text { Min } \\
(4)\end{array}$ & $\begin{array}{l}\operatorname{Max} \\
(5)\end{array}$ & $\begin{array}{l}\text { Median } \\
\text { (6) }\end{array}$ & $\begin{array}{l}\text { Mean } \\
(7)\end{array}$ & $\begin{array}{l}\text { SD } \\
(8)\end{array}$ \\
\hline 1. Transport & 7.07 & 10.87 & -1.27 & 1.48 & -0.07 & -0.05 & 0.38 \\
\hline 2. Food & 18.94 & 29.11 & -1.53 & 1.21 & -0.08 & -0.09 & 0.39 \\
\hline 3. Furnishings & 3.53 & 5.43 & -1.54 & 1.25 & -0.19 & -0.19 & 0.45 \\
\hline 4. Recreation \& culture & 3.19 & 4.90 & -1.56 & 1.37 & -0.16 & -0.16 & 0.46 \\
\hline 5. Miscellaneous & 5.01 & 7.70 & -1.75 & 1.42 & -0.21 & -0.21 & 0.50 \\
\hline 6. Alcohols \& tobacco & 2.30 & 3.54 & -2.22 & 1.95 & -0.13 & -0.13 & 0.52 \\
\hline 7. Restaurants \& hotels & 3.41 & 5.24 & -2.16 & 1.65 & -0.17 & -0.18 & 0.54 \\
\hline 8. Communication & 2.19 & 3.37 & -2.08 & 1.68 & -0.13 & -0.14 & 0.55 \\
\hline 9. Clothing \& footwear & 3.37 & 5.18 & -2.20 & 1.55 & -0.28 & -0.29 & 0.57 \\
\hline 10. Health & 2.60 & 4.00 & -2.74 & 2.35 & -0.37 & -0.38 & 0.73 \\
\hline 11. Housing \& utilities & 11.82 & 18.16 & -3.15 & 2.50 & -0.14 & -0.16 & 0.82 \\
\hline 12. Education & 1.62 & 2.49 & -3.93 & 3.76 & -0.22 & -0.23 & 1.28 \\
\hline 13. All household consumption & 65.05 & 100 & -3.93 & 3.76 & -0.17 & -0.19 & 0.65 \\
\hline 14. Gross domestic product & 100 & & -1.61 & 1.37 & -0.15 & -0.16 & 0.52 \\
\hline
\end{tabular}

1. The first 12 rows refer to the consumption categories listed under the "Individual Consumption Expenditure By Households" category published by the ICP (World Bank, 2013a). The second-to-last row refers to all items combined and the last row refers to the price indices for GDP.

2. Columns (2) - (3): Averages over countries.

3. Columns (4) - (6): Summary statistics of deviations from the LOP which, for a given category, is $\mathrm{k}_{\mathrm{c}, \mathrm{d}}=$ $\log \mathrm{p}_{\mathrm{c}}-\log \mathrm{p}_{\mathrm{d}}-\log \left(\mathrm{S}_{\mathrm{c}} / \mathrm{S}_{\mathrm{d}}\right)(\mathrm{c}, \mathrm{d}=1, \ldots, 155 ; \mathrm{c}<\mathrm{d}) . \mathrm{p}_{\mathrm{c}}$ and $\mathrm{p}_{\mathrm{d}}$ are prices of the item in countries $\mathrm{c}$ and $\mathrm{d}$, and $S_{c}$ and $S_{d}$ are the corresponding market exchange rates. For each item, there are $[155 \times(155-1)] / 2=11,935$ observations, which are the elements in the upper triangle of a skew-symmetric matrix $\mathbf{K}=\left[\mathrm{k}_{\mathrm{c}, \mathrm{d}}\right]$. The items are ranked in order of increasing standard deviation of $\mathrm{k}_{\mathrm{c}, \mathrm{d}}$.

are non-tradable (as expected), when combining with transport equipment and vehicles (which are tradable), the aggregate "Transport" group becomes the most tradable according to Table 3.1 .

But how large should the price dispersion be for an item to be classified as effectively "non-tradable"? In Figure 3.2, we present the cumulative number and total expenditure of items as a function of a cut-off value, denoted as $\omega$, that defines the traded/non-traded distinction. In particular, a good is defined as tradable if the corresponding standard deviation of $\mathrm{k}_{\mathrm{c}, \mathrm{d}}$ is larger than $\omega$. If we increase this cut-off, the pool of non-tradables shrinks. We opt to increase $\omega$ by a step of 1 percent in a range from 0 to 130 percent. ${ }^{6}$ According to Lombardo and Ravenna (2012), the share of the tradable sector, in terms of final goods for consumption, has an average value of between 49 and 55 percent. We specify that $\omega=70 \%$, on the basis that this value leads to a total share of tradables of approximately 50\% (as shown in panel A of Figure 3.2), which is the average threshold reported by Lombardo and Ravenna (2012). Further support for this choice of the cut-off is that international trade costs typically manifest into a $70 \%$ difference in the price of identical items (Anderson and van Wincoop, 2004).

Next, let the tradable share in country c be denoted by $w_{c}^{T}=\left(\Sigma_{i \in T} M_{i, c}\right) / M_{c}$ where $M_{i, c}$ and $\mathrm{M}_{\mathrm{c}}$ are the expenditures that people in $\mathrm{c}$ devote to $\mathrm{i}$ and all items, respectively. The non-

\footnotetext{
${ }^{6}$ The upper bound corresponds to the maximum standard deviation of prices.
} 
Figure 3.1: Price Dispersion, 125 Basic Headings, 155 Countries

120. Other edible oils and fats

113. Cheese

106. Food products nec

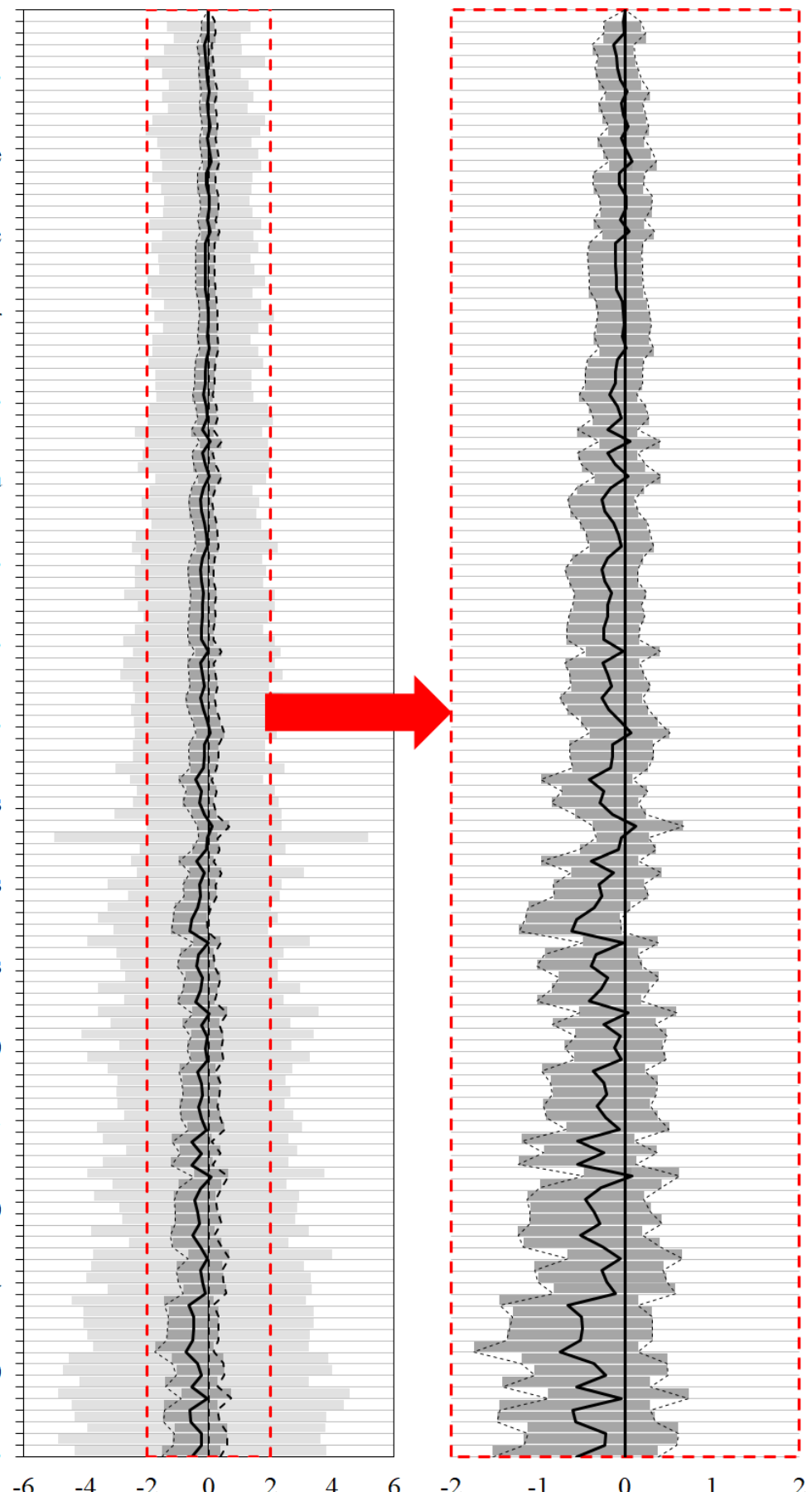

64. Telephone and telefax services

57. Motor cycles

50. Fresh or chilled potatoes

43. Other fuels

36. Transport (sea \& waterway)

29. Miscellaneous services dwelling

22. Transport (road)

15. Passenger transport by railway

8. Housing rents (actual \& imputed)

1. Medical services

Notes: This figure presents the distributions of deviations from the LOP for 125 basic headings across 155 countries. For each item $i$, this variable is defined as: $k_{c, d}=\log p_{c}-\log p_{d}-\log \left(S_{c} / S_{d}\right)(c, d=1, \ldots 155 ; c<d)$, so that there are 11,935 pairwise observations (given in each shaded bar of the figure). A selection of item numbers and names are given on the far left.

1. Left panel: The solid middle line is the median. The dark shaded area indicates the inter-quartile range (IQR). The light shaded area indicates the full range.

2. Right panel: A "blow-up" of the left which reproduces the median and IQR.

tradable share is $\mathrm{w}_{\mathrm{c}}^{\mathrm{N}}=\left(\sum_{\mathrm{i} \in \mathrm{N}} \mathrm{M}_{\mathrm{ic}}\right) / \mathrm{M}_{\mathrm{c}}=1-\mathrm{w}_{\mathrm{c}}^{\mathrm{T}}$. Then, a cross-country unweighted average of tradable shares is $\mu^{\mathrm{T}}=(1 / \mathrm{C}) \sum_{\mathrm{c}=1}^{\mathrm{C}} \mathrm{w}_{\mathrm{c}}^{\mathrm{T}}$ and the non-tradable counterpart is $\mu^{\mathrm{N}}=1-\mu^{\mathrm{T}}$. According 
Figure 3.2: Tradability, Price Dispersion, Budget Shares and Income

A. Tradability and Price Dispersion

Total world share

of tradables (\%)

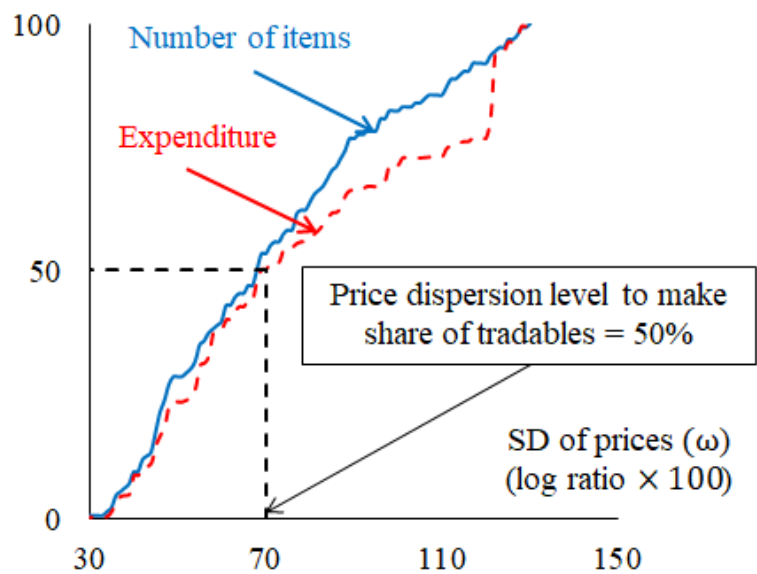

B. Budget Share and Income

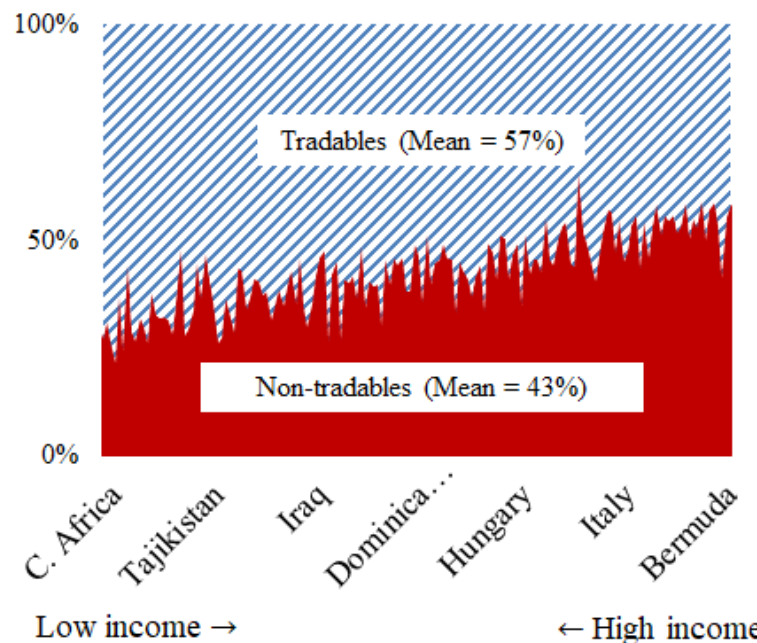

$\mathrm{P}^{\mathrm{N}} / \mathrm{P}^{\mathrm{T}}$

C. Relative Price of Non-tradables and Income

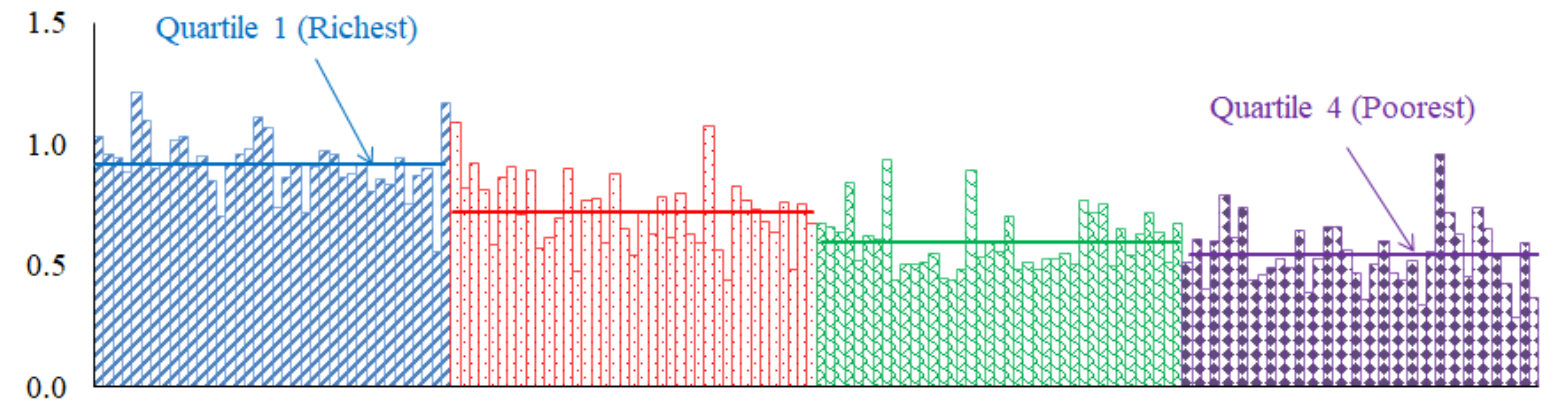

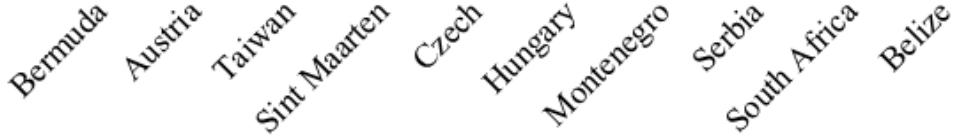

High income $\rightarrow$

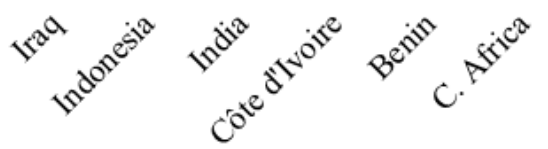

$\leftarrow$ Low income

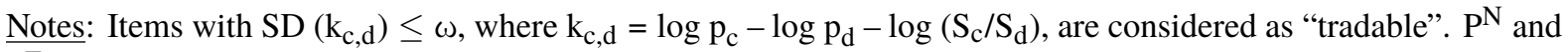
$\mathrm{P}^{\mathrm{T}}$ are constructed price indices of non-tradables and tradables, respectively.

1. Panel A: The number of tradable items and their cumulative share in total expenditure (in \$US) increases with the wider bandwidth $(\omega)$. For each item, total expenditure is computed by summing across countries.

2. Panel B: The shares of tradables and non-tradables across countries, as the sum of expenditures of items belonging to these baskets, on the basis of choosing $\omega=70 \%$. The unweighted mean tradable share is $\mu^{\mathrm{T}}=(1 / \mathrm{C}) \Sigma_{\mathrm{c}=1}^{\mathrm{C}} \mathrm{w}_{\mathrm{c}}^{\mathrm{T}}$ $(c=1, \ldots, 155)$, where $w_{c}^{T}$ is the share of tradables in $c . \mu^{N}=1-\mu^{T}$ denotes the mean share of non-tradables. Countries are ordered by increasing per capita income. 3. Panel $C$ : The ratio of non-tradable and tradable prices. Countries are ordered by decreasing per capita income. Horizontal lines indicate quartile-specific means.

to our computations, $\mu^{\mathrm{T}}=57 \%$ while $\mu^{\mathrm{N}}=43 \%$, as shown in panel B of Figure 3.2. These averages are, again, close to those dodumented by Lombardo and Ravenna (2012). ${ }^{7}$ Having defined which individual items are "tradable", we construct budget-share weighted indices of

\footnotetext{
${ }^{7}$ How do these values relate to the 50-percent share of tradables across all items and countries (as indicated in panel A, Figure 3.2)? If we instead use a country-specific budget share-weighted average, we have: $\mu^{\mathrm{T}^{\prime}}=$ $\Sigma_{\mathrm{c}=1}^{\mathrm{C}} \mathrm{w}_{\mathrm{c}}^{\mathrm{T}}\left(\mathrm{M}_{\mathrm{c}} / \mathrm{M}\right)=\Sigma_{\mathrm{c}=1}^{\mathrm{C}} \frac{\sum_{\mathrm{i}=1}^{\mathrm{n}_{\mathrm{T}}} \mathrm{M}_{\mathrm{i}, \mathrm{c}}}{\mathrm{M}_{\mathrm{c}}} \times \frac{\mathrm{M}_{\mathrm{c}}}{\mathrm{M}}=\Sigma_{\mathrm{c}=1}^{\mathrm{C}} \Sigma_{\mathrm{i}=1}^{\mathrm{n}_{\mathrm{T}}} \mathrm{M}_{\mathrm{i}, \mathrm{c}} / \mathrm{M}=50 \%$ where $\mathrm{n}_{\mathrm{T}}$ denotes the number of tradable items, so that $\mu^{\mathrm{N}^{\prime}}=1-\mu^{\mathrm{T}^{\prime}}=50 \%$.
} 
the prices of tradables and non-tradables, denoted as $\log \mathrm{P}_{\mathrm{c}}^{\mathrm{T}}$ and $\log \mathrm{P}_{\mathrm{c}}^{\mathrm{N}} \cdot 8$ As shown in panel $\mathrm{C}$ of Figure 3.2, the average of the ratio $\mathrm{P}^{\mathrm{N}} / \mathrm{P}^{\mathrm{T}}$ tends to fall as income falls, implying that non-tradables are relatively cheaper in richer countries. From these indices, we can reconstruct the overall price level of country $\mathrm{c}$ as:

$$
\begin{aligned}
& \mathrm{w}_{\mathrm{c}}^{\mathrm{T}} \log \mathrm{P}_{\mathrm{c}}^{\mathrm{T}}+\mathrm{w}_{\mathrm{c}}^{\mathrm{N}} \log \mathrm{P}_{\mathrm{c}}^{\mathrm{N}}=\log \mathrm{P}_{\mathrm{c}} \text {, or equivalently, } \\
& \mathrm{w}_{\mathrm{c}}^{\mathrm{T}} \log \widetilde{\mathrm{P}}_{\mathrm{c}}^{\mathrm{T}}+\mathrm{w}_{\mathrm{c}}^{\mathrm{N}} \log \widetilde{\mathrm{P}}_{\mathrm{c}}^{\mathrm{N}}=\log \widetilde{\mathrm{P}}_{\mathrm{c}}=0,
\end{aligned}
$$

where $\log \widetilde{\mathrm{P}}_{\mathrm{c}}^{\mathrm{T}}=\log \mathrm{P}_{\mathrm{c}}^{\mathrm{T}}-\log \mathrm{P}_{\mathrm{c}}$ and $\log \widetilde{\mathrm{P}}_{\mathrm{c}}^{\mathrm{N}}=\log \mathrm{P}_{\mathrm{c}}^{\mathrm{N}}-\log \mathrm{P}_{\mathrm{c}}$, termed "adjusted prices", are the prices of tradables and non-tradables' relative to the overall price level. It can be shown that the adjusted price level in each country is unity $\left(\widetilde{\mathrm{P}}_{\mathrm{c}}=1 \forall \mathrm{c}\right)$ which satisfies PPP.

\section{THE PRODUCTIVITY BIAS REVISITED}

Using a simple analytical framework, this section illustrates how the price indices of tradables and non-tradables constructed in Section 3 can help explain movements of real exchange rates. First, define price levels at the home country $c$ and abroad as $\mathrm{P}_{\mathrm{c}}=\left[\mathrm{P}_{\mathrm{c}}^{\mathrm{N}}\right]^{\mathrm{w}_{\mathrm{c}}^{\mathrm{N}}}\left[\mathrm{P}_{\mathrm{c}}^{\mathrm{T}}\right]^{1-\mathrm{w}_{\mathrm{c}}^{\mathrm{N}}}$ and $\mathrm{P}_{*}=\left[\mathrm{P}_{*}^{\mathrm{N}}\right]^{\mathrm{w}_{*}^{\mathrm{N}}}\left[\mathrm{P}_{*}^{\mathrm{T}}\right]^{1-\mathrm{w}_{*}^{\mathrm{N}}}$, where $\mathrm{w}_{\mathrm{c}}^{\mathrm{N}}=1-\mathrm{w}_{\mathrm{c}}^{\mathrm{T}}$ and $\mathrm{w}_{*}^{\mathrm{N}}=1-\mathrm{w}_{*}^{\mathrm{T}}$ are the expenditure shares of non-tradables in the two countries. Rearranging these terms and converting them into the same currency we have: $\mathrm{P}_{\mathrm{c}}=\mathrm{P}_{\mathrm{c}}^{\mathrm{T}}\left(\mathrm{P}_{\mathrm{c}}^{\mathrm{N}} / \mathrm{P}_{\mathrm{c}}^{\mathrm{T}}\right)^{\mathrm{w}_{\mathrm{c}}^{\mathrm{N}}}$ and $\mathrm{SP}_{*}=\mathrm{SP}_{*}^{\mathrm{T}}\left(\mathrm{P}_{*}^{\mathrm{N}} / \mathrm{P}_{*}^{\mathrm{T}}\right)^{\mathrm{w}_{*}^{\mathrm{N}}}$ where $\mathrm{S}$ denotes the local-currency-unit price of one foreign currency unit. In logarithmic form, the price ratio

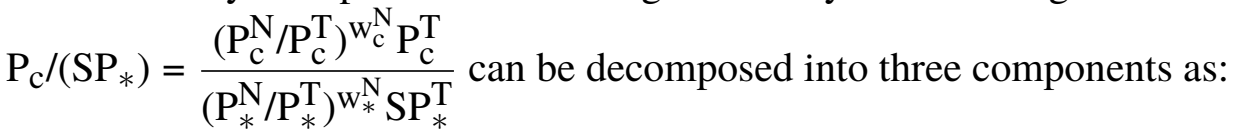

$$
\underbrace{\log \left(\frac{\mathrm{P}_{\mathrm{c}}}{\mathrm{SP}_{*}}\right)}_{\begin{array}{c}
\text { Real appreciation } \\
\text { of domestic currency }
\end{array}}=\underbrace{\mathrm{w}_{\mathrm{c}}^{\mathrm{N}} \log \left(\mathrm{P}_{\mathrm{c}}^{\mathrm{N}} / \mathrm{P}_{\mathrm{c}}^{\mathrm{T}}\right)}_{\begin{array}{c}
\text { Domestic } \\
\text { relative price } \\
\text { of non-tradables }
\end{array}}-\underbrace{\mathrm{w}_{*}^{\mathrm{N}} \log \left(\mathrm{P}_{*}^{\mathrm{N}} / \mathrm{P}_{*}^{\mathrm{T}}\right)}_{\begin{array}{c}
\text { Foreign } \\
\text { relative price } \\
\text { of non-tradables }
\end{array}}+\underbrace{\left(\log \mathrm{P}_{\mathrm{c}}^{\mathrm{T}}-\log \mathrm{P}_{*}^{\mathrm{T}}-\log \mathrm{S}\right)}_{\begin{array}{c}
\text { Real appreciation } \\
\text { of domestic tradables }
\end{array}} \text {. }
$$

Further assuming that the shares of tradable are the same in the two countries $\left(\mathrm{w}_{\mathrm{c}}^{\mathrm{T}}=\mathrm{w}_{*}^{\mathrm{T}}\right)$ and PPP holds for tradable goods (so that the third component vanishes), (4.1) simplifies to $\log \left(\mathrm{P}_{\mathrm{c}} / \mathrm{SP}_{*}\right)=\mathrm{w}_{\mathrm{c}}^{\mathrm{N}}\left[\log \left(\mathrm{P}_{\mathrm{c}}^{\mathrm{N}} / \mathrm{P}_{\mathrm{c}}^{\mathrm{T}}\right)-\log \left(\mathrm{P}_{*}^{\mathrm{N}} / \mathrm{P}_{*}^{\mathrm{T}}\right)\right]$. If productivity in the tradable sector is higher in the foreign country, while the cross-country non-tradables' productivity gap is negligible, domestic non-tradables will be relatively cheaper, i.e., $\mathrm{P}_{\mathrm{c}}^{\mathrm{N}} / \mathrm{P}_{\mathrm{c}}^{\mathrm{T}}<\mathrm{P}_{*}^{\mathrm{N}} / \mathrm{P}_{*}^{\mathrm{T}}$. This implies a lower purchasing power of the domestic currency: $\log \left(\mathrm{P}_{\mathrm{c}} / \mathrm{SP}_{*}\right)<0$. This phenomenon is referred to as the "Harrod-Balassa-Samuelson effect" (HBS) or the productivity-bias effect. 9

\footnotetext{
${ }^{8}$ Appendix A3 shows how our multilateral price indices can be constructed from bilateral budget-share weighted indices using the ICP's approach. Note that consumption units and currency units drop out of our indices, and we can use them directly in a cross-country comparison.

${ }^{9}$ Deaton and Aten (2017) (p.244) succinctly summarise this classical empirical regularity as: “Non-traded goods are typically cheaper in poorer economies, so that PPPs are typically lower than exchange rates for poor countries,
} 
A version of the above two-country, two-sector setting can be illustrated in Figure 4.3 (Clements and Lan, 2007, p. 472). In order to isolate the impact of differing relative price structures, we assume that the monetary side of the economy is the same in the two countries in the sense that both countries share the same absolute-price schedule (AA). Without loss of generality, let $\mathrm{P}_{*}$ now refers to a reference variable, a "world" price level. As before, assume that the "Rich" foreign country is more productive in making both goods, but relatively more so for tradables. As shown on the right-hand quadrant of Figure 4.3, a productivity differential is represented by a lower slope of the ray $\mathrm{OR}_{\mathrm{Rich}}$ than that of the ray $\mathrm{OR}_{\text {Poor }}$, i.e., $\left(\mathrm{P}^{\mathrm{N}} / \mathrm{P}^{\mathrm{T}}\right)_{\text {Rich }}>\left(\mathrm{P}^{\mathrm{N}} / \mathrm{P}^{\mathrm{T}}\right)_{\text {Poor }}$. If the nominal exchange rates (ERs) are solely determined in the market for traded goods, on the basis of Equation (3.1), the slope of the $\mathrm{OE}_{\mathrm{Rich}}$ ray is also lower than the $\mathrm{OE}_{\text {Poor }}$ ray, as shown on the left-hand quadrant. Keeping the world price level at $\mathrm{P}^{*}$, this means it costs more to buy a "world" currency unit with "Poor's" currency than with "Rich's" currency. ${ }^{10}$

Figure 4.3: Nominal Exchange Rates and Prices

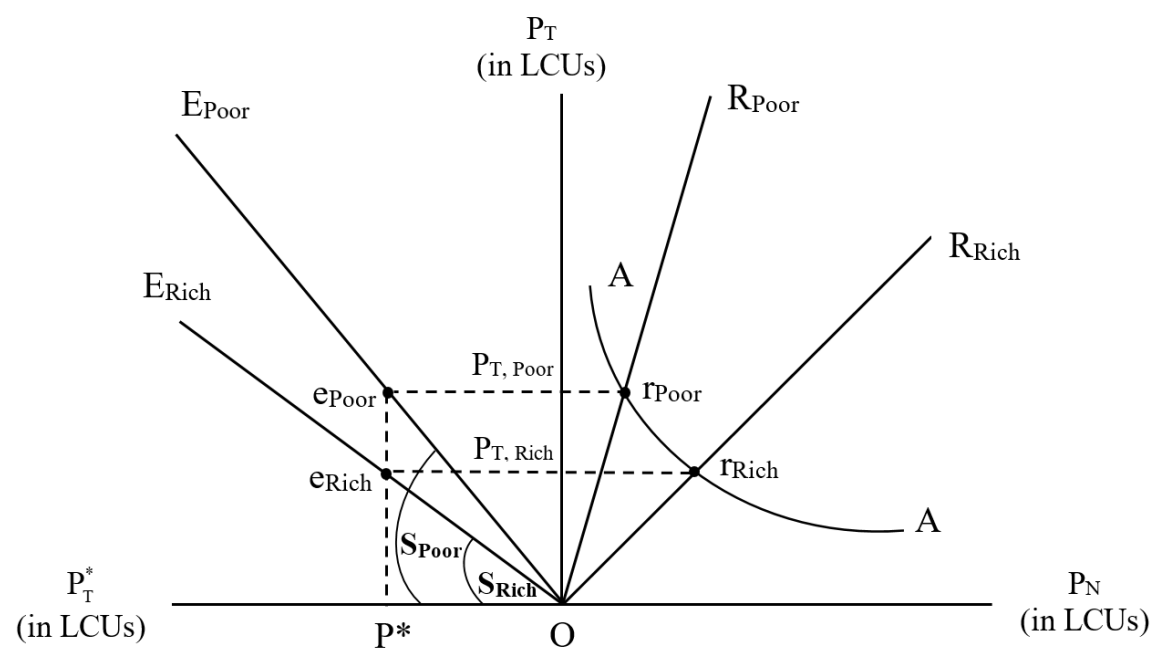

Notes: There are two countries: Rich and Poor, and two items: Tradable $(\mathrm{T})$ and Non-tradable $(\mathrm{N}) . \mathrm{P}^{\mathrm{T}}$ and $\mathrm{P}^{\mathrm{N}}$ denote the prices of $\mathrm{T}$ and $\mathrm{N}$ in local currency units (LCUs). The curve AA is the absolute-price schedule, which represents combinations of $\mathrm{P}^{\mathrm{T}}$ and $\mathrm{P}^{\mathrm{N}}$ consistent with a given price level. The PPP exchange rates for these countries are represented by the slopes of the two rays on the left-hand quadrant, $\mathrm{P}_{\mathrm{c}}^{\mathrm{T}} / \mathrm{P}_{*}^{\mathrm{T}}(\mathrm{c}=$ Poor, Rich $)$, where $\mathrm{P}_{*}^{\mathrm{T}}$ denotes the world price of tradables.

We can enrich Figure 4.3 with estimates of the slopes of price schedules using ICP data. In this setting, $\mathrm{P}_{\mathrm{c}}^{\mathrm{T}}$ and $\mathrm{P}_{\mathrm{c}}^{\mathrm{N}}$ represent the price indices of tradables and non-tradables constructed in Section 3. A country is classified as "Poor" ("Rich") if its income per capita is less (greater) than the world's median income. Panel A of Figure 4.4 presents a scatter plot and are more so the poorer the country".

${ }^{10}$ Equivalently, the difference in the slopes of the rays can also be interpreted as indicating the magnitude of ER appreciation when we move from"Poor" to "Rich". 
of $\mathrm{P}_{\mathrm{c}}^{\mathrm{T}}$ against $\mathrm{P}_{\mathrm{c}}^{\mathrm{N}}(\mathrm{c}=1, \ldots, 155)$. The fitted regression line for "Poor" countries takes the form $\mathrm{P}_{\text {Poor }}^{\mathrm{T}}=\mathrm{C}_{1}+0.45 \mathrm{P}_{\text {Poor }}^{\mathrm{N}}$, while the corresponding relative-price schedule for the "Rich" is $\mathrm{P}_{\text {Rich }}^{\mathrm{T}}=\mathrm{C}_{2}+0.3 \mathrm{P}_{\text {Rich }}^{\mathrm{N}}$, where $\mathrm{C}_{1}$ and $\mathrm{C}_{2}$ are non-zero intercepts. For simplicity, we do not show these intercepts in panel A.

Figure 4.4: Real Exchange Rates and Prices
A. $\underline{\text { Relative Price Schedules }}$
B. Absolute Price Schedule
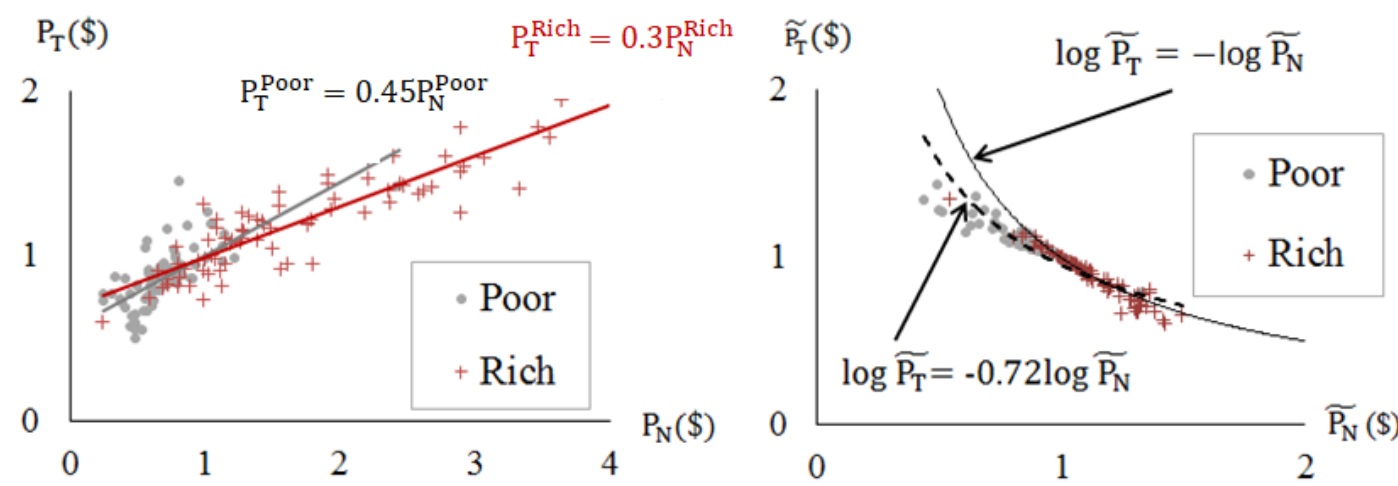

C. Real Exchange Rates and Price Schedules

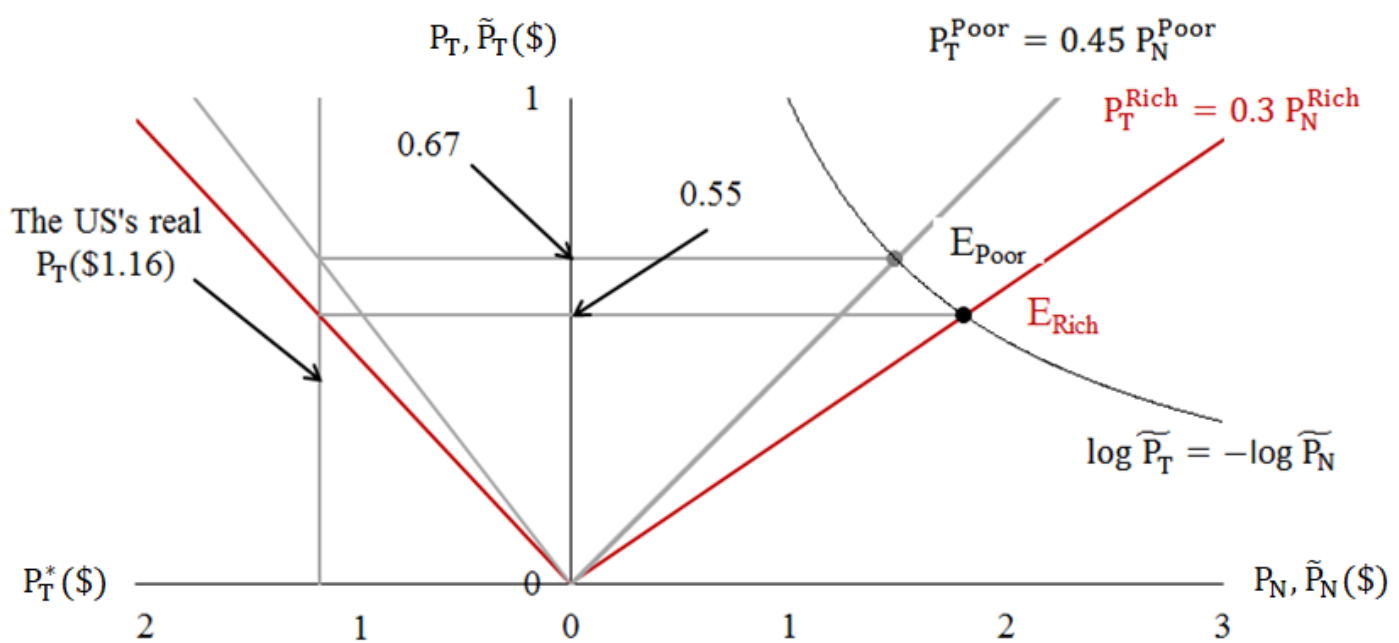

Notes:

1. There are two groups of countries: Rich and Poor, and two groups of items: Tradables and nontradables. Tradables are defined based on results presented in Figure 3.2. $\mathrm{P}_{\mathrm{T}}$ and $\mathrm{P}_{\mathrm{N}}$ denote the share-weighted average prices of tradables and non-tradables. $\widetilde{\mathrm{P}}_{\mathrm{T}}$ and $\widetilde{\mathrm{P}}_{\mathrm{N}}$ denote prices adjusted for overall price levels.

2. Panels $A$ and $B$ : Interpretations of these panels are similar to that of Figure 4.3.

3. Panel $C$ : The right-hand quadrant presents the fitted relative-price schedules of Rich and Poor. The left-hand quadrant indicates the the real exchange rates of Rich and Poor's currencies relative to the USD. See text for details.

To construct panel B of Figure 4.4, assume that all countries share the same absolute-price schedule:

$$
\log \widetilde{\mathrm{P}}_{\mathrm{c}}^{\mathrm{T}}=\left(-\mathrm{w}_{\mathrm{c}}^{\mathrm{N}} / \mathrm{w}_{\mathrm{c}}^{\mathrm{T}}\right) \log \widetilde{\mathrm{P}}_{\mathrm{c}}^{\mathrm{N}}(\mathrm{c}=1, \ldots, 155),
$$


where, as defined in Section 3, $\log \widetilde{\mathrm{P}}_{\mathrm{c}}^{\mathrm{T}}=\log \mathrm{P}_{\mathrm{c}}^{\mathrm{T}}-\log \mathrm{P}_{\mathrm{c}}$ and $\log \widetilde{\mathrm{P}}_{\mathrm{c}}^{\mathrm{N}}=\log \mathrm{P}_{\mathrm{c}}^{\mathrm{N}}-\log \mathrm{P}_{\mathrm{c}}$ are the adjusted prices and $\mathrm{w}_{\mathrm{c}}^{\mathrm{T}}$ and $\mathrm{w}_{\mathrm{c}}^{\mathrm{N}}$ are the budget shares of tradables and non-tradables, respectively. If, on average, the shares of the two goods are equal, i.e., $\mathrm{w}_{\mathrm{c}}^{\mathrm{T}}=\mathrm{w}_{\mathrm{c}}^{\mathrm{N}}=0.5 \forall \mathrm{c}$, (4.2) simplifies to $\log \widetilde{\mathrm{P}}_{\mathrm{c}}^{\mathrm{T}}=-\log \widetilde{\mathrm{P}}_{\mathrm{c}}^{\mathrm{N}}$. As can be seen from panel $\mathrm{B}$, the fitted absolute schedule (dashed curve) is slightly flatter than the simplified schedule (solid curve) but for our purpose, using $\log \widetilde{\mathrm{P}}_{\mathrm{c}}^{\mathrm{T}}=-\log \widetilde{\mathrm{P}}_{\mathrm{c}}^{\mathrm{N}}$ is a reasonable approximation for the absolute-price schedule. ${ }^{11}$

Finally, we merge panels A and B of Figure 4.4 into the right-hand quadrant of panel C. The slopes of two relative-price schedules show that on average, compared to the Poor countries, non-tradables is about 1.5 times more expensive in the Rich countries. ${ }^{12}$ This implies an equilibrium tradables' price of $\$ 0.67$ for Poor and $\$ 0.55$ for Rich. ${ }^{13}$ As shown in the left-hand quadrant, given the price level in the US $(\$ 1.16)$, the average real exchange rate for Poor is $0.67 / 1.16=0.57$ and 0.47 for Rich. From the PPP point of view, a productivity differential introduces a $(0.67-0.55) / 0.55=22 \%$ bias in "Rich's" purchasing power. This also explains why services (which tend to have a large non-tradable component) are relatively cheaper in poor countries (Bhagwati, 1984) or, equivalently, why manufactured goods (which are more tradable) are cheaper in rich countries (Podkaminer, 2011).

\section{THE DETERMINANTS OF GLOBAL PRICE AND CONSUMPTION DISPARITIES}

The previous discussions establish how real exchange rates are determined by the relative prices and consumption of tradable and non-tradable goods and illustrates the relevance of the PPP theory. In this section, we extend this line of research by examining the fundamental drivers of the cross-country prices and consumption of all ICP goods.

\subsection{Summarising ICP data}

For each country c, Equation (3.1) can be extended by specifying the relative price of $i$ as the average of bilateral price differences between $\mathrm{c}$ and all other countries:

$$
\overline{\mathrm{k}}_{\mathrm{i}, \mathrm{c}}=\frac{1}{155} \sum_{\mathrm{d}=1}^{155} \mathrm{k}_{\mathrm{c}, \mathrm{d}}=\frac{1}{155} \sum_{\mathrm{d}=1}^{155}\left[\log \frac{\mathrm{p}_{\mathrm{i}, \mathrm{c}}}{\mathrm{S}_{\mathrm{c}}}-\log \frac{\mathrm{p}_{\mathrm{i}, \mathrm{d}}}{\mathrm{S}_{\mathrm{d}}}\right]=\log \frac{\mathrm{p}_{\mathrm{i}, \mathrm{c}}}{\mathrm{S}_{\mathrm{c}}}-\frac{1}{155} \sum_{\mathrm{d}=1}^{155} \log \frac{\mathrm{p}_{\mathrm{i}, \mathrm{d}}}{\mathrm{S}_{\mathrm{d}}} .
$$

\footnotetext{
${ }^{11}$ As shown by Figure 3.2, the assumption of equal shares of tradables and non-tradables seem not to be unrealistic on an average basis.

${ }^{12}$ Keeping tradables' price constant across countries, so that PPP holds for tradables, $\mathrm{P}_{\mathrm{Rich}}^{\mathrm{N}} / \mathrm{P}_{\text {Poor }}^{\mathrm{N}}=\frac{\mathrm{P}_{\text {Rich }}^{\mathrm{T}} / 0.3}{\mathrm{P}_{\text {Poor }}^{\mathrm{T}} / 0.45}=$ 1.5 .

${ }^{13}$ To solve for the coordinates of the intersection between the absolute-price schedule and the "Rich" relativeprice schedule (the point $\mathrm{E}_{\text {Rich}}$ ), we substitute $\mathrm{P}_{\text {Rich }}^{\mathrm{T}}=0.3 \mathrm{P}_{\text {Rich }}^{\mathrm{N}}$ into $\log \mathrm{P}_{\text {Rich }}^{\mathrm{T}}=-\log \mathrm{P}_{\text {Rich }}^{\mathrm{N}}$, which yields $\mathrm{P}_{\text {Rich }}^{\mathrm{T}}=\sqrt{0.3}=0.55$ and $\mathrm{P}_{\text {Rich }}^{\mathrm{N}}=1.81$. The corresponding coordinates of $\mathrm{E}_{\mathrm{Poor}}$ are $\mathrm{P}_{\text {Poor }}^{\mathrm{T}}=0.67$ and $\mathrm{P}_{\text {Poor }}^{\mathrm{N}}=1.5$.
} 
That is, the relative price of item $\mathrm{i}$ in country $\mathrm{c}$ is the deviation from the "world" average price, $\mathrm{P}_{\mathrm{i}}=\frac{1}{155} \sum_{\mathrm{d}=1}^{155} \log \frac{\mathrm{p}_{\mathrm{i}, \mathrm{d}}}{\mathrm{S}_{\mathrm{d}}}$. Each country receives equal importance in the construction of the average price. ${ }^{14}$ We can then derive the average price matrix as

$$
\mathbf{K}=\left[\overline{\mathbf{k}}_{1}, \overline{\mathbf{k}}_{2}, \ldots, \overline{\mathbf{k}}_{125}\right] \text { where } \overline{\mathbf{k}}_{\mathrm{i}}=\left[\overline{\mathrm{k}}_{\mathrm{i}, \mathrm{c}}\right](\mathrm{i}=1, \ldots, \mathrm{n}) .
$$

An analogous matrix can be constructed for consumption

$$
\mathbf{Q}=\left[\overline{\mathbf{q}}_{1}, \overline{\mathbf{q}}_{2}, \ldots, \overline{\mathbf{q}}_{125}\right] \text { where } \overline{\mathbf{q}}_{\mathrm{i}}=\left[\overline{\mathrm{q}}_{\mathrm{i}, \mathrm{c}}\right]=\log \mathrm{q}_{\mathrm{i}, \mathrm{c}}-\frac{1}{155} \sum_{\mathrm{d}=1}^{155} \log \mathrm{q}_{\mathrm{i}, \mathrm{d}},
$$

where $\mathrm{q}_{\mathrm{i}, \mathrm{c}}=\mathrm{M}_{\mathrm{i}, \mathrm{c}} / \mathrm{p}_{\mathrm{i}, \mathrm{c}}$ is the real per capita consumption of $\mathrm{i}$ in $\mathrm{c} .{ }^{15}$

To summarise the information contained in the large number of pairwise correlations derived from $\mathbf{K}$ and $\mathbf{Q}$, we employ a principal component analysis (PCA) which exploits the co-movement tendency among commodities. Specifically we derive a new set of uncorrelated variables (the "principal components"), each of which is a linear combination of the original variable, and focus on the first two principal components (PC):

$$
\mathbf{p c}_{1}=\mathbf{X} \mathbf{a}_{1} ; \mathbf{p} \mathbf{c}_{2}=\mathbf{X} \mathbf{a}_{2}
$$

where $\mathbf{X}=\left[\mathbf{x}_{1}, \mathbf{x}_{2}, \ldots \mathbf{x}_{125}\right]$ is the matrix wherein each column is the standardised corresponding column of the underlying variable ( $\mathbf{K}$ or $\mathbf{Q})$. $\mathbf{a}_{1}$ and $\mathbf{a}_{2}$ are the first and second eigenvectors of the correlation matrix of $\mathbf{X} .^{16}$

Next, we examine the association between the constructed PCs and possible determinants of pricing and consumption across countries using the following model:

$$
\log \mathrm{PC}_{\mathrm{c}}=\alpha+\left(\beta+\lambda \mathrm{D}_{\mathrm{c}}\right) \log \left(\mathrm{Y}_{\mathrm{c}} / \overline{\mathrm{Y}}\right)+\Theta^{\prime} \mathbf{Z}_{\mathrm{c}}+\varepsilon_{\mathrm{c}}
$$

where $\log \mathrm{PC}_{\mathrm{c}}$ denotes the logarithm of the component scores obtained from the PCA for country c. $\log \left(\mathrm{Y}_{\mathrm{c}} / \overline{\mathrm{Y}}\right)$ is the per capita GDP of country c relative to its cross-country geometric mean (i.e., a measure of real income); $\mathrm{D}_{\mathrm{c}}$ is a dummy variable that equals one if $\mathrm{c}$ belongs to the "Poor" group (i.e., countries in the third and fourth income quartiles) and zero otherwise; $\mathbf{Z}_{\mathrm{c}}$ denotes a vector of controls [which are discussed by Cavallo et al. (2014)] and $\varepsilon_{\mathrm{c}}$ is a disturbance term. We also include the real exchange rates as a regressor. In the followings, we first discuss the results from the PCA of prices and quantities, then apply (5.1) to the first and second scores from these PCAs.

\footnotetext{
${ }^{14}$ Alternatively, we can use a weighted average world price, i.e., $\mathrm{P}_{\mathrm{i}}=\mathrm{w}_{\mathrm{i}, \mathrm{d}} \log \left(\mathrm{P}_{\mathrm{i}, \mathrm{d}} / \mathrm{S}_{\mathrm{d}}\right)$ where the weights are country shares in total world expenditure for $i$. But such a specification would introduce a bias toward larger countries which consume more and can have a bigger impact on the world price (Gerschenkron, 1947).

${ }^{15} \mathrm{~A}$ positive (negative) $\overline{\mathrm{k}}_{\mathrm{i}, \mathrm{c}}$ represents over-(under-) valuation of item $\mathrm{i}$ in country c, relative to the world. The grand mean of $\mathbf{K}$ over all $\mathrm{i}$ and $\mathrm{c}$ is zero, and the grand standard deviation is unity (Clements and Izan, 2012). Q exhibits the same characteristics.

${ }^{16}$ For details, see Appendix A4.
} 


\subsection{Applications}

The PCA results for consumption are presented in panel A of Table 5.2. Column (2) indicates the number of items at each aggregation level. Column (3) indicates that the first PC associated with this variable accounts from more than 40 percent of total data variation (at the basic heading level) to up to 96 percent (at the main aggregate level). Not surprisingly, these data exhibit less variation, which leads to higher explanatory power of PC1, when we use more aggregated variables. ${ }^{17}$ We can see that in this respect, the aggregation procedure serves as a complementary dimension reduction technique to PCA. Columns (5) and (6) display the coefficients and t-statistics of the correlations between the PC1s and real income. Overall, income is significantly and strongly related to consumption PC1, exhibiting an almost perfect correlation, and this is robust in respect to aggregation level. In contrast, PC2s show almost no correlation with income, and contribute little to the total data variation.

Table 5.2: PCA, Prices and Consumption

\begin{tabular}{|c|c|c|c|c|c|c|c|c|c|}
\hline \multirow{3}{*}{$\begin{array}{l}\text { ICP aggregation } \\
\text { level } \\
\text { (1) }\end{array}$} & \multirow{3}{*}{$\begin{array}{c}\text { No. of } \\
\text { variables/items } \\
\text { (2) }\end{array}$} & \multicolumn{2}{|c|}{ Variation contribution (\%) } & \multicolumn{4}{|c|}{ Correlation with income } & \multicolumn{2}{|c|}{$\underline{\mathrm{SD}}$} \\
\hline & & PC1 & $\mathrm{PC} 2$ & \multicolumn{2}{|c|}{$\underline{\mathrm{PC} 1}$} & \multicolumn{2}{|c|}{$\underline{\mathrm{PC} 2}$} & \multirow{2}{*}{$\begin{array}{l}\text { PC1 } \\
\text { (9) }\end{array}$} & \multirow{2}{*}{$\begin{array}{l}\mathrm{PC} 2 \\
\text { (10) }\end{array}$} \\
\hline & & (3) & (4) & $\begin{array}{l}\text { Coef. } \\
(5)\end{array}$ & $\begin{array}{l}\text { t-stat } \\
(6)\end{array}$ & $\begin{array}{c}\text { Coef. } \\
(7)\end{array}$ & $\begin{array}{c}\text { t-stat } \\
(8)\end{array}$ & & \\
\hline \multicolumn{10}{|c|}{ A. Consumption } \\
\hline Basic heading & 125 & 42.3 & 5.2 & 0.98 & 61.1 & 0.06 & 0.76 & 7.3 & 2.6 \\
\hline Class & 101 & 46.1 & 5.3 & 0.98 & 61.6 & 0.03 & 0.43 & 6.8 & 2.3 \\
\hline Group & 48 & 59.4 & 5.3 & 0.98 & 67.1 & 0.08 & 1.03 & 5.4 & 1.6 \\
\hline Category & 16 & 71.2 & 7.2 & 0.99 & 74.8 & 0.04 & 0.55 & 3.4 & 1.1 \\
\hline Main Aggregate & 2 & 95.8 & $\begin{array}{l}4.2 \\
\text { B. Prices } \\
\end{array}$ & 0.98 & 68.8 & 0.16 & 2.01 & 1.4 & 0.3 \\
\hline Basic heading & 125 & 86.5 & 4 & 0.24 & 3.11 & 0.85 & 19.7 & 10.4 & 2.2 \\
\hline Class & 101 & 86.6 & 3.7 & 0.26 & 3.35 & 0.84 & 18.9 & 9.4 & 1.9 \\
\hline Group & 48 & 88.8 & 3.3 & 0.26 & 3.39 & 0.74 & 13.8 & 6.5 & 1.3 \\
\hline Category & 16 & 91.4 & 3.4 & 0.28 & 3.56 & 0.58 & 8.74 & 3.8 & 0.7 \\
\hline Main Aggregate & 2 & 98 & 2 & 0.25 & 3.23 & 0.42 & 5.72 & 1.4 & 0.2 \\
\hline
\end{tabular}

\section{Notes:}

1. Column 2: The number of items at each aggregation level.

2. Columns 3 and 4: The contributions (in percent) of the first and second principal components to the total data variation.

3. Columns 5 - 8: The coefficients and t-stats of the correlation between income and PCs. Income refers to the real per capita GDP relative to its cross-country geometric mean.

4. Columns 9 - 10: The standard deviations of PC1 and PC2.

\footnotetext{
${ }^{17}$ In unreported results, the number of PCs required to explain at least 80 percent of the variation at the "basic heading" level is 24 . This implies that we can reasonably compress our 125-column database into a 24-column version, which represents a mere 19 percent of the original number of variables. However, the contributions of PC2 to PC24 to total variation are insignificant, ranging from 5 to 0.7 percent. Note also that the value of dimension reduction decreases substantially as we move to higher ICP aggregation levels: At the most aggregate level, there are only two "broad items" remained $(n=2)$, and the first PC contributes as much as 96 percent to the total variation. At the "category" level, if we only use the 12 household-related categories (which are analysed in Section 3) and exclude the government consumption categories, PC1 explains about 80 percent of the total variation, which corroborates with the finding made by Clements et al. (2006), who use a panel data analysis of essentially the same household items.
} 
Figure 5.5: First and Second Principal Component Scores

With outliers

Without outliers

\section{A. Consumption}
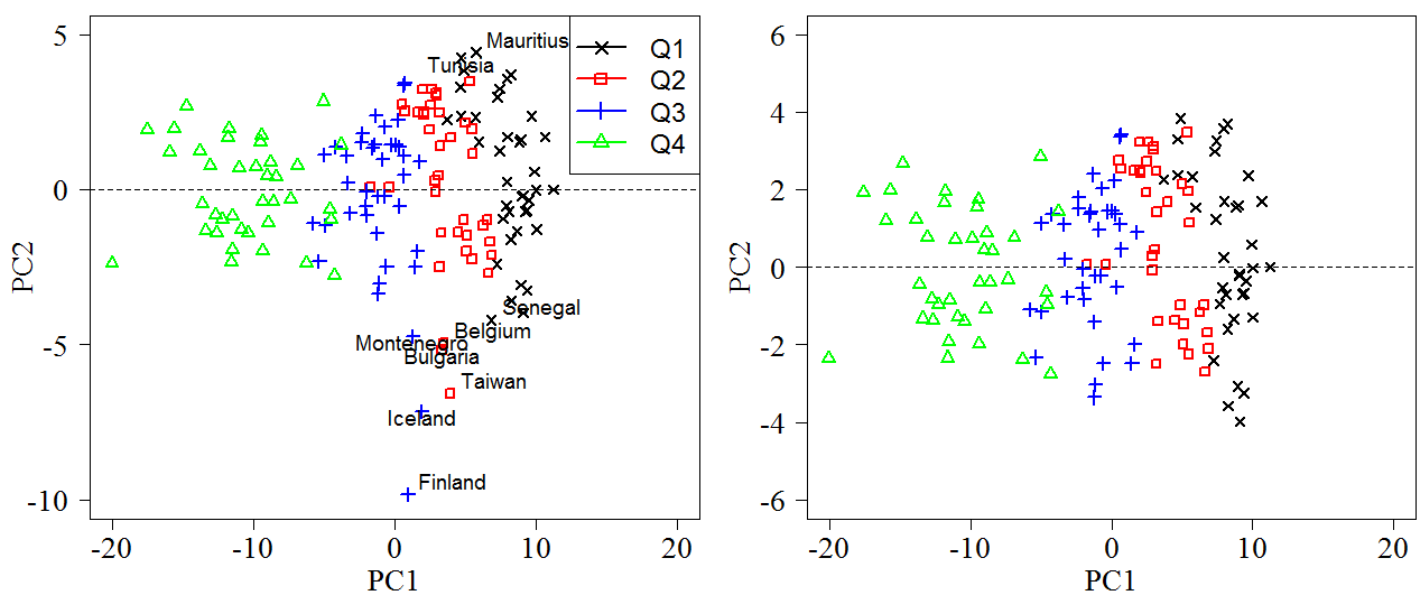

B. Relative Price
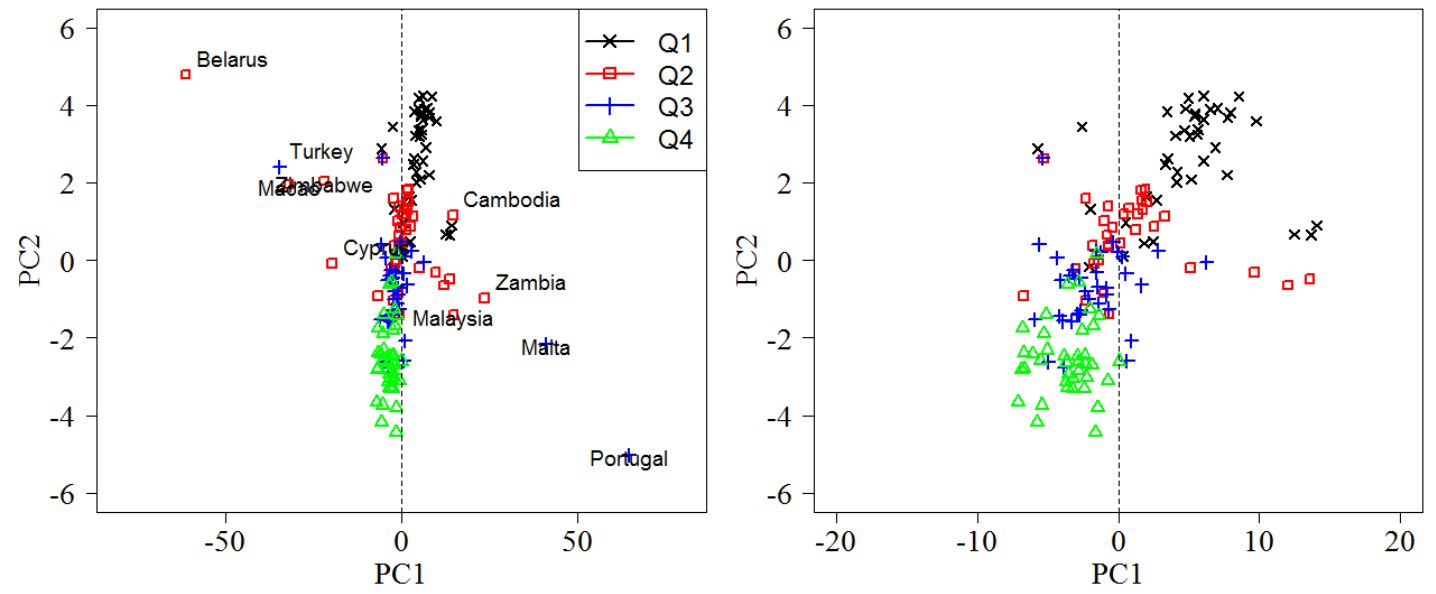

Notes:

1. Panel A: Scatterplot of the first two principal components for consumption in two settings. The "outliers" constitute the ten countries exhibiting the greatest absolute vertical distances from zero.

2. Panel B: Analogous values for relative prices, where outliers are defined as those with greatest horizontal distance to zero.

3. In both panels, countries are color-coded based on income quartiles, with Q1 being the richest and Q4 the poorest.

From panels A and B of Table 5.2, we can see that compared with consumption, it is easier to describe cross-country pricing with only the first PC. Specifically, column (3) shows that the price PC1 contributes from 86 percent to 98 percent of the total data variation. ${ }^{18}$ However, this $\mathrm{PC}$ is only weakly related to income, with a correlation coefficient of only 0.26 on average.

Panel A of Figure 5.5 plots consumption's PC1 against its PC2 at the basic heading level. Countries are classified into colour-coded income groups. In the left-hand side plot, where all

${ }^{18}$ As a result, we only need the first PCs to reasonably summarise the information contained in price correlation at all levels of aggregation. 
countries are included, we can see that they are arranged along the horizontal axis in an order that broadly agrees with the degree of affluence. In other words, richer countries generally have higher scores/PC1, reconfirming the results presented in panel A of Table 5.2. If we omit the 10 countries that are located the farthest from the horizontal zero line, this pattern becomes much clearer, as seen in the right-hand side plot of panel A.

Panel B of Figure 5.5 presents the scatterplots of relative-price PCs. It can be seen that if we consider all observations, no clear country arrangement is visible. More importantly, the greater dispersion of PC1 (which leads to an $86.5 \%$ total variation contribution [column (3) of panel B of Table 5.2) appears to be primarily driven by outliers. We then omit 10 possible outlying countries, defined as those that have the greatest horizontal distances to the vertical zero line. This results in an income-based arrangement along the second dimension, which explains why relative price PC2, though contributing only about $4 \%$ to the total variation, has a very high correlation (0.85) with income [column (7) of Table 5.2].

The above analysis implies that it is feasible to summarise a large number of variables with two PCs and that regardless of the variables used, there is almost invariably a strong association between the first PC and income [as shown in column (5) of Table 5.2].

\subsection{Explaining prices and consumption}

To further examine the determinants of cross-country prices and quantities, Table 5.3 presents the estimates of model (5.1) as a cross-sectional regression, for the basic heading level (i.e., the number of items is $n=125$ ). There are several important observations that can be made:

- First, as can be seen from specifications (1) and (2), real income plays a crucial role in explaining the cross-country variation of consumption $\mathrm{PC} 1$. The coefficient of $\log \left(\mathrm{Y}_{\mathrm{c}} / \overline{\mathrm{Y}}\right)$ indicates that the income elasticity of demand is 5.4 for rich countries, which is reasonable, considering the high share of non-tradable items they consumed (most of which can be considered as luxury goods). The coefficient of $\mathrm{D}_{\mathrm{c}} \times \log \left(\mathrm{Y}_{\mathrm{c}} / \overline{\mathrm{Y}}\right)$ shows that consumption in poor countries is $1.3 / 5.4=24 \%$ more income-elastic than rich countries. Currencies with one-percent higher purchasing power ("real ER") boost consumption by a significant 4.4\%. A one-percent increase in population size, on the other hand, only leads to a modest $0.2 \%$ increase in consumption per capita. Higher consumption is also observed for Eurozone and land-locked countries, though the latter effect is not very significant.

- In stark contrast, except for exchange rate-related factors, no other variable has a significant impact on the core component of relative prices, as can be seen from column (5).

- Income is a key driver of the second price principal component [columns (7) to (9)], while it does not affect the corresponding consumption factor [specification (3)]. Additionally, the "Eurozone effect" is significantly and positively associated with the price factor. Since most of the countries in this area have high income and price-inelastic demand, 


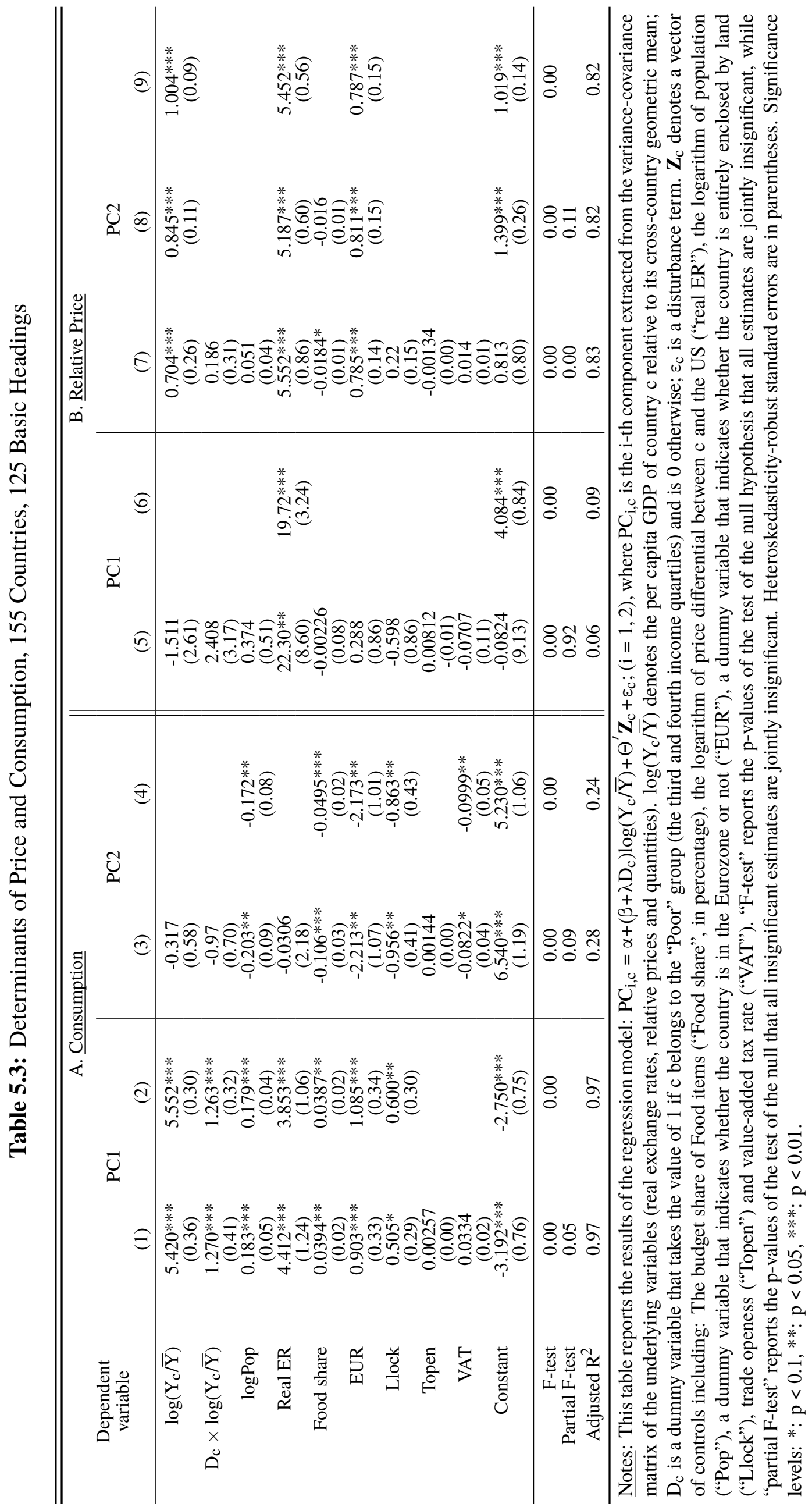


they may be subject to higher prices set by retailers, on the basis of price discrimination (Simonovska, 2015).

- The adjusted $\mathrm{R}^{2}$ values across specifications are in agreement with column (5) of Table 5.2 .

Given the strong effect of income on consumption, one can ask what happens when we "strip out" this effect. The answer is that PC1 of the residual consumption should have a much smaller correlation with income. In Appendix A5, we show that this is indeed the case: We repeat regression (5.1) with the PCs obtained from different formulations of consumption: (i) $\log \mathrm{q}_{\mathrm{ic}}-\log \left(\mathrm{Y}_{\mathrm{c}} / \overline{\mathrm{Y}}\right)$ and (ii) $\log \mathrm{q}_{\mathrm{ic}}-\sum_{\mathrm{i}=1}^{\mathrm{n}} \mathrm{w}_{\mathrm{ic}} \log \mathrm{q}_{\mathrm{ic}}$ and find that the explanatory power of income to residual consumption drops significantly, to a level comparable with that to relative price. $^{19}$

\section{Conclusions}

The International Comparison Program (ICP) collects retail prices and expenditures in almost all of the world's nations. These prices are at the heart of Purchasing Power Parity exchange rates and measures of cross-country living standards and poverty (Deaton and Aten, 2017) and are a major input into the Penn World Table (Feenstra et al., 2015). Despite its widespread use, the substantial heterogeneity of cross-country expenditure and pricing patterns can lead to difficulties in interpreting ICP results.

Due in large part to the difficulty of interpreting these data, empirical work in the tradablenontradable distinction has lagged behind theoretical developments. Our paper helps alleviate this problem by proposing a measure of tradability based on differentials in prices among 150+ countries. According to this measure, the higher the price dispersion, the lower the tradability of a good. This measure allows for the classification of ICP goods into tradables and non-tradables and the construction of price indices of the two categories. Using these indices, we illustrate that these two categories behave in accordance with the Harrod-Balassa-Samuelson hypothesis that as a country becomes more affluent, the fall in tradables' prices leads to a real appreciation of its currency.

We also introduced an alternative to traditional index-number theory that compresses the large volume of price and consumption data across 155 countries by identifying common

\footnotetext{
${ }^{19}$ In unreported results which are available upon request, we perform two additional robustness checks: First, using PC1 at other aggregation levels do not alter our main results qualitatively. Second, we add a dummy variable that is equal to one if the country is in a currency arrangement that is similar to the Eurozone (i.e., using common currencies) and zero otherwise. There are in total 28 such countries: 13 of them use the CFA Franc (XOF or XAF), 8 adopt the East Caribbean Dollar (XCD), 5 use the US dollar and 2 use the Netherlands Antillean Guilder (ANG). In all specifications, the coefficient for this dummy is not significant. This implies that the Eurozone effect is unique, in the sense that it is not similar to being in any other currency arrangements. This finding resonates that made by Cavallo et al. (2014).
} 
factors. This approach utilises principal component analysis (PCA) and found that: (i) The first principal component explains 42 percent of total consumption variation and 86 percent of the total price variation; (ii) income is responsible for 98 percent of the variation in the first principal component of consumption, but only $24 \%$ of price variation. In contrast to many previous economic applications of PCA, our results have a clear interpretation: A common factor of prices is identified as representing global forces such as trade and exchange-rate effects (consistent with the PPP theory). On the other hand, consumption is strongly influenced by local forces such as an income effect.

The recent deluge of high-quality data collected (via both conventional surveys at brickand-mortar retail stores and on online commerce platforms) can overwhelm even the most sophisticated analyst. This study has illustrated how the big data set of the ICP deliver a clear economic message once their dimensionality is dealt with in a coherent manner.

\section{REFERENCES}

Alessandria, G. and Kaboski, J. P. (2011). Pricing-to-market and the failure of absolute PPP. American Economic Journal: Macroeconomics, 3(1):91 - 127.

Anderson, J. E. and van Wincoop, E. (2004). Trade costs. Journal of Economic Literature, 42(3):691 - 751 .

Balassa, B. (1964). The purchasing power parity doctrine: A reappraisal. Journal of Political Economy, 72(6):584 - 96.

Bergin, P. R., Glick, R., and Taylor, A. M. (2006). Productivity, tradability, and the long-run price puzzle. Journal of Monetary Economics, 53(8):2041 - 66.

Betts, C. M. and Kehoe, T. J. (2017). Real exchange rate movements and the relative price of non-traded goods. USC-INET Research Paper No. 17-31. Working paper 14437, National Bureau of Economic Research.

Bhagwati, J. N. (1984). Why are services cheaper in the poor countries? Economic Journal, 94(374):279- 86.

Buera, F. J., Kaboski, J. P., and Shin, Y. (2011). Finance and development: A tale of two sectors. American Economic Review, 101(5):1964 - 2002.

Bunn, D. W., Chevallier, J., Le Pen, Y., and Sevi, B. (2017). Fundamental and financial influences on the co-movement of oil and gas prices. Energy Journal, 38(2):201 - 228.

Cavallo, A., Neiman, B., and Rigobon, R. (2014). Currency unions, product introductions, and the real exchange rate. Quarterly Journal of Economics, 129(2):529 - 95.

Chaudhuri, K. and Sheen, J. (2004). Purchasing power parity across states and goods within Australia. Economic Record, 80(250):314 - 29.

Clements, K., Wu, Y., and Zhang, J. (2006). Comparing international consumption patterns. Empirical Economics, 31(1):1 - 30.

Clements, K. W. and Izan, I. H. (2012). The pay parity matrix - a tool for analysing the structure of pay. Applied Economics, 44(34):4515 - 25.

Clements, K. W. and Lan, Y. (2007). Exchange rates, productivity, poverty and inequality. Applied Economics, 39(4):471 - 76.

Cross, R. and Laidler, D. E. W. (1976). Inflation, excess demand and expectations in fixed 
exchange rate open economies: Some preliminary empirical results. page 221-58. Manchester University Press, Manchester.

Crucini, M. J. and Yilmazkuday, H. (2014). Understanding long-run price dispersion. Journal of Monetary Economics, 66:226 - 40.

Cuthbert, J. (2009). Implicit data structure and properties of selected additive indices. In Rao, P., editor, Purchasing Power Parity: Recent Advances in Methods and Applications, volume 2, chapter 7, pages 160 - 80. Edward Elgar, Cheltenham.

de Nicola, F., De Pace, P., and Hernandez, M. A. (2016). Co-movement of major energy, agricultural, and food commodity price returns: A time-series assessment. Energy Economics, 57:28 - 41 .

Deaton, A. and Aten, B. (2017). Trying to understand the PPPs in ICP 2011: Why are the results so different? American Economic Journal: Macroeconomics, 9(1):243 - 64.

Dornbusch, R. (1973). Devaluation, money, and nontraded goods. American Economic Review, 63(5):871-80.

Dornbusch, R. (1988). Purchasing power parity. In The New Palgrave: A Dictionary of Economics. Stockton Press, New York.

Feenstra, R. C., Inklaar, R., and Timmer, M. P. (2015). The next generation of the Penn World Table. American Economic Review, 105(10):3150 - 82.

Fieleke, N. S. (1995). The soaring trade in "nontradables". New England Economic Review, pages $25-36$.

Frankel, J., Parsley, D., and Wei, S.-J. (2012). Slow pass-through around the world: A new import for developing countries? Open Economies Review, 23(2):213 - 51.

Frenkel, J. A. (1978). Purchasing power parity: Doctrinal perspective and evidence from the 1920s. Journal of International Economics, 8(2):169 - 91.

Froot, K. A. and Rogoff, K. (1995). Perspectives on PPP and long-run real exchange rates. volume 3 of Handbook of International Economics, chapter 32, pages 1647 - 88. Elsevier, The Netherlands.

Gerschenkron, A. (1947). The Soviet indices of industrial production. Review of Economics and Statistics, 29(4):217 - 26.

Goldstein, M. and Officer, L. H. (1979). New measures of prices and productivity for tradable and nontradable goods. Review of Income and Wealth, 25(4):413-27.

Harrod, R. F. (1939). International Economics, volume 8 of Cambridge Economic Handbooks. Nisbet, Cambridge.

Hassan, F. (2016). The price of development: The Penn-Balassa-Samuelson effect revisited. Journal of International Economics, 102:291 - 309.

Hulten, C. R. (1973). Divisia index numbers. Econometrica, 41(6):1017 - 25.

Inklaar, R. and Rao, D. (2017). Cross-country income levels over time: Did the developing world suddenly become much richer? American Economic Journal: Macroeconomics, 9(1):265 - 90 .

Konüs, A. A. (1939). The problem of the true index of the cost of living. Econometrica, pages $10-29$.

Lombardo, G. and Ravenna, F. (2012). The size of the tradable and non-tradable sectors: Evidence from input-output tables for 25 countries. Economics Letters, 116(3):558 61.

Lothian, J. R. and Taylor, M. P. (2008). Real exchange rates over the past two centuries: How important is the Harrod-Balassa-Samuelson effect? Economic Journal, 118(532):1742 $-63$.

Majumder, A., Ray, R., and Sinha, K. (2015). Estimating purchasing power parities from household expenditure data using complete demand systems with application to living standards comparison: India and Vietnam. Review of Income and Wealth, 61(2):302 28.

Manzur, M., editor (2008). Purchasing Power Parity. International Library of Critical Writings 
in Economics. Edward Elgar Publishing, Cheltenham, UK.

Marsh, I. W., Passari, E., and Sarno, L. (2012). Purchasing power parity in tradable goods. In J. James, I. W. M. and Sarno, L., editors, Handbook of Exchange Rates, volume 2, chapter 7, pages $189-220$. Wiley.

Murray, T. and Ginman, P. J. (1976). An empirical examination of the traditional aggregate import demand model. Review of Economics and Statistics, pages 75-80.

Oulton, N. (2008). Chain indices of the cost-of-living and the path-dependence problem: An empirical solution. Journal of Econometrics, 144(1):306 - 24.

Podkaminer, L. (2011). Why are goods cheaper in rich European countries? Beyond the Balassa-Samuelson effect. Metroeconomica, 62(4):712-28.

Ponomareva, N., Sheen, J., and Wang, B. Z. (2019). The common component of bilateral US exchange rates: To what is it related? Empirical Economics, 56(4):1251 - 68.

Rao, D. P., Rambaldi, A., and Doran, H. (2010). Extrapolation of purchasing power parities using multiple benchmarks and auxiliary information: A new approach. Review of Income and Wealth, 56(S1):59 - 98.

Ray, R. (2017). The role of prices in welfare comparisons: Methodological developments and a selective survey of the empirical literature. Economic Record, 93(301):314 - 32.

Ray, R. (2018). Household Behaviour, Prices, and Welfare: A Collection of Essays Including Selected Empirical Studies. Themes in Economics. Springer, Singapore.

Rogoff, K. (1996). The purchasing power parity puzzle. Journal of Economic Literature, 34(2):647-68.

Salter, W. E. G. (1959). Internal and external balance: The role of price and expenditure effects. Economic Record, 35(71):226-38.

Samuelson, P. A. (1964). Theoretical notes on trade problems. Review of Economics and Statistics, 46(2): 145 - 54.

Simonovska, I. (2015). Income differences and prices of tradables: Insights from an online retailer. Review of Economic Studies, 82(4):1612 - 56.

Sposi, M. (2015). Trade barriers and the relative price of tradables. Journal of International Economics, 96(2):398 - 411.

Taylor, A. M. and Taylor, M. P. (2004). The purchasing power parity debate. Journal of Economic Perspectives, 18(4):135 - 58.

Vo, L. H. (2020). Exchange rates, Prices and Consumption. Ph.D thesis, Economics Department, Business School, the University of Western Australia. Avaialable at: https://research-repository.uwa.edu.au/en/publications/ exchange-rates-prices-and-consumption.

World Bank (2013a). Measuring the Real Size of the World Economy: The Framework, Methodology, and Results of the International Comparison Program - ICP. World Bank, Washington, DC.

World Bank (2013b). 2011 International Comparison Program Data for Researchers. Unpublished. 


\title{
Supplementary Materials for \\ "Understanding International \\ Price and Consumption Disparities" *
}

\author{
Long Hai $\mathrm{Vo}^{\dagger}$ \\ Economics Department, Business School, The University of Western Australia \\ Research Center in Business, Economics and Resources, HCMC Open University \\ Faculty of Banking, Finance and Business Administration, Quy Nhon University
}

\begin{abstract}
This document complements the content of the paper "Understanding International Price and Consumption Disparities".
\end{abstract}

JEL classifications: F40, E01, C43

Keywords: Economic measurement; Price and consumption; Principal component analysis; Tradability

\footnotetext{
*Acknowledgements: This paper is based on part of the author's Ph.D thesis at the University of Western Australia (UWA) (Vo, 2020), where he received financial support from an Australian Government Research Training Program Scholarship. Comments by Simon Chang, Chia-lin Chang, Ken Clements, Indrajit Coomaraswamy, Yihui Lan, James Lothian, Ranjan Ray, Jeffrey Sheen, Duc Vo and participants at the $3^{\text {rd }}$ Vietnam Business and Economics Research Conference at HCMC Open University, the $12^{\text {th }}$ International Research Conference at the Central Bank of Sri Lanka and various seminars at UWA help improve the paper. For provision of unpublished data, I thank the ICP administrators at the World Bank. All errors remain with the author.

${ }^{\dagger}$ Contact: Economics Department, Business School, UWA. 35 Stirling Highway, Crawley, WA 6009, Australia. Email: long.vo@uwa.edu.au.
} 


\section{A1. Dissecting The ICP Data}

This section first gives a brief overview of the construction of PPP and expenditure measures at multiple aggregation levels of the ICP data. Generally speaking, there are two main sources of ICP data: Price (from global surveys) and expenditure (from national accounts). A reasonable degree of consistency in terms of item coverage must be maintained between these two sources. For example, when considering a certain aggregate, such as "Food", the items identified for surveys must relate to the types of food that are used in deriving that expenditure aggregate in the national account. To reduce the length of a global list of products to be priced by all participating countries, the ICP adopts a regionalised approach which at first determines regional-specific lists. ${ }^{1}$ This takes advantage of the homogeneity of preferences among participants within a region, to ensure that items included are both comparable and representative. Subsequently, cross-regional compilation is done via a "linking" process that uses the global item list. In total the ICP data have 7 main levels of aggregation: disaggregated "Global core list" and "Regional list" products, basic headings ${ }^{2}$, classes, groups, categories, main aggregations and GDP.

The hierarchical structure of these levels is illustrated via Figure A1.1. At the second level from the top, GDP can be decomposed into 7 main aggregates, namely: "Individual consumption expenditure by households", "Individual consumption expenditure by non-profit institutions serving households (NPISH)", "Individual consumption expenditure by government", "Collective consumption expenditure by government", "Gross fixed capital formation", "Changes in inventories and net acquisitions of valuables" and "Balance of exports and imports". For the purposes outlined in World Bank (2013b), GDP is then divided into 26 major categories, which are further sub-divided into 61 groups and then into 126 classes. An example of a category is "Food and non-alcoholic beverages," which is divided further into two groups: "Food" and "Non-alcoholic beverages". The category "Clothing and footwear" is similarly split into two groups. Groups are then broken into classes - for example, the food group contains 11 classes that include bread and cereals, meat, fish and seafood, and so forth. Each of these classes is then divided into basic headings - for example, rice is a basic heading in the bread and cereals class.

\footnotetext{
${ }^{1}$ Despite considerable effort to ensure regional homogeneity of consumption baskets, diverse regions such as AsiaPacific and Africa include sub-regions with markedly different baskets. This is a subject of intensive research among regional coordinators (Rao, 2013).

${ }^{2}$ These headings are the lowest levels of aggregation where nominal expenditure data are available in national accounts.
} 
Figure A1.1: ICP Classification of Final Expenditure on GDP

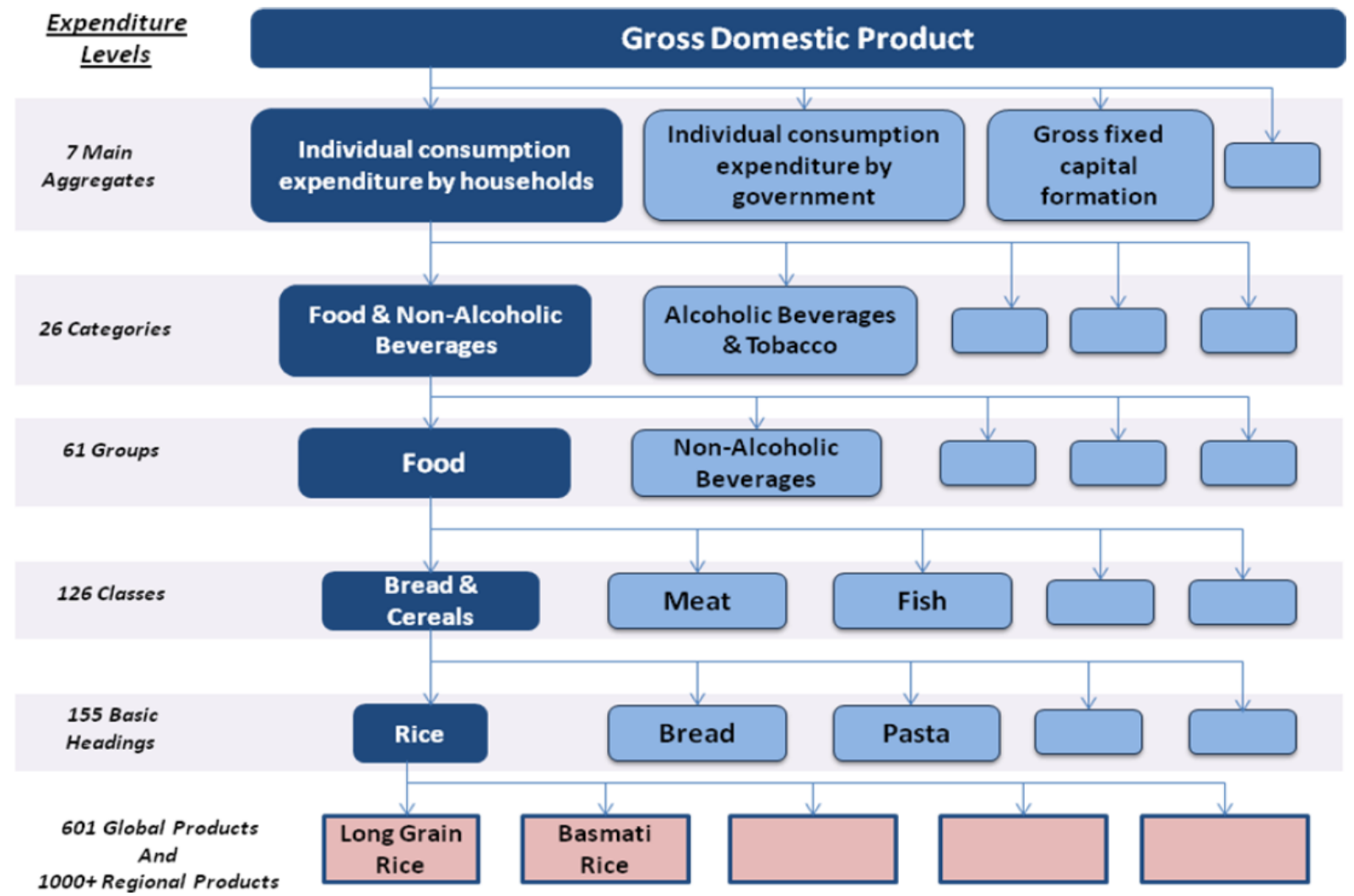

Notes: This figure is extracted from Annex 1 of ICP (2011, p. 6).

The data structure across 155 countries can also be visualized by Figure A1.2. In this paper, we exclude all non-consumption categories, and only study the 131 consumption headings. The main justifications are the pattern of pricing may differ significantly between consumption and non-consumption items, and the former occupy a larger portion of individuals and households' budget. After computing the Purchasing Power Parities (PPPs) and expenditures at all levels, we perform another data treatment. At each level, items associated with receipts from sales of government services, value of imports, value of inventories, and final consumption of nonresidents are excluded. These are effectively "balancing items" for which expenditures can be negative for accounting purposes (Cuthbert, 2009). Details about the omitted items are presented in Table A1.3. ${ }^{3}$ A diagram outlining all primary steps in the aggregation and construction of the three main variables is provided in Figure A1.3.

\section{ICP 2011 main results}

The purpose of this Section is to provide a "snapshot" of the main results of the latest round of the ICP. Panel A of Figure A1.4 presents a bubble scatter plot. The bubble sizes are proportional to the countries' GDP in PPP terms. The vertical axis is price level index,

\footnotetext{
${ }^{3}$ Additionally, there are no nominal expenditure data available for "Individual Consumption Expenditure by Nonprofit Institution Serving Households", for any country, at any level.
} 
computed as the ratio between PPP rates and exchange rates, with the world average level equals 100. As such, the bubbles lying above the world average line represent countries that have a price level higher than average and vice versa. The horizontal axis is GDP (in \$US per capita) in PPP terms. This means the bubbles on the far right represent the most affluent countries. As can be seen, in general there is a strong positive association between price levels and income, which accords with the productivity bias hypothesis. However, there are some exceptions to the rule: some Asia and Western Asia economies (among which are Singapore, Macao, United Arab Emirates and Qatar) with very high income per capita exhibit the same levels of price as countries with much lower income. It turns out that large economies do not always have higher price levels. Following Clements and Lan (2007), in panel B we compare two measures of GDP per capita as published by the ICP: One uses the market exchange rate (MER), the other uses PPP rates. We can see that for the majority of the countries, income as measured in PPP terms is larger than that measured in MER terms. This is because PPPs are typically lower than MER and more so for poor countries, due to lower prices of non-tradables in these countries (Deaton and Aten, 2017). Indeed, the departure of the bubbles from the $45^{\circ}$ line is substantial for the least affluent countries. Apparently, using MER (which lacks proper accounting for purchasing power of currencies) could lead to a significant underestimation of real income. Additionally, since we use the \$US as the numeraire, the arrangement observed in panel B could also reflect a strong Dollar effect. That is, in 2011 the \$US is overvalued compared with most of the currencies.

\section{Data cleaning}

Next, we provide an overview of the underlying data from the ICP. Sections 2 to 5 in the main text draw upon the PPP and expenditure data at the "basic heading" level. These are all from the end-user's point of view, that is, consumers. The 2011 round of ICP data contains disaggregated expenditures and prices of 155 basic headings for 182 countries. Total consumption refers to the sum of the first 132 basic headings; this follows the ICP's definition of "Actual Household Consumption", which is the total value of the individual consumption expenditures of households, non-profit institutions serving households, and general government at purchasers' prices. Within the 132 basic headings, we consider the first 32 as food items.

We make two adjustments to the data. Firstly, we remove duplicate entries for three countries (Russia, Sudan and Egypt), each of which is a dual participant in the ICP. Next, Cuba and Bonaire do not have complete data and are omitted. Second, we combine some commodities. Many West Asia countries have little to no PPP real expenditure per capita on pork due to religious reasons. We partially solve this by combining the "Pork" and "Lamb, 
mutton and goat" groups; so food now consists of 31 basic headings. ${ }^{4}$ Using a minimum cut-off of per capita consumption of $\$ 0.01$, the following 22 countries are omitted: Algeria, Angola, Bangladesh, Brunei Darussalam, Burundi, Egypt, Ethiopia, Iran, Kuwait, Lao PDR, Malawi, Maldives, Mauritania, Myanmar, Nicaragua, Pakistan, Palestinian Territory, Saudi Arabia, Sudan, Tanzania, Togo and Yemen. Our final sample thus contains 182 (the starting number of countries) -3 (duplicates) -2 (Cuba and Bonaire) $-22($ small consumption $)=155$ countries. One limitation of the ICP data is that the 31 basic headings exclude food consumed away from home, which is important in some high-income countries.

\section{Notes on the "Category" level}

In the unpublished ICP data that we have access to, both PPP rates and nominal expenditures (in local currency unit, hereafter LCU) are only available at the second most disaggregated level (basic headings), plus a level that is not included in the hierarchical structure as illustrated in Figure A1.1. The latter level is known as the "analytical categories". Some of these analytical categories are aggregations of other analytical categories (which are themselves components of GDP), so that sum of all categories is greater than GDP, thus making themselves "non-hiarchical". This system of accounting appears in public World Bank documents.

It is interesting to contrast the "analytical categories" against the unpublished version that corresponds to the third level from the top (namely "categories"), which is a hierarchical system. ${ }^{5}$ The exposition of these systems and the relationship between their components, which has not been discussed hitherto in the literature, is a useful benchmark for future research using ICP data. The definitions of the analytical categories are provided in Table A1.1 which is provided by the ICP. Table A1.2 shows how the two systems are linked. This Table provides an essential guidance for researchers to navigate the ICP database and consistently construct data series at the intermediate aggregation levels.

\footnotetext{
${ }^{4}$ To maintain internal consistency when we combine, expenditures (in both domestic currency units and in US dollars, that is, real expenditures) are summed over the sub-components, whilst the purchasing power parity of the combination is the ratio of nominal to real expenditures. For an extensive study of the consumption pattern of these 31 headings, see Clements and $\mathrm{Si}$ (2017).

${ }^{5}$ At a casual investigation, the difference between the two systems is somewhat dubious due to the fact that, incidentally, the number of analytical categories and that of categories for the 2011 round are the same (both at 26 items). In the 2005 round, the number of major categories is just 13, while that of analytical categories is 24 . The analytical categories serve as the building blocks of GDP and therefore their number changes very little in 2011: The two newly added types are "Domestic absorption" and "Individual consumption expenditure by households without housing".
} 
Table A1.1: ICP Analytical Categories

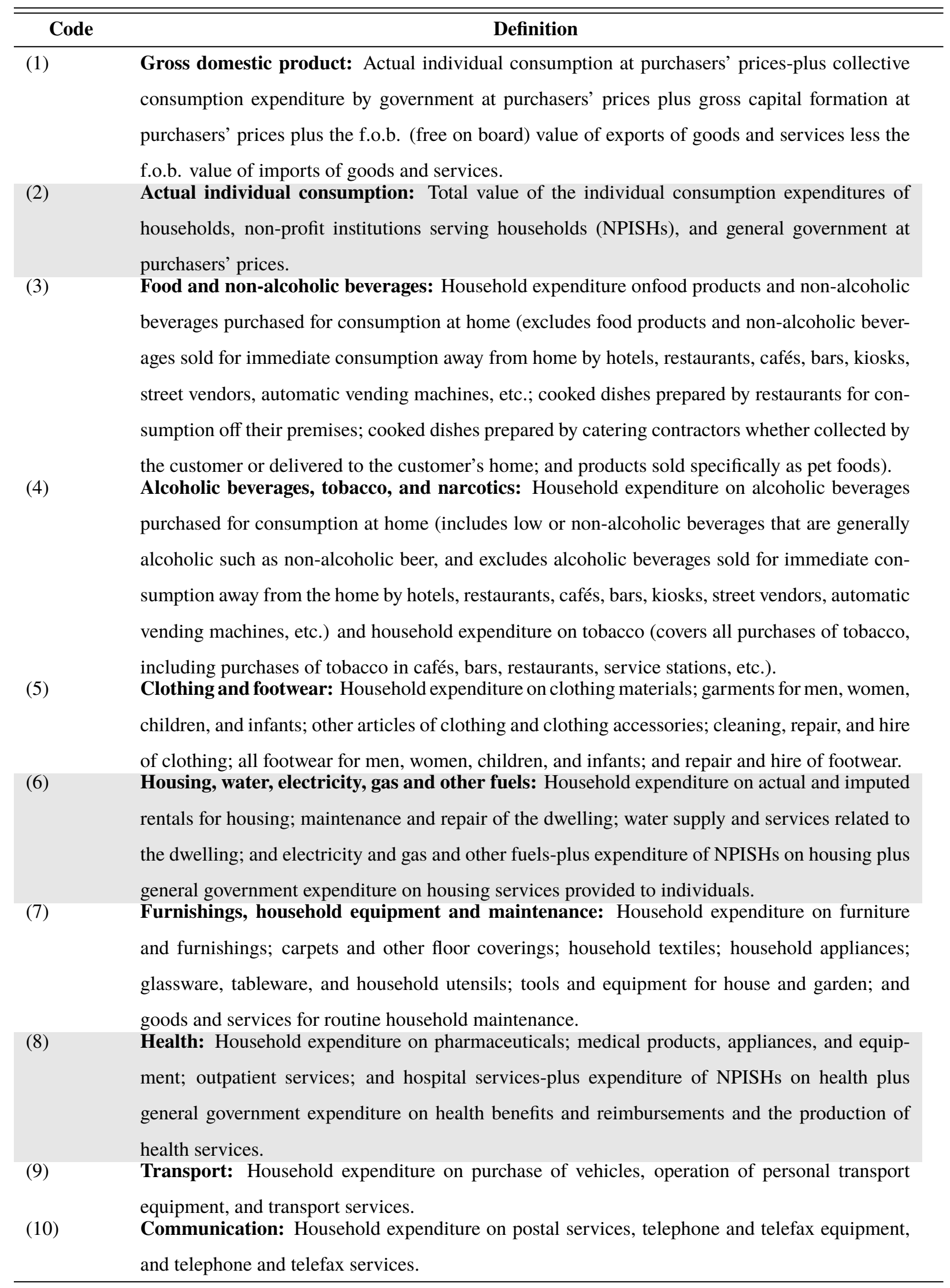


Table A1.1: ICP Analytical Categories (continued)

Code Definition

(11) Recreation and culture: Household expenditure on audio-visuals, photographic, and information processing equipment; other major durables for recreation and culture; other recreational items and equipment; gardens and pets; recreational and cultural services; newspapers, books, and stationery; and package holidays-plus expenditure of NPISHs on recreation and culture plus general government expenditure on recreation and culture.

(12) Education: Household expenditure on pre-primary, primary, secondary, postsecondary, and tertiary education-plus expenditure of NPISHs on education plus general government expenditure on educational benefits and reimbursements and the production of educational services.

(13) Restaurants and hotels: Household expenditure on food products and beverages sold for immediate consumption away from the home by hotels, restaurants, cafés, bars, kiosks, street vendors, automatic vending machines, etc. (includes cooked dishes prepared by restaurants for consumption off their premises; cooked dishes prepared by catering contractors, whether collected by the customer or delivered to the customer's home); and household expenditure on accommodation services provided by hotels and similar establishments.

(14) Miscellaneous goods and services: Household expenditure on personal care, personal effects, social protection, insurance, and financial and other services-plus expenditure by NPISHs on social protection and other services plus general government expenditure on social protection.

(15) Net purchases abroad: Purchases by resident households outside the economic territory of the economy-less purchases by non-residential households in the economic territory of the economy. (16) Individual consumption expenditure by households: Total value of actual and imputed final consumption expenditures incurred by households on individual goods and services; also includes expenditure on individual goods and services sold at prices that are not economically significant. Individual consumption expenditure by government: Total value of actual and imputed final consumption expenditures incurred by general government on individual goods and services. Collective consumption expenditure by government: Final consumption expenditure of general government on collective services

Gross fixed capital formation: Total value of acquisitions-less disposals of fixed assets by resident institutional units during the accounting period plus additions to the value of the nonproduced assets realized by the productive activity of resident institutional units.

(20) Machinery and equipment: Capital expenditure on fabricated metal products, general-purpose machinery, special-purpose machinery, electrical and optical equipment, transport equipment, and other manufactured goods.

(21) Construction: Capital expenditure on the construction of new structures and the renovation of existing structures. Structures include residential buildings, non-residential buildings, and civil engineering works.

(22) Other products: Capital expenditure on plantation, orchard, and vineyard development; change in stocks of breeding stock, draft animals, dairy cattle, animals raised for wool clippings, etc.; computer software that a producer expects to use in production for more than one year; land improvement, including dams and dikes that are part of flood control and irrigation projects; mineral exploration; acquisition of entertainment, literary, or artistic originals; and other intangible fixed assets. 
Table A1.1: ICP Analytical Categories (continued)

\begin{tabular}{ll}
\hline \multicolumn{1}{c}{ Code } & \multicolumn{1}{c}{ Definition } \\
\hline (23) & Changes in inventories and valuables: The acquisition, less disposals, of stocks of raw materials, \\
& semi-finished goods, and finished goods that are held by producer units prior to their being further \\
& processed or sold or otherwise used; and the acquisition, less disposals, of valuables (produced \\
& assets that are not used primarily for production or consumption but are purchased and held as \\
& stores of value). \\
& Balance of exports and imports: The f.o.b. value of exports of goods and services minus the \\
& f.o.b. value of imports of goods and services. \\
& Domestic absorption: Actual individual consumption at purchasers' prices-plus collective con- \\
& sumption expenditure by government at purchasers' prices plus gross capital formation at pur- \\
& chasers' prices. \\
& Individual consumption expenditure by households without housing: Individual consumption \\
& expenditure by households in column (16) without the actual and imputed rentals included in \\
& column (06).
\end{tabular}

Notes: The shaded categories in the list below are "non-hierarchical" - that is, they combine items outside of the hierarchical ICP classification (e.g., "Education" combines the household expenditures on education with those of non-profit institutions serving households and of the government). Categories not shaded are hierarchical. Data source: ICP 2011 published results. Available at http://siteresources.worldbank.org/ICPEXT/ Resources/ICP_2011.html

In the main text, we focus on only the (first) 131 consumption basic headings. The main justification is that the pattern of pricing and consumption may differ significantly between consumption and non-consumption items. At each level, we opt for omitting items that have either negative expenditure for some countries or zero expenditure for all countries. This is to ensure that our consumption measure, $\log q_{i c}$, is valid. Table A1.3 lists the omitted items that are excluded from subsequent analyses.

\section{A2. Aggregation to LeVels higher than BaSiC Headings}

With the data structure as presented in Section A1, we proceed to construct the PPPs at levels higher than basic headings using the celebrated Gini-Eltetö- Köves-Szulc (hereafter GEKS $)^{6}$ method (Diewert, 2013). To illustrate, we first describe the application of this method to aggregate our basic heading PPP and real expenditure. Note that our starting point is the processed "global" basic heading PPPs and the corresponding nominal expenditure (in local currency unit) data compiled from national accounts.

For simplicity, we use as an example the $5 \times 155$ matrix $\mathbf{P}$ which refers solely to the 5

\footnotetext{
${ }^{6}$ Named after Gini (1931), Eltetö and Köves (1964) and Szulc (1964). Beside this method, there are many alternative multilateral indices suggested by the ICP Technical Advisory Group (TAG). It should be noted that instead of following the "region to global" approach used in the 2011 ICP, without access to regional disaggregated data, we simply use the ICP-given global results and aggregate them up.
} 
SUPPLEMENTARY MATERIALS

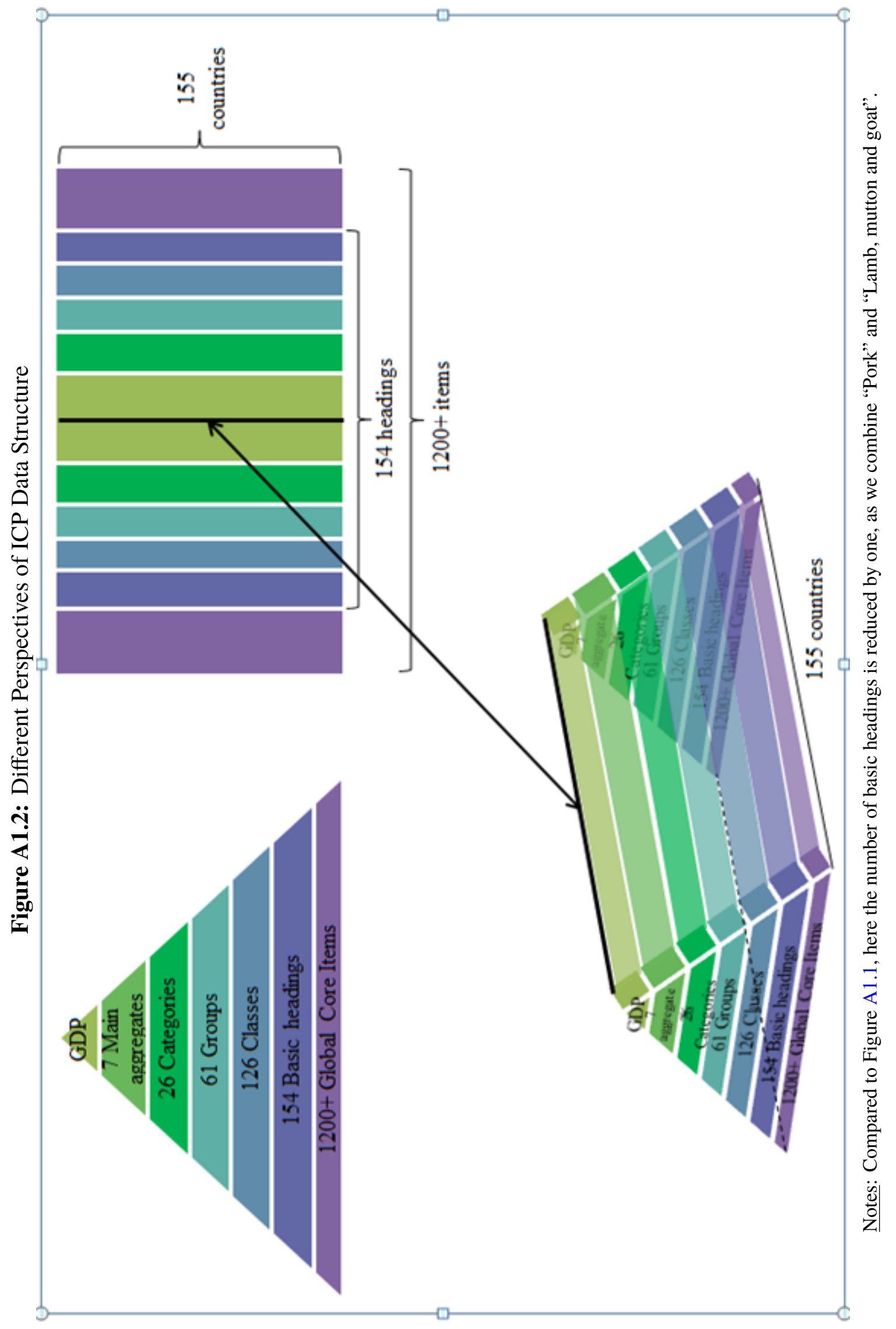


Figure A1.3: Diagram of Data Treatment

1- Exclude non-

\section{consumption items}

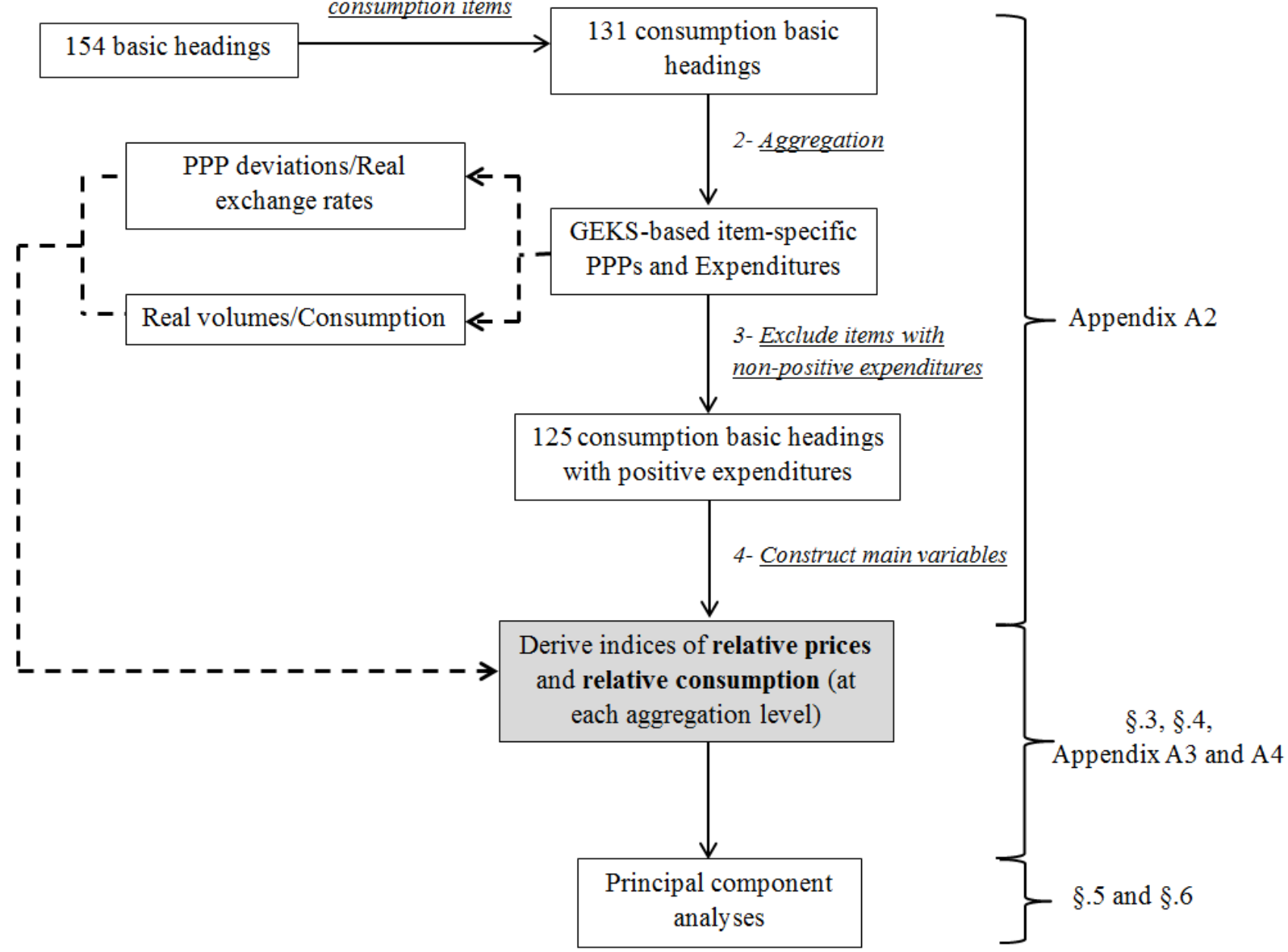

Notes: This figure presents a flow of data treatment throughout the paper. The four primary treatment steps are enumerated. The section numbers indicate where corresponding data are constructed and/or examined. Emboldened texts in the shaded box indicate our main variables of interest. 
Figure A1.4: 2011 ICP Primary Results, 177 Countries

\section{A. Price and income}

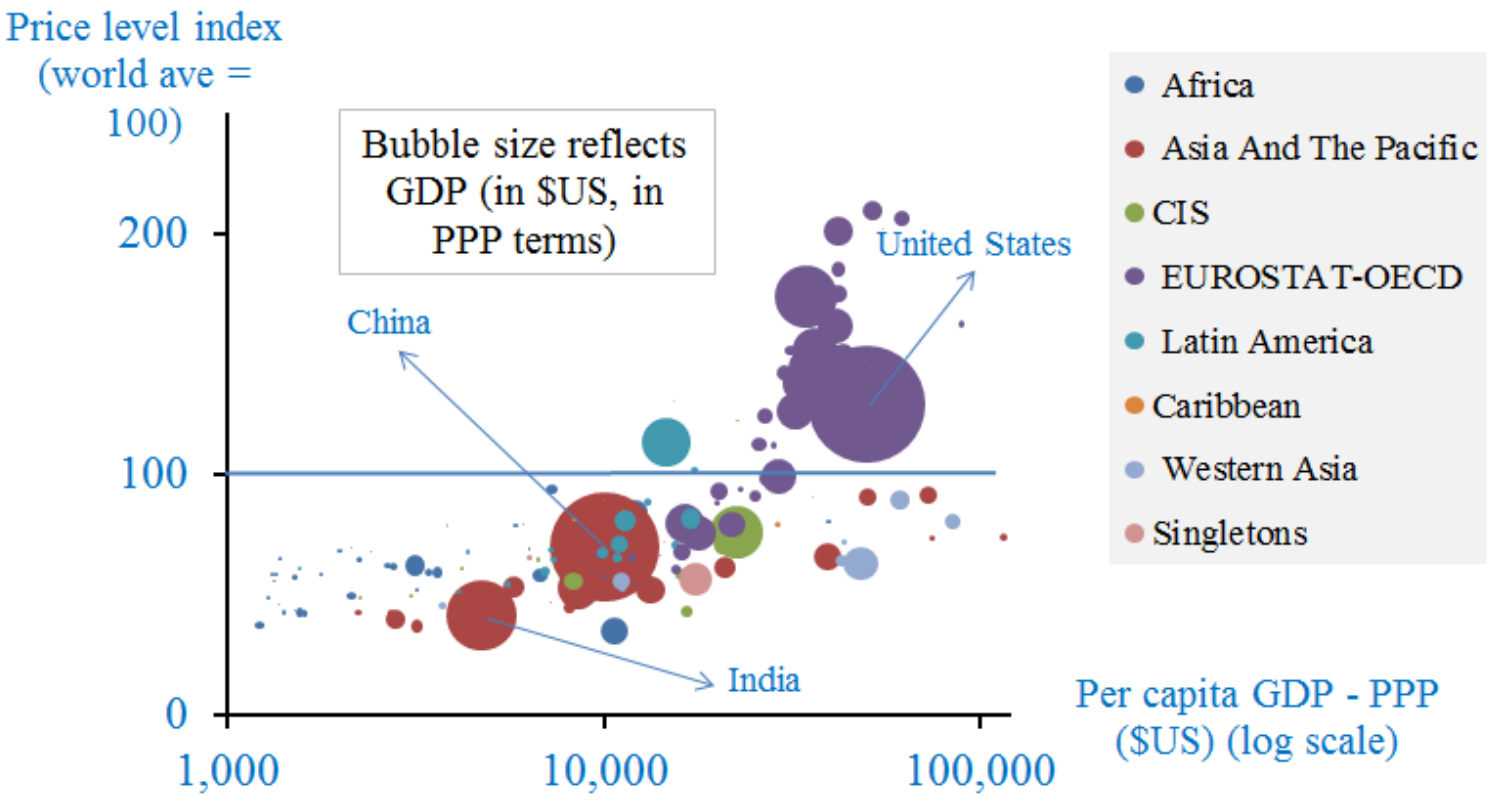

Per capita GDP - MER

B. Two income measures

(\$US) (Log scale)

\section{$45^{\circ}$ line}

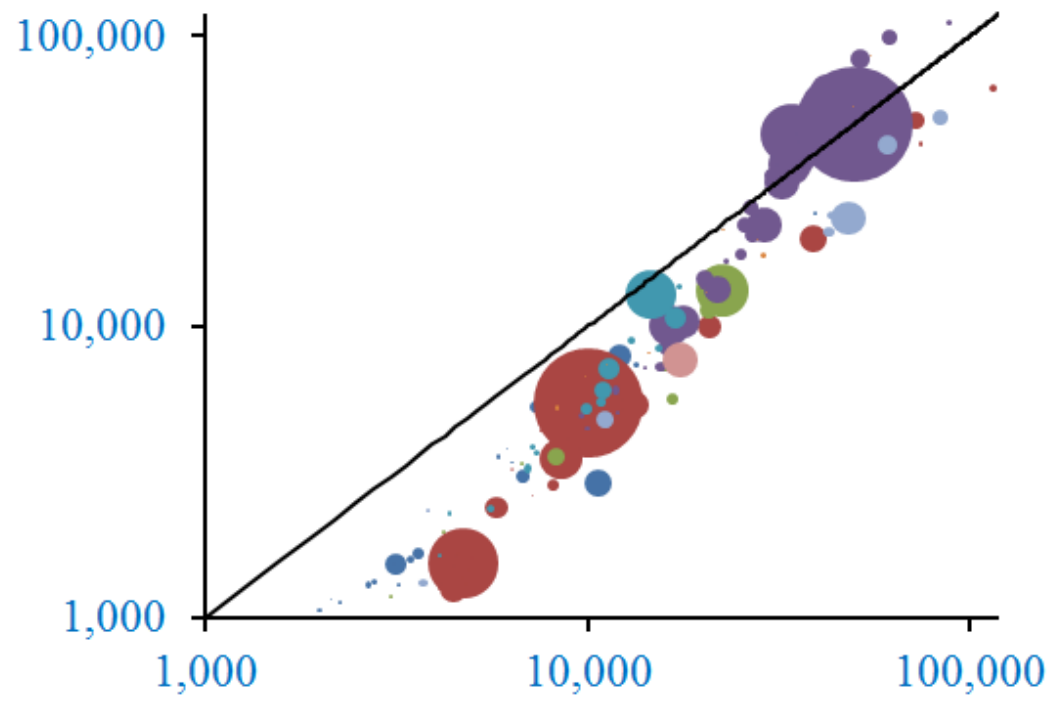

Per capita GDP - PPP

(\$US) (Log scale)

Notes: "MER" = "Market exchange rate"; "CIS" = "Commonwealth of Independent Countries".

1. There are originally 182 economies in the published ICP database (three of which are dual-participants, meaning they take part in surveys of two regions at the same time: Egypt, Sudan and Russian Federation). After omitting the duplicates, we further exclude Cuba and Bonaire because of incomplete data (as a result of methodological comparability issues).

2. Panel A: This is a replication of the figure used in a presentation by the World Bank's ICP, which is available at http://www. worldbank.org/en/news/video/2017/03/28/icp-tutorial-video-2. The vertical axis represents the ratio between PPP rates and MER.

3. Panel B: The numeraire country (US) lies on the $45^{\circ}$ axis, since the two measures are equal for the US.

4. In both panels, the sizes of the bubbles are proportional to the size of the countries, as measured by total GDP (in PPP terms). 
SUPPLEMENTARY MATERIALS

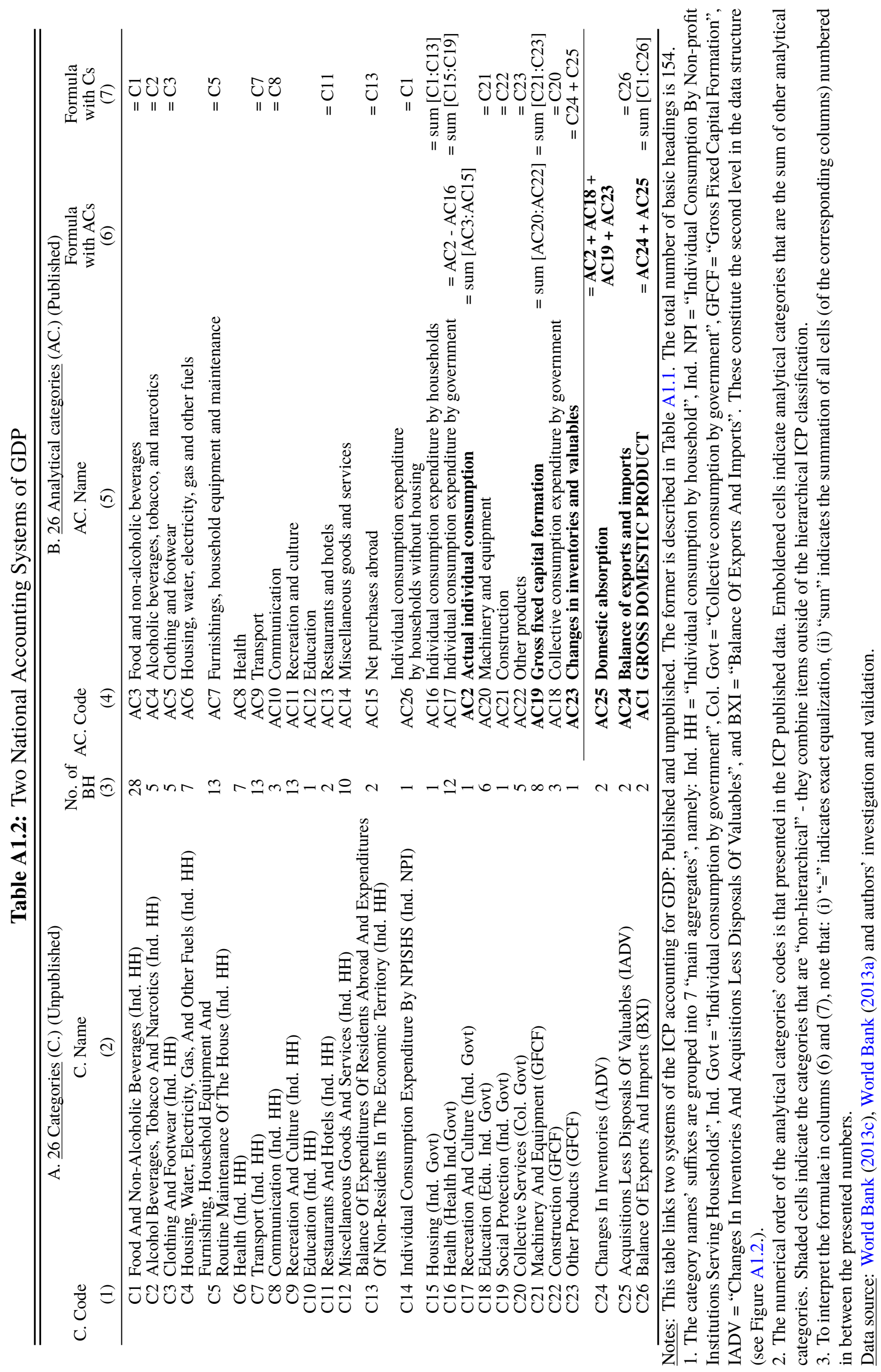




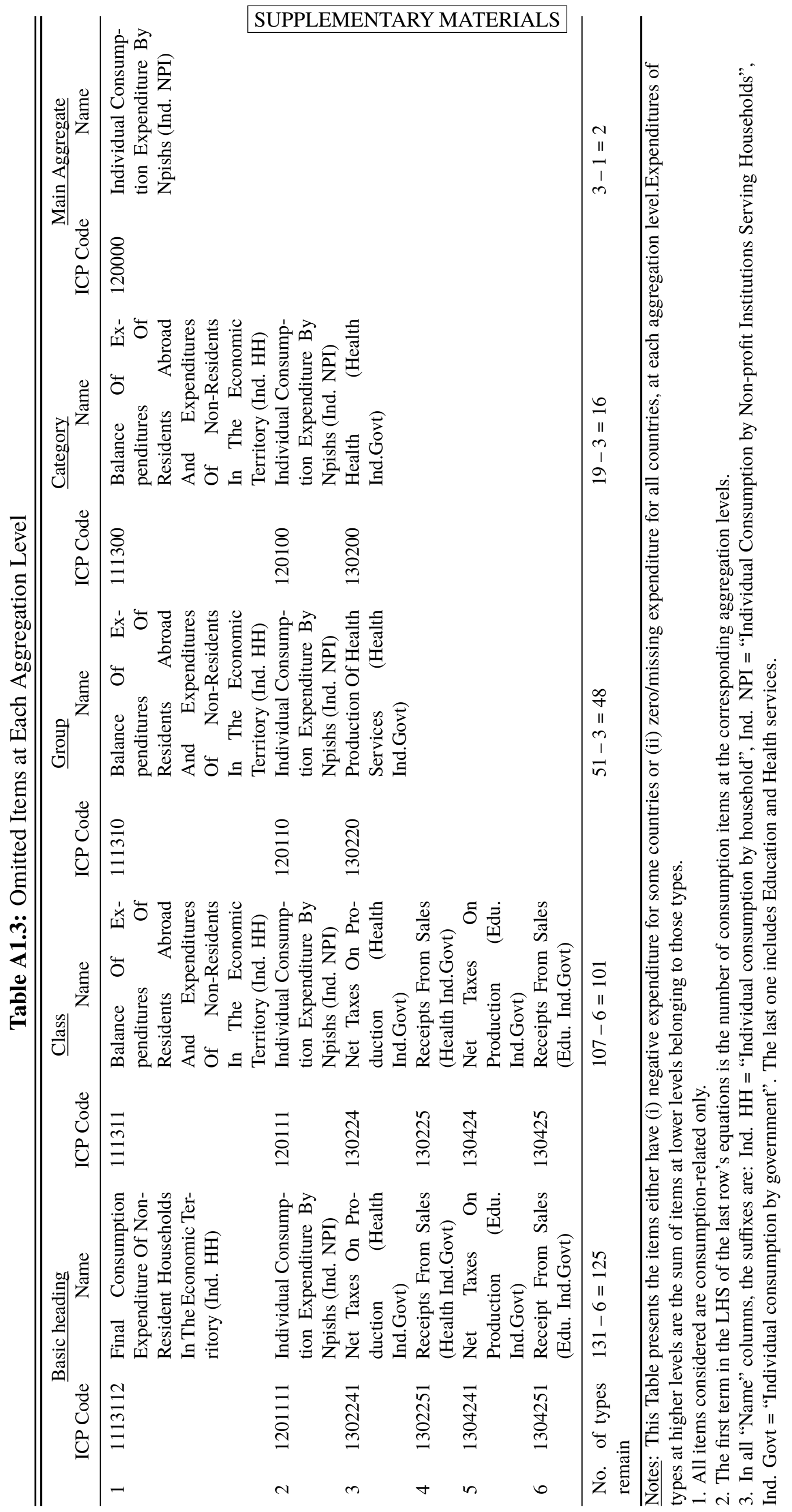


headings in the first broad food group - "Bread and Cereals". P can be expressed as:

$$
\begin{aligned}
& \begin{array}{lllll}
\text { Benin } & \ldots & \text { US } & \ldots & \text { Georgia }
\end{array} \\
& \mathbf{P}=\begin{array}{c}
\text { Rice } \\
\text { Other cereals } \\
\vdots \\
\text { Pasta products }
\end{array}\left(\begin{array}{ccccc}
\mathrm{p}_{1}^{1} & \ldots & 1 & \ldots & \mathrm{p}_{155}^{1} \\
\mathrm{p}_{1}^{2} & \ldots & 1 & \ldots & \mathrm{p}_{155}^{2} \\
\vdots & \ldots & 1 & \ldots & \vdots \\
\mathrm{p}_{1}^{5} & \ldots & 1 & \ldots & \mathrm{p}_{155}^{5}
\end{array}\right)=\left[\mathrm{p}_{\mathrm{i}, \mathrm{c}}\right]
\end{aligned}
$$

where $p_{i, c}$ denotes the "global PPP" between country c and the numeraire country (the US) for item i. The matrix of corresponding real volumes (or implicit quantity levels) has the same dimension as $\mathbf{P}: \mathbf{Q}=\left[\mathrm{q}_{\mathrm{i}, \mathrm{c}}\right]=\left[\mathrm{M}_{\mathrm{i}, \mathrm{c}} / \mathrm{p}_{\mathrm{i}, \mathrm{c}}\right]$ where $\mathrm{M}_{\mathrm{i}, \mathrm{c}}$ is the nominal expenditure devoted to item $i$ in c. We can then construct the $155 \times 155$ Laspeyres-type bilateral index matrix as:

$$
\mathbf{P}_{\text {Las }}=\left[\frac{\widetilde{\mathbf{p}}_{\mathrm{c}} \cdot \widetilde{\mathbf{q}}_{\mathrm{d}}}{\widetilde{\mathbf{p}}_{\mathrm{d}} \cdot \widetilde{\mathbf{q}}_{\mathrm{d}}}\right](\mathrm{c}, \mathrm{d}=1, \ldots, 155)
$$

where $\widetilde{\mathbf{p}}_{\mathrm{c}} \cdot \widetilde{\mathbf{q}}_{\mathrm{d}}=\left(\sum_{\mathrm{i}=1}^{5} \mathrm{p}_{\mathrm{i}, \mathrm{c}} \mathrm{q}_{\mathrm{i}, \mathrm{d}}\right) /\left(\sum_{\mathrm{i}=1}^{5} \mathrm{p}_{\mathrm{i}, \mathrm{d}} \mathrm{q}_{\mathrm{i}, \mathrm{d}}\right)$ is the inner product of the $\mathrm{c}^{\text {th }}$ row of $\mathbf{P}^{\prime}$ and $\mathrm{d}^{\text {th }}$ column of $\mathbf{Q}$. Similarly, a Paasche-type index can be constructed as:

$$
\mathbf{P}_{\text {Paas }}=\left[\frac{\widetilde{\mathbf{p}}_{\mathrm{c}} \cdot \widetilde{\mathbf{q}}_{\mathrm{c}}}{\widetilde{\mathbf{p}}_{\mathrm{d}} \cdot \widetilde{\mathbf{q}}_{\mathrm{c}}}\right](\mathrm{c}, \mathrm{d}=1, \ldots, 155) .
$$

We then combine the two matrices to derive a Fisher-type index matrix:

$$
\mathbf{P}_{\text {Fish }}=\left[\left(\frac{\widetilde{\mathbf{p}}_{\mathrm{c}} \cdot \widetilde{\mathbf{q}}_{\mathrm{d}}}{\widetilde{\mathbf{p}}_{\mathrm{d}} \cdot \widetilde{\mathbf{q}}_{\mathrm{d}}} \times \frac{\widetilde{\mathbf{p}}_{\mathrm{c}} \cdot \widetilde{\mathbf{q}}_{\mathrm{c}}}{\widetilde{\mathbf{p}}_{\mathrm{d}} \cdot \widetilde{\mathbf{q}}_{\mathrm{c}}}\right)^{1 / 2}\right]=\left[\mathrm{P}_{\mathrm{c}, \mathrm{d}}\right](\mathrm{c}, \mathrm{d}=1, \ldots, 155),
$$

of which each element is the geometric mean of the corresponding elements in the Laspeyres and Paasche matrices. ${ }^{7}$

\section{Justifications for a GEKS system}

What are the primary justifications for adopting a GEKS approach to cross-country comparison in the 2011 ICP? In the index number literature, there are typically two approaches to evaluate the making of the multilateral index numbers comparison. As shall be seen, these two approaches, if used independently, amount to the well-known problems of measurement without theory and theory without measurement. The first is known as the "test" or "axiomatic" approach. The work by Diewert (1999) indicates that the GEKS system (using the Fisher ideal

\footnotetext{
${ }^{7}$ As a prerequisite for the construction of these price index matrices, for any given basic heading, the recorded PPPs must be either different from zero for all countries, or equal to zero for all countries. Since we are using the "processed" global PPPs, there are no all-zero rows in P. For expenditure, there are missing data for some items for a given country c (i.e. the $c^{\text {th }}$ column of $\mathbf{Q}$ is zero). This makes the Laspeyres-, Paasche- and Fisher-type PPPs between the two countries $\mathrm{c}$ and $\mathrm{d}$ undefined. In such cases the ICP suggests that these indices be approximated by the ratio of geometric means of the basic heading PPPs. For example, for the class "Bread and Cereals" we could set $\left(\mathrm{p}_{\text {Las }}\right)_{\mathrm{c}, \mathrm{d}}=\left(\mathrm{p}_{\text {Paas }}\right)_{\mathrm{c}, \mathrm{d}}=\left(\mathrm{p}_{\text {Fish }}\right)_{\mathrm{c}, \mathrm{d}} \approx \frac{\left(\Pi_{\mathrm{i}=1}^{5} \mathrm{p}_{\mathrm{i}, \mathrm{c}}\right)^{1 / 5}}{\left(\Pi_{\mathrm{i}=1}^{5} \mathrm{p}_{\mathrm{i}, \mathrm{d}}\right)^{1 / 5}}$. We use this approach to all other items, and at all higher aggregate levels.
} 
index as the basic building block) passes 9 out of the 11 tests for "desirable" properties (three most relevant for cross-sectional comparisons are transitivity, characteristicity and matrix consistency (Neary, 2004). The second approach relies on the critical assumption that consumers have preferences over different bundles of goods depend on their relative prices. That is, this "economic" approach takes into account the (multilateral) substitution bias. Additive index numbers, such as the Geary-Khamis (Geary, 1958 and Khamis, 1972) (GK) index and the IkléDikhanov-Balk (Iklé, 1972; Dikhanov, 1997 and Balk, 1996) (IDB) index are not consistent with substitution effects. In particular, adoption of single reference relative price will give rise to different inferred consumption volumes of countries that are all located on the same indifference curve. To make matter worse, the substitution bias is much larger in cross-sectional (multilateral) context than in intertemporal context, since both price and volume are more variable in the former. In the words of Diewert (1999, p. 50), this example of the classical index number problem is stated as: “(...) the quest for an additive multilateral method with good economic properties (i.e., a lack of substitution bias) is a doomed venture: Non-linear preferences and production functions cannot be adequately approximated by linear functions." In contrast, the GEKS with a flexible functional form exhibits a reasonable degree of approximation to the indifference curve (Diewert, 2013). GEKS can be regarded as being consistent with an economic approach.

Notwithstanding the consumer-theory inconsistency of the additive indices, the economic approach to index number itself attracts two important criticisms, namely, the uniform preferences across all final purchasers and homothetic preference. ${ }^{8}$ The recent literature on international comparison makes several important discussions regarding the second point. Neary (2004) proposes a multilateral system known as the Geary-Allen International Accounts (GAIA), which is consistent with non-homothetic preferences. The GAIA system 's main weakness is its single set of "global" reference relative prices that may be inappropriate considering the cross-country price differences (see, e.g., Deaton and Heston, 2010 and Feenstra, Ma, and Rao, 2009). An econometric generalization of the Neary model is proposed by Barnett, Diewert, and Zellner (2009), namely, to use a set of representative reference prices for each country. The equal-weighted geometric average of the resulting country-specific parities is conjectured to be close to the (point estimate) GEKS index. ${ }^{9}$ It is noteworthy that, in any application, the usefulness of the multilateral indices is partially dictated by the users' purpose. With respect to ours, the GEKS proves to be an ideal candidate.

\footnotetext{
${ }^{8}$ That is, preferences are represented by a homogeneous utility function.

${ }^{9}$ Nevertheless, this econometric approach to index number problem is generally not feasible due to the exhaustive number of parameters to be estimated (Diewert, 2013, p.161).
} 


\section{Potential modifications to the GEKS index}

When comparing prices internationally, we cannot directly use the individual items' local prices $\mathrm{p}_{\mathrm{i}, \mathrm{c}}$, since these implicitly contain not only different currency units, but also different quantities of consumption (i.e, $1 \mathrm{~kg}$ of rice, 1 gallon of water etc.). The bilateral index derived by (A2.1), which is a Fisher ideal index, accounts (to some degree) for consumption unit differentials, by allowing the volume unit to be the same in the numerators and denominators. Nevertheless, aggregating across different consumption units is, in practice, a less than ideal approach. To circumvent this issue, we takes an average of the disparities between c's currency and the rest of the world's (Diewert, 2013, p. 123) and construct the price level of c as: $\mathrm{P}_{\mathrm{c}}=\left(\prod_{\mathrm{d}=1}^{155} \mathrm{P}_{\mathrm{c}, \mathrm{d}}\right)^{1 / 155}$. However, the different currency units problem remain unresolved: The ratio of the relative prices between $\mathrm{a}$ and $\mathrm{b}$ and between a and $\mathrm{c}$ does not equal to the price between $b$ and $c .{ }^{10}$ To account for this issue, we divide the price level of $\mathrm{c}$ by the US's:

$$
\mathrm{P}_{\mathrm{c}} / \mathrm{P}_{\mathrm{US}}=\left(\prod_{\mathrm{d}=1}^{155} \frac{\mathrm{P}_{\mathrm{c}, \mathrm{d}}}{\mathrm{P}_{\mathrm{US}, \mathrm{d}}}\right)^{1 / 155} \quad(\mathrm{c}, \mathrm{d}=1, \ldots, 155),
$$

and thus convert the average price difference to the difference between $\mathrm{c}$ and the US. This method of weighting is a democratic one, that is, each country (d) gets the same weight in the geometric mean of the separate country (c) estimates (Barnett et al., 2009). $\mathrm{P}_{\mathrm{c}} / \mathrm{P}_{\mathrm{US}}$ can be interpreted as the number of units of country c's currency required to purchase one Dollar's worth of "Bread and Cereals" and receive an equivalent amount of utility.

As of 2011, the ICP publishes the values of $\mathrm{P}_{\mathrm{c}} / \mathrm{P}_{\mathrm{US}}$ only at the category level, but by following the above procedure, we are able to extend compute this ratio for other item classes aside from "Bread and Cereals", and then at all aggregation levels, up to "GDP". The hierarchical structure of these levels is provided in Table A1.2). The corresponding aggregated expenditures are simply the sum of the level-specific component items' expenditures. Note that at each level, we use the derived prices and volumes of the immediate lower level as a starting point, rather than keep aggregating from the basic heading data. ${ }^{11}$ The output of this process is a $\mathrm{n} \times 155$ matrix of PPPs and a corresponding $\mathrm{n} \times 155$ matrix of expenditure where $\mathrm{n}$ denotes the number

\footnotetext{
${ }^{10}$ Mathematically, the matrix $\mathbf{P}_{\text {Fish is not yet transitive. That is, it does not satisfy the condition that PPP computed }}$ between two countries should be the same whether it is computed directly or indirectly via a third one (Rao, 2013).

${ }^{11}$ We adopt this sequential approach, due to a technical reason. For some basic headings, net expenditures (used as weights) for a number of countries are large and negative, leading to negative values of the Laspeyres and/or Paasche matrices and computation of the Fisher index matrix is not feasible. This issue has not been covered in the ICP methodology documents. Adding up expenditures at the higher levels resolves some of this problem, however, negative values of Laspeyres and Paasche matrices can still exist if the negative expenditure figures are sufficiently large. We follow recommendation by the ICP: For these cases, all indices are replaced by the ratio of geometric means of the basic heading PPPs between each of the two countries and the US. As shown later on, negative expenditures are also omitted when computing relative prices and real volume.
} 
of level-specific item groups. ${ }^{12}$

One could argue that using $\mathrm{P}_{\mathrm{c}} / \mathrm{P}_{\mathrm{US}}$ does not satisfactorily account for the problems of averaging over vastly distinct consumption units and currency units (in both the numerator and denominator). Additionally we still have to rely on selecting a (arguably arbitrage) numeraire. A third disadvantage of this approach is that the weight vector is not a normalized one (i.e., $\left.\sum_{\mathrm{i}} \mathrm{q}_{\mathrm{i}} \neq 1\right)$. Nevertheless, to facilitate direct comparison with the ICP results and the previous literature, we follow the above approach to construct aggregated price indices. However, for price comparison at the basic heading level, in the next section we introduce a new budget-share weighted, currency-neutral price measurement that arguably avoids the described setbacks.

\section{A3. Derivations of A REAL COST-OF-living INDiCES}

As pointed out in the previous section, we seek to account for the effects of different currencies and consumption units. Recall that from Section 3, we do this by using the difference between the Dollar price in one country (c) and another (d):

$$
\mathrm{k}_{\mathrm{i}, \mathrm{c}, \mathrm{d}}=\mathrm{k}_{\mathrm{i}, \mathrm{c}}-\mathrm{k}_{\mathrm{i}, \mathrm{d}}=\underbrace{\log \left(\mathrm{p}_{\mathrm{i}, \mathrm{c}} / \mathrm{S}_{\mathrm{c}}\right)}_{\text {\$ price of } \mathrm{i} \text { in } \mathrm{c}}-\underbrace{\log \left(\mathrm{p}_{\mathrm{i}, \mathrm{d}} / \mathrm{S}_{\mathrm{d}}\right)}_{\text {\$ price of } \mathrm{i} \text { in } \mathrm{d}}=\log \left(\mathrm{p}_{\mathrm{i}, \mathrm{c}} / \mathrm{p}_{\mathrm{i}, \mathrm{d}}\right)-\log \left(\mathrm{S}_{\mathrm{c}} / \mathrm{S}_{\mathrm{d}}\right),
$$

where $S_{c}$ and $S_{d}$ are the exchange rates of $c$ and $d$, respectively. By construction, the term $\log \left(\mathrm{p}_{\mathrm{i}, \mathrm{c}} / \mathrm{p}_{\mathrm{i}, \mathrm{d}}\right)$ neutralizes the effect of different consumption units, while the term $\log \left(\mathrm{S}_{\mathrm{c}} / \mathrm{S}_{\mathrm{d}}\right)$ neutralizes the effect of different currencies. For simplicity, where it is straightforward to do so, we suppress the item subscript $\mathrm{i}$ when referring to the bilateral price differences and simply use $\mathrm{k}_{\mathrm{c}, \mathrm{d}}$.

\section{A generalized index}

For item $\mathrm{i}$, as before define the vector of cross-country Dollar prices as: $\widetilde{\mathbf{k}}_{\mathbf{i}}=\left[\mathrm{k}_{\mathrm{i}, 1}, \mathrm{k}_{\mathrm{i}, 2} \ldots, \mathrm{k}_{\mathrm{i}, 155}\right]^{\prime}$ and the corresponding weight (budget shares) vector as $\widetilde{\mathbf{w}}_{\mathrm{i}}=\left[\mathrm{w}_{\mathrm{i}, 1}, \mathrm{w}_{\mathrm{i}, 2}, \ldots, \mathrm{w}_{\mathrm{i}, 155}\right]^{\prime}$. Define the matrix of price differentials as

$$
\mathbf{K}_{\mathrm{i}}=\left[\begin{array}{cccc}
0 & \mathrm{k}_{1,2} & \ldots & \mathrm{k}_{1,155} \\
\mathrm{k}_{2,1} & 0 & \ldots & \mathrm{k}_{2,155} \\
\vdots & \vdots & \ddots & \vdots \\
\mathrm{k}_{155,1} & \mathrm{k}_{155,2} & \ldots & 0
\end{array}\right]=\widetilde{\mathbf{k}}_{\mathrm{i}} \widetilde{\imath}-\widetilde{\imath} \widetilde{\mathbf{k}}_{\mathrm{i}}^{\prime}
$$

where $\vec{\imath}=[1,1, \ldots, 1]$ is a 155 -element vector of 1 . Since $k_{c, d}=0$ when $c=d$ and $k_{c, d}=-k_{d, c}$, $\mathbf{K}_{\mathbf{i}}$ is a skew-symmetric matrix.

\footnotetext{
${ }^{12}$ Using this approach, we are able to derive a series of cross-country PPPs at GDP level that has an almost perfect correlation with the corresponding published PPPs (that includes both consumption and non-consumption items). The implied root mean squared errors (RMSE) is 9.5. That is, the average difference between our measure and the published one by the ICP is 9.5 units of local currency.
} 
Next, we compute the multilateral price index of country $\mathrm{c}$ as the average of the weighted price differentials between $\mathrm{c}$ and the rest of the world (including c):

(A3.1) $\log \mathrm{P}_{\mathrm{i}, \mathrm{c}}=\frac{1}{155} \sum_{\mathrm{d}=1}^{155} \frac{\mathrm{w}_{\mathrm{i}, \mathrm{c}}+\mathrm{w}_{\mathrm{i}, \mathrm{d}}}{2} \mathrm{k}_{\mathrm{c}, \mathrm{d}} ; \Sigma_{\mathrm{i}=1}^{125} \mathrm{w}_{\mathrm{i}, \mathrm{c}}=\Sigma_{\mathrm{i}=1}^{125} \mathrm{w}_{\mathrm{i}, \mathrm{d}}=1(\mathrm{c}, \mathrm{d}=1, \ldots, 155)$.

Then, the vector of price indices can be defined as the sum of two terms:

$$
\widetilde{\mathbf{P}}_{\mathrm{i}}=\left[\begin{array}{c}
\log \mathrm{P}_{\mathrm{i}, 1} \\
\log \mathrm{P}_{\mathrm{i}, 2} \\
\vdots \\
\log \mathrm{P}_{\mathrm{i}, 155}
\end{array}\right]=\frac{1}{2} \frac{1}{155} \times\left[\begin{array}{c}
\Sigma_{\mathrm{d}=1}^{155} \mathrm{w}_{\mathrm{i}, 1} \mathrm{k}_{1, \mathrm{~d}} \\
\Sigma_{\mathrm{d}=1}^{155} \mathrm{w}_{\mathrm{i}, 2} \mathrm{k}_{2, \mathrm{~d}} \\
\vdots \\
\Sigma_{\mathrm{d}=1}^{155} \mathrm{w}_{\mathrm{i}, 155} \mathrm{k}_{155, \mathrm{~d}}
\end{array}\right]+\frac{1}{2} \frac{1}{155} \times \underbrace{\left[\begin{array}{c}
\Sigma_{\mathrm{d}=1}^{155} \mathrm{w}_{\mathrm{i}, \mathrm{d}} \mathrm{k}_{1, \mathrm{~d}} \\
\Sigma_{\mathrm{d}=1}^{155} \mathrm{w}_{\mathrm{i}, \mathrm{d}} \mathrm{k}_{2, \mathrm{~d}} \\
\vdots \\
\Sigma_{\mathrm{d}=1}^{155} \mathrm{w}_{\mathrm{i}, \mathrm{d}} \mathrm{k}_{155, \mathrm{~d}}
\end{array}\right]}_{\mathbf{K}_{\mathrm{i}} \widetilde{\mathbf{w}}_{\mathrm{i}}} .
$$

In essence, this approach is close to the construction of the Fisher Ideal Index underlying the GEKS methodology (as in (A2.1)), in the sense that we measure the bilateral difference with a "mid-point" weight.

Next, define the matrices $\mathbf{A}_{\mathrm{i}}$ and $\mathbf{B}_{\mathrm{i}}$ as:

$$
\begin{aligned}
& \mathbf{A}_{\mathrm{i}}=\widetilde{\mathbf{k}}_{\mathrm{i}} \tau \widetilde{\imath} \widetilde{\mathbf{w}}_{\mathrm{i}}^{\prime}=155\left[\begin{array}{cccc}
\mathrm{w}_{\mathrm{i}, 1} \mathrm{k}_{\mathrm{i}, 1} & \mathrm{w}_{\mathrm{i}, 2} \mathrm{k}_{\mathrm{i}, 1} & \ldots & \mathrm{w}_{\mathrm{i}, 155} \mathrm{k}_{\mathrm{i}, 1} \\
\mathrm{w}_{\mathrm{i}, 1} \mathrm{k}_{\mathrm{i}, 2} & \mathrm{w}_{\mathrm{i}, 2} \mathrm{k}_{\mathrm{i}, 2} & \ldots & \mathrm{w}_{\mathrm{i}, 155} \mathrm{k}_{\mathrm{i}, 2} \\
\vdots & \vdots & \ldots & \vdots \\
\mathrm{w}_{\mathrm{i}, 1} \mathrm{k}_{\mathrm{i}, 155} & \mathrm{w}_{\mathrm{i}, 2} \mathrm{k}_{\mathrm{i}, 155} & \ldots & \mathrm{w}_{\mathrm{i}, 155} \mathrm{k}_{\mathrm{i}, 155}
\end{array}\right] ; \\
& \mathbf{B}_{\mathrm{i}}=\widetilde{\imath} \widetilde{\mathbf{k}}_{\mathrm{i}}^{\prime} \tau \widetilde{\mathbf{w}}_{\mathrm{i}}^{\prime}=\sum_{\mathrm{d}=1}^{155} \mathrm{k}_{\mathrm{i}, \mathrm{d}}\left[\begin{array}{cccc}
\mathrm{w}_{\mathrm{i}, 1} & \mathrm{w}_{\mathrm{i}, 2} & \ldots & \mathrm{w}_{\mathrm{i}, 155} \\
\mathrm{w}_{\mathrm{i}, 1} & \mathrm{w}_{\mathrm{i}, 2} & \ldots & \mathrm{w}_{\mathrm{i}, 155} \\
\vdots & \vdots & \ldots & \vdots \\
\mathrm{w}_{\mathrm{i}, 1} & \mathrm{w}_{\mathrm{i}, 2} & \ldots & \mathrm{w}_{\mathrm{i}, 155}
\end{array}\right] .
\end{aligned}
$$

It can be shown that the first term of $\widetilde{\mathbf{P}}_{\mathrm{i}}$ is a vector proportional to the main diagonal of the matrix $\mathbf{A}_{\mathrm{i}}-\mathbf{B}_{\mathrm{i}}$. A typical element of this diagonal vector is $\Sigma_{\mathrm{d}=1}^{155} \mathrm{w}_{\mathrm{i}, \mathrm{c}}\left(\mathrm{k}_{\mathrm{i}, \mathrm{c}}-\mathrm{k}_{\mathrm{i}, \mathrm{d}}\right)(\mathrm{c}, \mathrm{d}=1, \ldots, 155)$. We can express this difference term by $\widetilde{\eta}_{\mathbf{i}}-\widetilde{\vartheta}_{\mathbf{i}}$, where $\widetilde{\eta}_{\mathrm{i}}$ and $\widetilde{\vartheta}_{\mathrm{i}}$ denote the main diagonal of $\mathbf{A}_{\mathbf{i}}$ and $\mathbf{B}_{\mathrm{i}}$, respectively. Then, $\widetilde{\mathbf{P}}_{\mathrm{i}}=\frac{1}{2 \times 155}\left(\mathbf{K}_{\mathrm{i}} \widetilde{\mathbf{w}}_{\mathrm{i}}+\left[\widetilde{\eta}_{\mathrm{i}}-\widetilde{\vartheta}_{\mathrm{i}}\right]\right)$. How do we interpret $\widetilde{\eta}_{\mathrm{i}}$ and $\widetilde{\vartheta}_{\mathrm{i}}$ ? As shown in the subsequent discussions, $\widetilde{\eta}_{\mathrm{i}}$ is proportional to the vector cost-of-living indices defined in a conventional way: That is, by weighting the local prices with local budget shares rather than weighting average prices with average shares. As for $\widetilde{\vartheta}_{i}$, it is the vector of price indices that weights all countries' prices by each country's budget shares, one at a time.

Finally, aggregating the item-specific price vectors gives us a formulation of the vector of 
cost-of-living index:

$$
\widetilde{\mathbf{P}}=\sum_{\mathrm{i}=1}^{125} \widetilde{\mathbf{P}}_{\mathrm{i}}=\left[\begin{array}{c}
\sum_{\mathrm{i}=1}^{125} \log \mathrm{P}_{\mathrm{i}, 1} \\
\sum_{\mathrm{i}=1}^{125} \log \mathrm{P}_{\mathrm{i}, 2} \\
\vdots \\
\Sigma_{\mathrm{i}=1}^{125} \log \mathrm{P}_{\mathrm{i}, 155}
\end{array}\right]=\frac{1}{2 \times 155} \sum_{\mathrm{i}=1}^{125}\left(\mathbf{K}_{\mathrm{i}} \widetilde{\mathbf{w}}_{\mathrm{i}}+\left[\widetilde{\eta}_{\mathrm{i}}-\widetilde{\vartheta}_{\mathrm{i}}\right]\right) .
$$

Since both consumption units and currency units drop out of these indices, we can use them in cross-country comparisons. Another major advantage of this approach is that rather than relying on a single numeraire, as normally is the case in PPP computations, all bilateral differences are taken into account.

\section{An intermediate index}

If, when computing the price for country c, we do not use the bilateral average weights as above, and instead only use the weights corresponding to $\mathrm{c}$, the multilateral price index (A3.1) becomes: $\log \mathrm{P}_{\mathrm{i}, \mathrm{c}}^{*}=\frac{1}{155} \sum_{\mathrm{d}=1}^{155} \mathrm{w}_{\mathrm{i}, \mathrm{c}} \mathrm{k}_{\mathrm{c}, \mathrm{d}}(\mathrm{c}, \mathrm{d}=1, \ldots, 155)$, and the individual price index vector is proportional to the difference between the main diagonals of $\mathbf{A}_{\mathbf{i}}$ and $\mathbf{B}_{\mathrm{i}}$ :

$$
\widetilde{\mathbf{P}}_{\mathrm{i}}^{*}=\left[\begin{array}{c}
\log \mathrm{P}_{\mathrm{i}, 1}^{*} \\
\log \mathrm{P}_{\mathrm{i}, 2}^{*} \\
\vdots \\
\log \mathrm{P}_{\mathrm{i}, 155}^{*}
\end{array}\right]=\frac{1}{155}\left[\begin{array}{c}
\sum_{\mathrm{d}=1}^{155} \mathrm{w}_{\mathrm{i}, 1} \mathrm{k}_{1, \mathrm{~d}} \\
\Sigma_{\mathrm{d}=1}^{155} \mathrm{w}_{\mathrm{i}, 2} \mathrm{k}_{2, \mathrm{~d}} \\
\vdots \\
\Sigma_{\mathrm{d}=1}^{155} \mathrm{w}_{\mathrm{i}, 155} \mathrm{k}_{155, \mathrm{~d}}
\end{array}\right]=\frac{1}{155}\left(\widetilde{\eta}_{\mathrm{i}}-\widetilde{\vartheta}_{\mathrm{i}}\right) .
$$

The corresponding cost-of-living indices are:

$$
\widetilde{\mathbf{P}}^{*}=\sum_{\mathrm{i}=1}^{125} \widetilde{\mathbf{P}}_{\mathrm{i}}^{*}=\frac{1}{155} \sum_{\mathrm{i}=1}^{125}\left(\widetilde{\eta}_{\mathrm{i}}-\widetilde{\vartheta}_{\mathrm{i}}\right) .
$$

Subtract both sides of (A3.4) from (A3.3) we have:

$$
\widetilde{\mathbf{P}}-\widetilde{\mathbf{P}}^{*}=\frac{1}{2 \times 155} \sum_{\mathrm{i}=1}^{125}\left(\mathbf{K}_{\mathrm{i}} \widetilde{\mathbf{w}}_{\mathrm{i}}-\left[\widetilde{\eta}_{\mathrm{i}}-\widetilde{\vartheta}_{\mathrm{i}}\right]\right) \therefore 2 \widetilde{\mathbf{P}}-\widetilde{\mathbf{P}}^{*}=\frac{1}{155} \sum_{\mathrm{i}=1}^{125} \mathbf{K}_{\mathrm{i}} \widetilde{\mathbf{w}}_{\mathrm{i}} .
$$

\section{The conventional index}

We can further simplify the generalized index by replacing price differentials in (A3.1) with the local prices at $\mathrm{c}$ and weight them by the local budget shares, so that: $\log \mathrm{P}_{\mathrm{i}, \mathrm{c}}^{* *}=$ $\mathrm{w}_{\mathrm{i}, \mathrm{c}} \log \frac{\mathrm{p}_{\mathrm{i}, \mathrm{c}}}{\mathrm{S}_{\mathrm{c}}}$ and $\Sigma_{\mathrm{i}=1}^{125} \mathrm{w}_{\mathrm{i}, \mathrm{c}}=1(\mathrm{c}=1, \ldots, 155)$. Then, the individual price index vector is proportional to the main diagonal of $\mathbf{A}_{\mathrm{i}}$ :

$$
\widetilde{\mathbf{P}}_{\mathrm{i}}^{* *}=\left[\begin{array}{c}
\log \mathrm{P}_{\mathrm{i}, 1}^{* *} \\
\log \mathrm{P}_{\mathrm{i}, 2}^{* *} \\
\vdots \\
\log \mathrm{P}_{\mathrm{i}, 155}^{* *}
\end{array}\right]=\frac{1}{155}\left[\begin{array}{c}
155 \mathrm{w}_{\mathrm{i}, 1} \mathrm{k}_{1, \mathrm{c}} \\
155 \mathrm{w}_{\mathrm{i}, 2} \mathrm{k}_{2, \mathrm{c}} \\
\vdots \\
155 \mathrm{w}_{\mathrm{i}, 155} \mathrm{k}_{155, \mathrm{c}}
\end{array}\right]=\frac{1}{155}\left(\widetilde{\eta}_{\mathrm{i}}\right) .
$$


The corresponding cost-of-living indices are:

$$
\widetilde{\mathbf{P}}^{* *}=\sum_{\mathrm{i}=1}^{125} \widetilde{\mathbf{P}}_{\mathrm{i}}^{* *}=\frac{1}{155} \sum_{\mathrm{i}=1}^{125}\left(\widetilde{\eta}_{\mathrm{i}}\right) \text {. }
$$

The indices $\widetilde{\mathbf{P}}^{* *}$ are popularly used to (i) compute a "real" consumption measure (by deflating international consumptions with them) and (ii) compute a relative price measure (by subtracting them from the domestic prices). The difference between (A3.3) and (A3.5) can be expressed as:

$$
\widetilde{\mathbf{P}}-\widetilde{\mathbf{P}}^{* *}=\frac{1}{2 \times 155} \sum_{\mathrm{i}=1}^{125}\left(\mathbf{K}_{\mathrm{i}} \widetilde{\mathbf{w}}_{\mathrm{i}}-\left[\widetilde{\eta}_{\mathrm{i}}+\widetilde{\vartheta}_{\mathrm{i}}\right]\right) \therefore 2 \widetilde{\mathbf{P}}-\widetilde{\mathbf{P}}^{* *}=\frac{1}{155} \sum_{\mathrm{i}=1}^{125}\left(\mathbf{K}_{\mathrm{i}} \widetilde{\mathbf{w}}_{\mathrm{i}}-\widetilde{\vartheta}_{\mathrm{i}}\right) .
$$

And the difference between (A3.4) and (A3.5) is:

$$
\widetilde{\mathbf{P}}^{*}-\widetilde{\mathbf{P}}^{* *}=-\frac{1}{155} \widetilde{\vartheta}_{\mathrm{i}}
$$

\section{Comparison of the three indices}

On the left-hand side (LHS) of Figure A3.5 we present the scatterplots of $\widetilde{\mathbf{P}}^{*}$ and $\widetilde{\mathbf{P}}^{* *}$ against $\widetilde{\mathbf{P}}$. It can be seen that the intermediate indices track the generalized indices much better than the conventional indices. Specifically, panel B reveals that the generalized index is systematically lower than the conventional index. Intuitively, when we use the generalized indices as a benchmark, not accounting for differences in consumption unit introduces substantial biases. We label 10 countries with the greatest absolute vertical distance from the $45^{\circ}$ line, in descending order: Iraq, Antigua and Barbuda , Jamaica, Suriname, Oman, Anguilla, Bahrain, Jordan, UAE and Qatar. Of these, 6 are Middle East and OPEC countries.

When we plot the differences between these indices $\left(\widetilde{\mathbf{P}}-\widetilde{\mathbf{P}}^{*}\right.$ and $\widetilde{\mathbf{P}}-\widetilde{\mathbf{P}}^{* *}$, respectively) against income (on the right-hand side of Figure A3.5), we can see that the biases tend to be significantly larger for poorer countries. The magnitude of the biases are much larger when using the conventional indices than when using the intermediate indices, and in some cases the difference is tenfold. The same "outliers" are labelled.

\section{Generalized indices for tradables and nontradables}

Now, we restrict the construction of the generalized price index to the basket of tradables: That is, $\mathrm{i} \in \mathrm{T}$ where $\mathrm{T}$ denotes the subset of tradable items. ${ }^{13}$ There are $\mathrm{m}<125$ items in this subset. Define the price of a tradable item in c as:

$$
\log \mathrm{P}_{\mathrm{i}, \mathrm{c}}^{\mathrm{T}}=\frac{1}{155} \sum_{\mathrm{d}=1}^{155} \frac{\mathrm{w}_{\mathrm{i}, \mathrm{c}}^{\mathrm{T}}+\mathrm{w}_{\mathrm{i}, \mathrm{d}}^{\mathrm{T}}}{2} \mathrm{k}_{\mathrm{c}, \mathrm{d}}^{\mathrm{T}}(\mathrm{c}, \mathrm{d}=1, \ldots, 155),
$$

\footnotetext{
${ }^{13}$ Definition of tradability is discussed in Section 3 of the main text.
} 
Figure A3.5: Price Indices and Income, 155 Countries, 2011

\section{A. Intermediate Index}
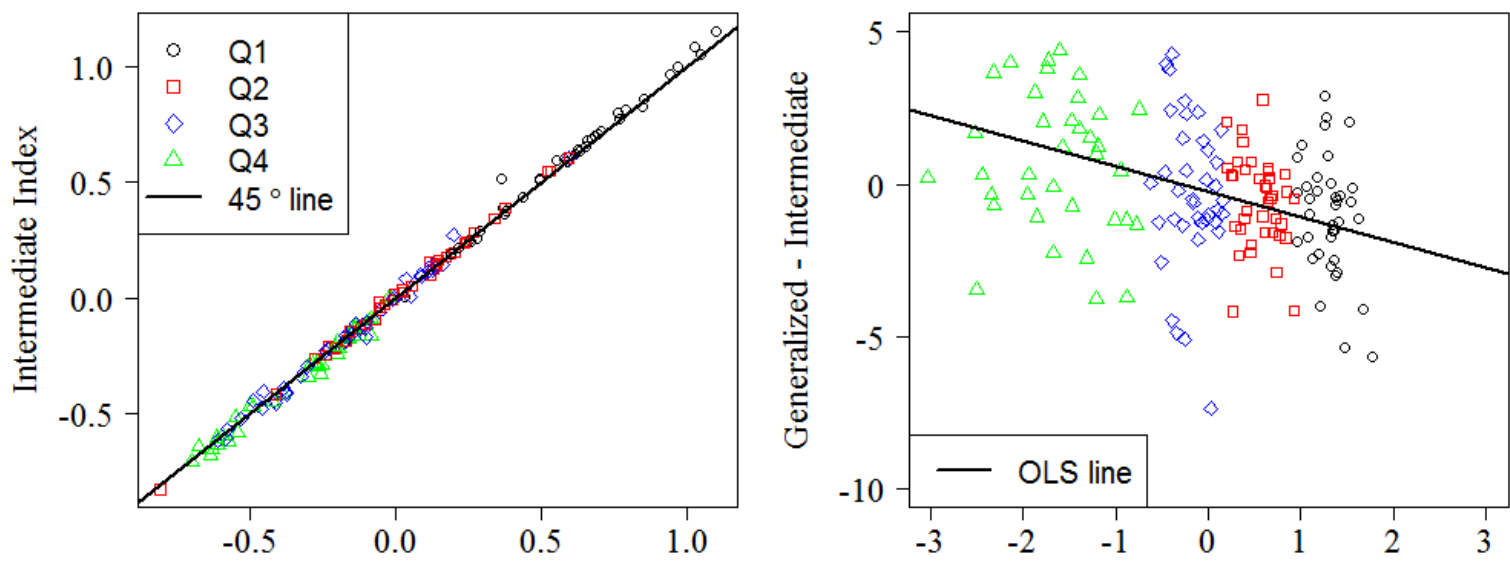

Generalized index

Income

\section{B. Conventional Index}

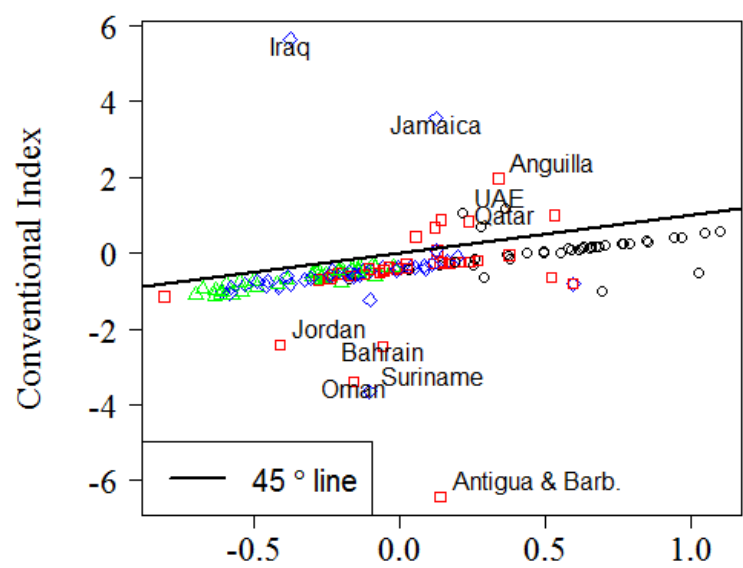

Generalized index

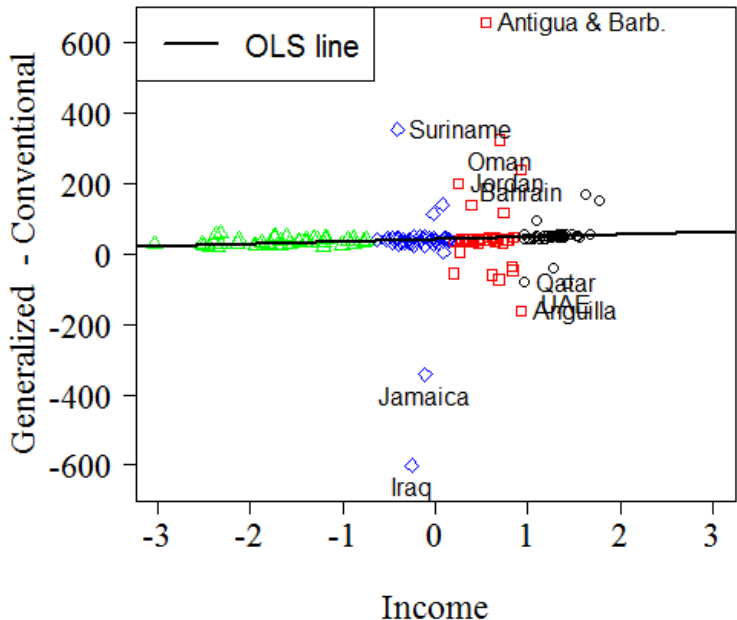

Notes: This figure compares the generalized index with the intermediate index (panel A) and with the conventional one (panel B).

1. Each point represents one country. These are color-coded based on income quartiles: Q4 the poorest and Q1 the richest. Income is defined as $\log (\mathrm{Y} / \overline{\mathrm{Y}})$ where $\mathrm{Y}$ denotes the real per capita consumption and $\overline{\mathrm{Y}}$ is the cross-country geometric mean of $Y$.

2. The left-hand side figures give the scatter plot of the intermediate and conventional indices against the generalized index.

3. The right-hand side figures plot the differences between the two indices and the generalized index against income.

where $\mathrm{w}_{\mathrm{i}, \mathrm{c}}^{\mathrm{T}}=\mathrm{M}_{\mathrm{i}, \mathrm{c}}^{\mathrm{T}} /\left(\sum_{\mathrm{i}=1}^{\mathrm{m}} \mathrm{M}_{\mathrm{i}, \mathrm{c}}^{\mathrm{T}}\right)$ and $\mathrm{w}_{\mathrm{i}, \mathrm{d}}^{\mathrm{T}}=\mathrm{M}_{\mathrm{i}, \mathrm{d}}^{\mathrm{T}} /\left(\sum_{\mathrm{i}=1}^{\mathrm{m}} \mathrm{M}_{\mathrm{i}, \mathrm{d}}^{\mathrm{T}}\right)$ are the tradable-conditional budget shares of $i(i \in T)$ in $c$ and $d . M_{i, c}^{T}$ and $M_{i, d}^{T}$ are the expenditure devoted to $i$ in $c$ and $d$. The budget shares satisfy $\sum_{\mathrm{i}=1}^{\mathrm{m}} \mathrm{w}_{\mathrm{i}, \mathrm{c}}^{\mathrm{T}}=\sum_{\mathrm{i}=1}^{\mathrm{m}} \mathrm{w}_{\mathrm{i}, \mathrm{d}}^{\mathrm{T}}=1 . \mathrm{k}_{\mathrm{c}, \mathrm{d}}^{\mathrm{T}}$ denotes the difference of $\mathrm{i}$ 's Dollar prices in $\mathrm{c}$ and $\mathrm{d}$. Then, (A3.3) is modified to arrive at a tradable price index vector:

$$
\widetilde{\mathbf{P}}^{\mathrm{T}}=\left[\sum_{\mathrm{i}=1}^{\mathrm{m}} \log \mathrm{P}_{\mathrm{i}, \mathrm{c}}^{\mathrm{T}}\right]=\sum_{\mathrm{i}=1}^{\mathrm{m}} \widetilde{\mathbf{P}}_{\mathrm{i}}^{\mathrm{T}}=\frac{1}{2 \times 155} \sum_{\mathrm{i}=1}^{\mathrm{m}}\left(\mathbf{K}_{\mathrm{i}}^{\mathrm{T}} \widetilde{\mathbf{w}}_{\mathrm{i}}^{\mathrm{T}}+\left[\widetilde{\eta}_{\mathrm{i}}^{\mathrm{T}}-\widetilde{\vartheta}_{\mathrm{i}}^{\mathrm{T}}\right]\right)(\mathrm{c}=1, \ldots, 155),
$$


where $\mathbf{K}_{\mathbf{i}}^{\mathrm{T}}, \widetilde{\mathbf{w}}_{\mathbf{i}}^{\mathrm{T}}, \widetilde{\eta}_{\mathrm{i}}^{\mathrm{T}}$ and $\widetilde{\vartheta}_{\mathbf{i}}^{\mathrm{T}}$ are the tradable counterparts of $\mathbf{K}_{\mathbf{i}}, \widetilde{\mathbf{w}}_{\mathbf{i}}, \widetilde{\eta}_{\mathrm{i}}$ and $\widetilde{\vartheta}_{\mathbf{i}}$. Similar indices can be constructed for the $125-\mathrm{m}$ non-tradables items as

$$
\widetilde{\mathbf{P}}^{\mathrm{N}}=\left[\sum_{\mathrm{i}=\mathrm{m}+1}^{125} \log \mathrm{P}_{\mathrm{i}, \mathrm{c}}^{\mathrm{N}}\right]=\sum_{\mathrm{i}=\mathrm{m}+1}^{125} \widetilde{\mathbf{P}}_{\mathrm{i}}^{\mathrm{N}}=\frac{1}{2 \times 155} \sum_{\mathrm{i}=\mathrm{m}+1}^{125}\left(\mathbf{K}_{\mathrm{i}}^{\mathrm{N}} \widetilde{\mathbf{w}}_{\mathrm{i}}^{\mathrm{N}}+\left[\widetilde{\eta}_{\mathrm{i}}^{\mathrm{N}}-\widetilde{\vartheta}_{\mathrm{i}}^{\mathrm{N}}\right]\right)(\mathrm{c}=1, \ldots, 155),
$$

where $\mathrm{N}$ denotes the subset of non-tradables. $\widetilde{\mathbf{P}}^{\mathrm{T}}$ and $\widetilde{\mathbf{P}}^{\mathrm{N}}$ form the basis of the analyses in Section 5 .

How can $\widetilde{\mathbf{P}}^{\mathrm{T}}$ and $\widetilde{\mathbf{P}}^{\mathrm{N}}$ be related to $\widetilde{\mathbf{P}}$ ? To answer this question, consider a typical elements of each of these three vectors (which pertains to the price index in a single country):

$$
\begin{aligned}
\log \mathrm{P}_{\mathrm{c}}=\sum_{\mathrm{i}} \log \mathrm{P}_{\mathrm{i}, \mathrm{c}} & =\frac{1}{2 \times 155} \sum_{\mathrm{i}} \sum_{\mathrm{d}}\left(\mathrm{w}_{\mathrm{i}, \mathrm{c}}+\mathrm{w}_{\mathrm{i}, \mathrm{d}}\right) \mathrm{k}_{\mathrm{c}, \mathrm{d}} \\
& =\frac{1}{2 \times 155} \sum_{\mathrm{i} \in \mathrm{T}} \sum_{\mathrm{d}}\left(\mathrm{w}_{\mathrm{i}, \mathrm{c}}+\mathrm{w}_{\mathrm{i}, \mathrm{d}}\right) \mathrm{k}_{\mathrm{c}, \mathrm{d}}^{\mathrm{T}}+\frac{1}{2 \times 155} \sum_{\mathrm{i} \in \mathrm{N}} \sum_{\mathrm{d}}\left(\mathrm{w}_{\mathrm{i}, \mathrm{c}}+\mathrm{w}_{\mathrm{i}, \mathrm{d}}\right) \mathrm{k}_{\mathrm{c}, \mathrm{d}}^{\mathrm{N}} ;
\end{aligned}
$$

$\log \mathrm{P}_{\mathrm{c}}^{\mathrm{T}}=\sum_{\mathrm{i} \in \mathrm{T}} \log \mathrm{P}_{\mathrm{i}, \mathrm{c}}^{\mathrm{T}}=\frac{1}{2 \times 155} \sum_{\mathrm{i} \in \mathrm{T}} \sum_{\mathrm{d}}\left(\mathrm{w}_{\mathrm{i}, \mathrm{c}}^{\mathrm{T}}+\mathrm{w}_{\mathrm{i}, \mathrm{d}}^{\mathrm{T}}\right) \mathrm{k}_{\mathrm{c}, \mathrm{d}}^{\mathrm{T}}$;

$\log \mathrm{P}_{\mathrm{c}}^{\mathrm{N}}=\sum_{\mathrm{i} \in \mathrm{N}} \log \mathrm{P}_{\mathrm{i}, \mathrm{c}}^{\mathrm{N}}=\frac{1}{2 \times 155} \sum_{\mathrm{i} \in \mathrm{N}} \sum_{\mathrm{d}}\left(\mathrm{w}_{\mathrm{i}, \mathrm{c}}^{\mathrm{N}}+\mathrm{w}_{\mathrm{i}, \mathrm{d}}^{\mathrm{N}}\right) \mathrm{k}_{\mathrm{c}, \mathrm{d}}^{\mathrm{N}}$.

Define the total weight of tradables in $\mathrm{c}$ as $\mathrm{w}_{\mathrm{c}}^{\mathrm{T}}=\left(\sum_{\mathrm{i} \in \mathrm{T}} \mathrm{M}_{\mathrm{i}, \mathrm{c}}^{\mathrm{T}}\right) /\left(\sum_{\mathrm{i}} \mathrm{M}_{\mathrm{i}, \mathrm{c}}\right)$ and that of nontradables as $\mathrm{w}_{\mathrm{c}}^{\mathrm{N}}=1-\mathrm{w}_{\mathrm{c}}^{\mathrm{T}}$. It follows that $\mathrm{w}_{\mathrm{c}}^{\mathrm{T}} \times \mathrm{w}_{\mathrm{i}, \mathrm{c}}^{\mathrm{T}}=\frac{\sum_{\mathrm{i} \in \mathrm{T}} \mathrm{M}_{\mathrm{i}, \mathrm{c}}^{\mathrm{T}}}{\sum_{\mathrm{i}} \mathrm{M}_{\mathrm{i}, \mathrm{c}}} \times \frac{\mathrm{M}_{\mathrm{i}, \mathrm{c}}}{\sum_{\mathrm{i} \in \mathrm{T}} \mathrm{M}_{\mathrm{i}, \mathrm{c}}^{\mathrm{T}}}=\frac{\mathrm{M}_{\mathrm{i}, \mathrm{c}}}{\sum_{\mathrm{i}} \mathrm{M}_{\mathrm{i}, \mathrm{c}}}=$ $w_{i, c}$ and similarly, $w_{d}^{T} \times w_{i, d}^{T}=w_{i, d}$. Then, multiplying both sides of the third line in (A3.7) by $\mathrm{w}_{\mathrm{c}}^{\mathrm{T}}$ yields:

$$
\begin{aligned}
\mathrm{w}_{\mathrm{c}}^{\mathrm{T}} \sum_{\mathrm{i} \in \mathrm{T}} \log \mathrm{P}_{\mathrm{i}, \mathrm{c}}^{\mathrm{T}} & =\frac{1}{2 \times 155} \sum_{\mathrm{i} \in \mathrm{T}} \sum_{\mathrm{d}} \mathrm{w}_{\mathrm{c}}^{\mathrm{T}}\left(\mathrm{w}_{\mathrm{i}, \mathrm{c}}^{\mathrm{T}}+\mathrm{w}_{\mathrm{i}, \mathrm{d}}^{\mathrm{T}}\right) \mathrm{k}_{\mathrm{c}, \mathrm{d}}^{\mathrm{T}} \\
& =\frac{1}{2 \times 155} \sum_{\mathrm{i} \in \mathrm{T}} \sum_{\mathrm{d}}\left(\mathrm{w}_{\mathrm{i}, \mathrm{c}}+\frac{\mathrm{w}_{\mathrm{c}}^{\mathrm{T}}}{\mathrm{w}_{\mathrm{d}}^{\mathrm{T}}} \mathrm{w}_{\mathrm{i}, \mathrm{d}}\right) \mathrm{k}_{\mathrm{c}, \mathrm{d}}^{\mathrm{T}} .
\end{aligned}
$$

Multiplying both sides of the last line in (A3.7) by $\mathrm{w}_{\mathrm{c}}^{\mathrm{N}}$ then add them to each side of (A3.8) gives:

$$
\begin{aligned}
\mathrm{w}_{\mathrm{c}}^{\mathrm{T}} \sum_{\mathrm{i} \in \mathrm{T}} \log \mathrm{P}_{\mathrm{i}, \mathrm{c}}^{\mathrm{T}}+\mathrm{w}_{\mathrm{c}}^{\mathrm{N}} \sum_{\mathrm{i} \in \mathrm{N}} \log \mathrm{P}_{\mathrm{i}, \mathrm{c}}^{\mathrm{N}} & =\frac{1}{2 \times 155} \sum_{\mathrm{i} \in \mathrm{T}} \sum_{\mathrm{d}}\left(\mathrm{w}_{\mathrm{i}, \mathrm{c}}+\frac{\mathrm{w}_{\mathrm{c}}^{\mathrm{T}}}{\mathrm{w}_{\mathrm{d}}^{\mathrm{T}}} \mathrm{w}_{\mathrm{i}, \mathrm{d}}\right) \mathrm{k}_{\mathrm{c}, \mathrm{d}}^{\mathrm{T}} \\
& +\frac{1}{2 \times 155} \sum_{\mathrm{i} \in \mathrm{N}} \sum_{\mathrm{d}}\left(\mathrm{w}_{\mathrm{i}, \mathrm{c}}+\frac{\mathrm{w}_{\mathrm{c}}^{\mathrm{N}}}{\mathrm{w}_{\mathrm{d}}^{\mathrm{N}}} \mathrm{w}_{\mathrm{i}, \mathrm{d}}\right) \mathrm{k}_{\mathrm{c}, \mathrm{d}}^{\mathrm{N}} .
\end{aligned}
$$

Finally, subtract both sides of (A3.9) from each side of the second line in (A3.8) gives:

$$
\log \mathrm{P}_{\mathrm{c}}-\left(\mathrm{w}_{\mathrm{c}}^{\mathrm{T}} \log \mathrm{P}_{\mathrm{c}}^{\mathrm{T}}+\mathrm{w}_{\mathrm{c}}^{\mathrm{N}} \log \mathrm{P}_{\mathrm{c}}^{\mathrm{N}}\right)=\frac{1}{2 \times 155}\left(\sum_{\mathrm{i} \in \mathrm{T}} \sum_{\mathrm{d}}\left[1-\frac{\mathrm{w}_{\mathrm{c}}^{\mathrm{T}}}{\mathrm{w}_{\mathrm{d}}^{\mathrm{T}}}\right] \mathrm{w}_{\mathrm{i}, \mathrm{d}} \mathrm{k}_{\mathrm{c}, \mathrm{d}}^{\mathrm{T}}+\sum_{\mathrm{i} \in \mathrm{N}} \sum_{\mathrm{d}}\left[1-\frac{\mathrm{w}_{\mathrm{c}}^{\mathrm{N}}}{\mathrm{w}_{\mathrm{d}}^{\mathrm{N}}}\right] \mathrm{w}_{\mathrm{i}, \mathrm{d}} \mathrm{k}_{\mathrm{c}, \mathrm{d}}^{\mathrm{N}}\right) \text {. }
$$


Now, define new tradable and non-tradable price indices for $\mathrm{c}$ as:

$$
\log \Pi_{\mathrm{c}}^{\mathrm{T}}=\frac{1}{155} \sum_{\mathrm{i} \in \mathrm{T}} \sum_{\mathrm{d}} \mathrm{w}_{\mathrm{i}, \mathrm{d}} \mathrm{k}_{\mathrm{c}, \mathrm{d}}^{\mathrm{T}} ; \log \Pi_{\mathrm{c}}^{\mathrm{N}}=\frac{1}{155} \sum_{\mathrm{i} \in \mathrm{T}} \sum_{\mathrm{d}} \mathrm{w}_{\mathrm{i}, \mathrm{d}} \mathrm{k}_{\mathrm{c}, \mathrm{d}}^{\mathrm{N}} \text {. }
$$

These new indices are similar to the intermediate index introduced earlier. The only difference is that they use the weights specific to country d, rather than to c. Substituting them into (A3.10) allows us to write:

$\Delta \mathrm{P}_{\mathrm{c}}=\log \mathrm{P}_{\mathrm{c}}-\left(\mathrm{w}_{\mathrm{c}}^{\mathrm{T}} \log \mathrm{P}_{\mathrm{c}}^{\mathrm{T}}+\mathrm{w}_{\mathrm{c}}^{\mathrm{N}} \log \mathrm{P}_{\mathrm{c}}^{\mathrm{N}}\right)=\log \Pi_{\mathrm{c}}^{\mathrm{T}}\left(\frac{1}{2} \sum_{\mathrm{d}}\left[1-\frac{\mathrm{w}_{\mathrm{c}}^{\mathrm{T}}}{\mathrm{w}_{\mathrm{d}}^{\mathrm{T}}}\right]\right)+\log \Pi_{\mathrm{c}}^{\mathrm{N}}\left(\frac{1}{2} \sum_{\mathrm{d}}\left[1-\frac{\mathrm{w}_{\mathrm{c}}^{\mathrm{N}}}{\mathrm{w}_{\mathrm{d}}^{\mathrm{N}}}\right]\right)$.

It can be seen that the difference between the weighted price index and the generalized index is attributable to the overall weights $\left(\mathrm{w}_{\mathrm{c}}^{\mathrm{T}}\right.$ and $\left.\mathrm{w}_{\mathrm{c}}^{\mathrm{N}}\right)$ being specific to country $\mathrm{c}$, as opposed to bilateral weights that are averaged when constructing generalized index. Nevertheless, the difference is not significant: The cross-country mean of $\Delta \mathrm{P}_{\mathrm{c}}$ is $-3 \%$. Following the conventional practice in the literature, we use $\left(\mathrm{w}_{\mathrm{c}}^{\mathrm{T}} \log \mathrm{P}_{\mathrm{c}}^{\mathrm{T}}+\mathrm{w}_{\mathrm{c}}^{\mathrm{N}} \log \mathrm{P}_{\mathrm{c}}^{\mathrm{N}}\right)$ as the price level index.

The validity of the HBS model rests on two crucial assumptions: (i) homothetic preference of consumers (that is, the shares of tradables/non-tradables are the same across countries) and (ii) LOP holds for tradables. But as shown in Figures 3.2, these assumptions are not realistic: Budget share of tradable falls while its price rises (though not as fast as non-tradable price) as income rises. Recall that in Section ?? we defined the real exchange rate, at the price level,

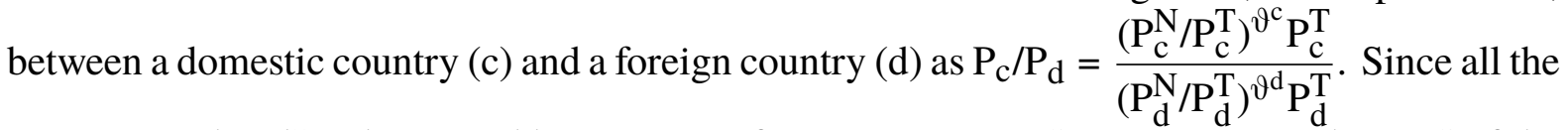
new "generalized" indices used here are unit-free, we can omit S. We can write the LHS of the above expression as $\mathrm{P}_{\mathrm{c}} / \mathrm{P}_{\mathrm{d}}=\left[\left(\mathrm{P}_{\mathrm{c}} / \mathrm{P}_{\mathrm{d}}\right) \times\left(\mathrm{P}_{\mathrm{d}}^{\mathrm{T}} / \mathrm{P}_{\mathrm{c}}^{\mathrm{T}}\right)\right] \times\left(\mathrm{P}_{\mathrm{c}}^{\mathrm{T}} / \mathrm{P}_{\mathrm{d}}^{\mathrm{T}}\right)$. The term in the squared bracket can thus be interpreted as the differential in relative prices of non-tradables in $\mathrm{c}$ and $\mathrm{d}$ (or the HBS effect). We denote this term as $\mathrm{K}_{\mathrm{c}, \mathrm{d}}^{\mathrm{N}}=\left(\mathrm{P}_{\mathrm{c}} / \mathrm{P}_{\mathrm{d}}\right) \times\left(\mathrm{P}_{\mathrm{d}}^{\mathrm{T}} / \mathrm{P}_{\mathrm{c}}^{\mathrm{T}}\right)=\left(\mathrm{P}_{\mathrm{c}}^{\mathrm{N}} / \mathrm{P}_{\mathrm{c}}^{\mathrm{T}}\right)^{\vartheta^{\mathrm{c}}}\left(\mathrm{P}_{\mathrm{d}}^{\mathrm{T}} / \mathrm{P}_{\mathrm{d}}^{\mathrm{N}}\right)^{\vartheta^{\mathrm{d}}} \cdot{ }^{14}$ The second term, denoted as $\mathrm{K}_{\mathrm{c}, \mathrm{d}}^{\mathrm{T}}=\mathrm{P}_{\mathrm{c}}^{\mathrm{T}} / \mathrm{P}_{\mathrm{d}}^{\mathrm{T}}$, is the differential in tradable prices. Since there are only two goods in this context, the decomposition takes a simple form of an identity. In logarithmic form

$$
\log \mathrm{P}_{\mathrm{c}}-\log \mathrm{P}_{\mathrm{d}}=\log \mathrm{K}_{\mathrm{c}, \mathrm{d}}^{\mathrm{N}}+\log \mathrm{K}_{\mathrm{c}, \mathrm{d}}^{\mathrm{T}},(\mathrm{c}, \mathrm{d}=1, \ldots, 155),
$$

If the HBS hypothesis holds, we expect to observe a large value of $\log \mathrm{K}_{\mathrm{c}, \mathrm{d}}^{\mathrm{N}}$ with respect to $\log \mathrm{K}_{\mathrm{c}, \mathrm{d}}^{\mathrm{T}}$.

To implement this decomposition, we first consider the case of a single base country, the United States. That is, we set $\mathrm{c}=\mathrm{US}$ and derive the corresponding vectors of $\left[\log \mathrm{K}_{\mathrm{US}, \mathrm{d}}^{\mathrm{N}}\right]$ and

\footnotetext{
${ }^{14}$ We circumvent the need to use a specific functional form of the price level (i.e. ignoring $\vartheta^{\mathrm{c}}$ and $\vartheta^{\mathrm{d}}$ ) and only need bilateral information on the price level indices and tradable price indices to infer the real exchange rate (Betts and Kehoe, 2017). This is, in essence, a cross-sectional counterpart to the conventional time series "PPP-accounting" exercise (see e.g. Engel, 1999).
} 
$\left[\log \mathrm{K}_{\mathrm{US}, \mathrm{d}}^{\mathrm{N}}\right]$. Table A3.4 documents the elements of these vectors, together with their respective contributions in total changes in the US-based bilateral real exchange rates. We partition the countries into income quartiles. On average, the contribution of the changes in non-tradable price is comparable to those in tradable price (both are about 15\%, albeit with opposite signs) for the richest quartile. For the other three poorer quartiles, however, the contribution of the HBS effect is much higher, from 2 to 1.4 times that of the changes in tradable price. Productivity differentials between the US and the rich countries are probably smaller than between the US and the poor, hence the smaller HBS effect for the rich. The "grand" mean real exchange rate between the US and the rest of the world is $53 \%$. That is, on average, using the derived price indices, the US Dollar is 53\% over-valued compared with other currencies. This number can be decomposed into a differential of $15 \%$ in tradable prices, and $38 \%$ in non-tradables prices.

We repeat this exercise by consecutively using the rest of the countries as the base of comparison and report the country-specific grand means in Table A3.5. On average, using either the richest or poorest countries as bases leads to the domination of tradable price effect over the HBS effect, while both effects are of equal importance for the middle income countries. Additionally, for the second quartile, since their incomes/productivities are closer to the world average, their deviations from PPP are small. Compared to the rest of the world, these countries exhibit negligible differentials in both tradable and non-tradable prices $(1 \%$ and $3 \%$, respectively).

\section{A4. A pilot study using PCA}

The use of principal component analysis (hereafter PCA) has a long standing in modern macroeconomics research. PCA applications have been primarily associated with time series data. Stock and Watson (2002a) show that for large sample sizes, using principal components that represent common latent factors extracted from a large number of predictors could provide asymptotically efficient forecasts in the context of stationary time series. In a related paper, Stock and Watson (2002b) apply their dynamic factor model to 215 economic variables as possible predictors of 8 monthly US macroeconomics time series. Notwithstanding the difficulties in exchange rate modelling due to the disconnection of economic fundamentals, in a recent paper, Ponomareva, Sheen, and Wang (2019) propose using PCA to extract a common factor that explains about fifty percent of the cross-sectional variance in the returns of 15 US-based exchange rates. These authors find that the common component is highly correlated with various trade-weighted multilateral US exchange rates, and can be related to US fundamentals and commodity prices. We distinct our paper from the above studies in the data aspect: 
Rather than using either within-country time series of many variables (e.g. US macroeconomic indicators) or cross-country time series of one variable (e.g. US bilateral exchange rates), we use cross-country data for many variables. ${ }^{15}$

\section{Relative prices and consumption}

Here we examine closer the price comparison matrix: ${ }^{16}$

$$
\mathbf{K}_{\mathrm{i}}=\left[\begin{array}{cccc}
0 & \mathrm{k}_{1,2} & \ldots & \mathrm{k}_{1,155} \\
\mathrm{k}_{2,1} & 0 & \ldots & \mathrm{k}_{2,155} \\
\vdots & \vdots & \ddots & \vdots \\
\mathrm{k}_{155,1} & \mathrm{k}_{155,2} & \ldots & 0
\end{array}\right]=\widetilde{\mathbf{k}}_{\mathrm{i}} \widetilde{\imath}-\widetilde{\imath} \widetilde{\mathbf{k}}_{\mathrm{i}}^{\prime}
$$

where $\widetilde{\mathbf{k}}_{\mathrm{i}}=\left[\mathrm{k}_{\mathrm{i}, 1}, \mathrm{k}_{\mathrm{i}, 2} \ldots, \mathrm{k}_{\mathrm{i}, 155}\right]^{\prime}$ is the vector of cross-country Dollar prices. Consider the vector of row averages of $\mathbf{K}_{\mathrm{i}}$ :

$$
\overline{\mathbf{k}}_{\mathbf{i}}=\mathbf{M} \widetilde{\mathbf{k}}_{\mathbf{i}}, \text { with } \mathbf{M}=\mathbf{I}-\frac{1}{155} \widetilde{\imath} \widetilde{\imath},
$$

where $\mathbf{I}$ is an identity matrix, $\mathbf{M}$ is a symmetric idempotent matrix (so that $\mathbf{M}^{\prime} \mathbf{M}=\mathbf{M}$ ) of order $155 \times 155$. A typical element of $\overline{\mathbf{k}}_{\mathrm{i}}$ is $\overline{\mathrm{k}}_{\mathrm{i}, \mathrm{c}}=\frac{1}{155} \sum_{\mathrm{d}=1}^{155}\left[\log \left(\mathrm{p}_{\mathrm{i}, \mathrm{c}} / \mathrm{S}_{\mathrm{c}}\right)-\log \left(\mathrm{p}_{\mathrm{i}, \mathrm{d}} / \mathrm{S}_{\mathrm{d}}\right)\right](\mathrm{c}, \mathrm{d}=$ $1, \ldots, 155)$. In the previous section, we point out that $\overline{\mathrm{k}}_{\mathrm{i}, \mathrm{c}}$ is free of currency units and consumption units. The unilateral price vector $\widetilde{\mathbf{p}}_{\mathbf{i}}$ coincides with the multilateral price vector $\overline{\mathbf{k}}_{\mathbf{i}}$ when $\mathbf{M}=\mathbf{I}$.

The equivalence of a "relative volume" measure can be defined in a similar manner to that of prices:

$$
\mathbf{Q}_{i}=\left[\begin{array}{cccc}
0 & \left(\log \mathrm{q}_{\mathrm{i}, 1}-\log \mathrm{q}_{\mathrm{i}, 2}\right) & \ldots & \left(\log \mathrm{q}_{\mathrm{i}, 1}-\log \mathrm{q}_{\mathrm{i}, 155}\right) \\
\left(\log \mathrm{q}_{\mathrm{i}, 2}-\log \mathrm{q}_{\mathrm{i}, 1}\right) & 0 & \ldots & \left(\log \mathrm{q}_{\mathrm{i}, 2}-\log \mathrm{q}_{\mathrm{i}, 155}\right) \\
\vdots & \vdots & \ddots & \vdots \\
\left(\log \mathrm{q}_{\mathrm{i}, 155}-\log \mathrm{q}_{\mathrm{i}, 1}\right) & \left(\log \mathrm{q}_{\mathrm{i}, 155}-\log \mathrm{q}_{\mathrm{i}, 2}\right) & \ldots & 0
\end{array}\right]=\widetilde{\mathbf{q}}_{\mathrm{i}} \widetilde{\iota}^{\prime}-\widetilde{\imath} \widetilde{\mathbf{q}}_{\mathrm{i}}^{\prime},
$$

where $\widetilde{\mathbf{q}}_{\mathrm{i}}=\left[\mathrm{q}_{\mathrm{i}, 1}, \mathrm{q}_{\mathrm{i}, 2} \ldots, \mathrm{q}_{\mathrm{i}, 155}\right]^{\prime}$ is a vector of consumption volumes. A typical element of this vector is the logarithmic real consumption: $\log \mathrm{q}_{\mathrm{i}, \mathrm{c}}=\log \left(\mathrm{M}_{\mathrm{i}, \mathrm{c}} / \mathrm{p}_{\mathrm{i}, \mathrm{c}}\right)(\mathrm{c}=1, \ldots, 155)$, where

\footnotetext{
${ }^{15}$ The study that is closest in spirit to ours is Cuthbert (2009), who examine and compare the properties of 6 primary PPP aggregation methods used by PPP. Broadly speaking, these indices can be considered as the equivalence of our aggregated measures. This author posits that the underlying traits of ICP data, in particular the large negative price elasticities of demand, are useful for sorting countries into groups represented by consumption behaviour. These data characteristics are then shown to be related to two principal components that strongly describe the cross-country variability of the indices. The purpose and approach of this study is also different from ours: While Cuthbert seeks to explore the similarity, or co-movement, among a small number of aggregated volume indices with the ultimate goal of exposing their strengths and weaknesses in measuring real income, we are more interested in both price and consumption structures of a large number of disaggregated items. Additionally, we allow the aggregation level to vary, and show that the main results do not change substantially with aggregation (see Section 5.2).

${ }^{16}$ This matrix has the same form as the "pay parity" matrix from the paper with the same title of Clements, Lan, and Seah (2012), in which case $\widetilde{\mathbf{p}}$ refers to a vector of executive remuneration.
} 
$\mathrm{M}_{\mathrm{i}, \mathrm{c}}=\mathrm{p}_{\mathrm{i}, \mathrm{c}} \mathrm{q}_{\mathrm{i}, \mathrm{c}}$ is the per capita expenditure devoted to item $\mathrm{i}$ in country $\mathrm{c}$. It is helpful to again note that even though $\mathrm{q}_{\mathrm{i}, \mathrm{c}}$ is free of currency units, it is not free of consumption units. Therefore, cross-item comparison of consumption necessitates the use of $\mathbf{Q}_{\mathrm{i}}$. Similar to price matrices, we can "compress" the matrix $\mathbf{Q}_{\mathbf{i}}$ by using the averages of the bilateral consumption differentials as:

$$
\overline{\mathbf{q}}_{\mathrm{i}}=\mathbf{M} \widetilde{\mathbf{q}}_{\mathbf{i}}
$$

From (A4.1) and (A4.2), it follows that:

$$
\overline{\mathbf{k}}_{\mathrm{i}}^{\prime} \overline{\mathbf{q}}_{\mathrm{i}}=\left(\mathbf{M} \widetilde{\mathbf{k}}_{\mathrm{i}}\right)^{\prime} \mathbf{M} \widetilde{\mathbf{q}}_{\mathrm{i}}=\widetilde{\mathbf{k}}_{\mathrm{i}}^{\prime} \mathbf{M} \widetilde{\mathbf{q}}_{\mathrm{i}}=\widetilde{\mathbf{k}}_{\mathrm{i}}^{\prime} \overline{\mathbf{q}}_{\mathrm{i}},
$$

since $\mathbf{M}^{\prime} \mathbf{M}=\mathbf{M}$. This means that the product of the cross-country average Dollar prices and relative volumes is equal to the product of the original Dollar prices and relative volumes. Finally, define the matrices of average relative prices and average relative volumes as:

$$
\mathbf{K}=\left[\overline{\mathbf{k}}_{1}, \overline{\mathbf{k}}_{2}, \ldots, \overline{\mathbf{k}}_{125}\right] ; \mathbf{Q}=\left[\overline{\mathbf{q}}_{1}, \overline{\mathbf{q}}_{2}, \ldots, \overline{\mathbf{q}}_{125}\right]
$$

The above approach can be applied to data at higher aggregated levels constructed in Section A2. $\mathbf{K}$ and $\mathbf{Q}$ form the basis of the analyses in Sections A4 and A5 of the Appendix, as well as Sections 5 and 5.2 of the main text.

\section{The correlation of food prices}

We discuss the principal component analysis (hereafter PCA) via a simplified example. Assume that there is only two items in the world's food consumption basket: "Bread" and "Rice". As above, define the relative price for bread in country c as: $\overline{\mathrm{k}}_{\mathrm{B}, \mathrm{c}}=(1 / 155) \Sigma_{\mathrm{d}=1}^{155}\left[\mathrm{k}_{\mathrm{B}, \mathrm{c}}-\mathrm{k}_{\mathrm{B}, \mathrm{d}}\right](\mathrm{c}, \mathrm{d}=$ $1, \ldots, 155)$, where $\mathrm{k}_{\mathrm{B}, \mathrm{c}}$ and $\mathrm{k}_{\mathrm{B}, \mathrm{d}}$ are the logarithmic Dollar prices of bread in $\mathrm{c}$ and $\mathrm{d}$, respectively. ${ }^{17}$ Similarly, the price of rice is denoted as $\overline{\mathrm{k}}_{\mathrm{R}, \mathrm{c}}$. Together these price vectors constitute the $\mathrm{c} \times 2$ matrix $\mathbf{K}=\left[\overline{\mathbf{k}}_{\mathrm{B}}, \overline{\mathbf{k}}_{\mathrm{R}}\right]$. The covariance matrix of these two variables can be computed as $\Sigma=(1 / 154) \mathbf{K}^{\prime} \mathbf{K} .{ }^{18}$ A linear combination of the variables can be expressed as $\mathbf{y}_{1}=\mathrm{a}_{1} \overline{\mathbf{k}}_{\mathrm{B}}+\mathrm{a}_{2} \overline{\mathbf{k}}_{\mathrm{R}}=\mathbf{K} \mathbf{a}_{1}$ where $\mathbf{a}_{1}$ denotes the coefficient vector: $\mathbf{a}_{1}=\left[\mathrm{a}_{1}, \mathrm{a}_{2}\right]$. According to Theil (1971), a PCA maximizes the sample variance of $\mathbf{y}$, subject to the constraint $\mathbf{a}_{1}^{\prime} \mathbf{a}_{1}=1$. This leads to the characteristic equation (also referred to as an "eigendecomposition"):

$$
\left(\Sigma-\lambda_{1} \mathbf{I}\right) \mathbf{a}_{1}=\mathbf{0},
$$

where $\mathbf{I}$ is a $2 \times 2$ identity matrix and $\mathbf{0}$ is a vector of zeroes. It follows that $\mathbf{a}_{1}=$.

The second eigenvector $\mathbf{a}_{2}$ can be solved via $\left(\Sigma-\lambda_{2} \mathbf{I}\right) \mathbf{a}_{2}=\mathbf{0}$ with $\lambda_{2}$ being the second

\footnotetext{
${ }^{17}$ Due to the almost uniformly unitary correlation between cross-country PPP prices (from ICP publications) and market exchange rates (MER), if we use PPP prices as our underlying variable, the first principal component would inevitably account for almost $100 \%$ of the data variation and is highly correlated with MER.

${ }^{18}$ This is a result of $\overline{\mathbf{k}}_{\mathrm{B}}$ and $\overline{\mathbf{k}}_{\mathrm{B}}$ both having a zero mean by construction.
} 
eigenvalue. ${ }^{19}$ We can then compute the second principal component as $\mathbf{y}_{2}=\mathbf{K a} \mathbf{a}_{2}$. it can be shown that $\mathbf{y}_{2}$ is orthogonal to $\mathbf{y}_{1}$. An important result is that the sum of the variances of the original variable is equal to that of the new variables:

$$
\operatorname{Var}\left(\mathbf{y}_{1}\right)+\operatorname{Var}\left(\mathbf{y}_{2}\right)=\lambda_{1}+\lambda_{2}=\operatorname{Var}\left(\overline{\mathbf{k}}_{\mathrm{B}}\right)+\operatorname{Var}\left(\overline{\mathbf{k}}_{\mathrm{R}}\right)
$$

Additionally, due to each successive component accounts for the maximum amount of variation "left-over" from the previous eigendecomposition and the orthogonality of the components, we have $\lambda_{1}>\lambda_{2}$ (Campbell and Atchley, 1981). This approach is generalized in the following discussion. ${ }^{20}$

\section{More data}

Next, we extend the above approach to the 14 food headings that account for about $70 \%$ of the world's total food consumption. These includes, in order of increasing consumption, "Fresh or chilled vegetables other than potatoes", "Rice", "Fresh, chilled or frozen fish and seafood", "Food products nec", "Fresh or chilled fruit", "Mineral waters, soft drinks, fruit and vegetable juices", "Bread", "Pork + Lamb, mutton and goat", "Other bakery products", "Confectionery, chocolate and ice cream", "Beer", "Other meats and meat preparations", "Beef and veal" and "Poultry". Following Clements and Si (2017), we also group them into 6 broad groups, namely "Staples", "Meat and seafood", "Fruits and vegetables", "Alcohol", "Sweet things" and "Other food".

Internal consistency when computing relative prices is maintained by using, as a benchmark, a food price index derived solely from these 14 price series. The starting point is the data matrix $\mathbf{K}=\left[\overline{\mathbf{k}}_{1}, \overline{\mathbf{k}}_{2}, \ldots, \overline{\mathbf{k}}_{14}\right]$ where $\overline{\mathbf{k}}_{\mathbf{i}}$ denotes the vector of average bilateral differences in the prices of i (see Equation (A4.1)). We standardize each column of $\mathbf{K}$ and obtain $\mathbf{X}=\left[\mathbf{x}_{1}, \mathbf{x}_{2}, \ldots \mathbf{x}_{14}\right]$. We can think of this matrix as containing 14 variables (corresponding to the 14 food items), each has 155 observations. The basic idea of PCA is to find a way to describe these 14 variables with a smaller number of new variables, called "principal components", that preserves most of the original information.

Similar to the 2 variables case, we derive the 14-element vector $\mathbf{a}_{1}$ and the corresponding value $\lambda_{1}$ so that they satisfy the characteristic equation: $\left(\mathbf{X}^{\prime} \mathbf{X}-\lambda_{1} \mathbf{I}\right) \mathbf{a}_{1}=\mathbf{0}$ where $\mathbf{I}$ is an identity matrix and $\mathbf{0}$ is a 14-element zero vector. That is, $\mathbf{a}_{1}$ is a characteristic vector of the $14 \times 14$ positive definite matrix $\mathbf{X}^{\prime} \mathbf{X}$, that corresponds to the largest root $\lambda_{1} \cdot{ }^{21}$ From here, the first

\footnotetext{
${ }^{19}$ Another constraint is that the two eigenvectors are orthogonal, i.e. $\mathbf{a}_{1}^{\prime} \mathbf{a}_{2}=0$. Let $\mathbf{A}=\left[\mathbf{a}_{1}, \mathbf{a}_{2}\right]$. The eigenvectors satisfy $\mathbf{A}^{\prime} \mathbf{A}=\mathbf{A} \mathbf{A}^{\prime}=\mathbf{I}$ (Campbell and Atchley, 1981).

${ }^{20}$ Equivalently, we can say that $\lambda_{1}$ is the largest root of $\operatorname{det}(\Sigma-\lambda \mathbf{I})=0$ where $\operatorname{det}($.) means determinant.

${ }^{21}$ As shown in Table A4.8, in stead of the data matrix $\mathbf{X}^{\prime} \mathbf{X}$, we can perform PCA on the covariance matrix, denoted as $\Sigma=\mathbf{X}^{\prime} \mathbf{X} /(\mathrm{m}-1)$ where $\mathrm{m}=155$. Since we standardized the variables, it is also the correlation matrix.
} 
principal component is constructed as the linear combination of the original variables with the weights (or loadings) given by $\mathbf{a}_{1}$ : $\mathbf{p c}_{1}=\mathbf{X} \mathbf{a}_{1}$. In columns 2 to 5 of Table A4.6, we present the entries of the first three eigenvectors $\left(\mathbf{a}_{1}, \mathbf{a}_{2}, \mathbf{a}_{3}\right)$, the variance of the corresponding principal components (hereafter PCs), and the contributions of them in the total variance. It can be seen that the first two principal components account for $30 \%$ and $18 \%$ of the total relative price variation, respectively. In total the first 3 PCs account for about $60 \%$ of data variation. Figure A4.6 shows the percentage contributions of all principal components.

How many components should we use to efficiently represent our data? In other words, what is the optimal number of dimensions should we "compress" our 14-dimension data into? A rule of thumb for data compression is to select the PCs that can explain at least $100 / 14=7.14 \%$ of the total variance which is the proportion that a standardized original variable explains. ${ }^{22}$ In Figure A4.6, the blue bars represent the percentage of price variance explained for each of the first 10 PCs. This is known as a "Scree plot", a term coined by Cattell (1966). Based on the above rule and the PCA result, the first 4 PCs can be used to sufficiently describe the price data.

Figure A4.6: Contribution of the First 10 Principal Components to Data Variation $\%$ of explained variance

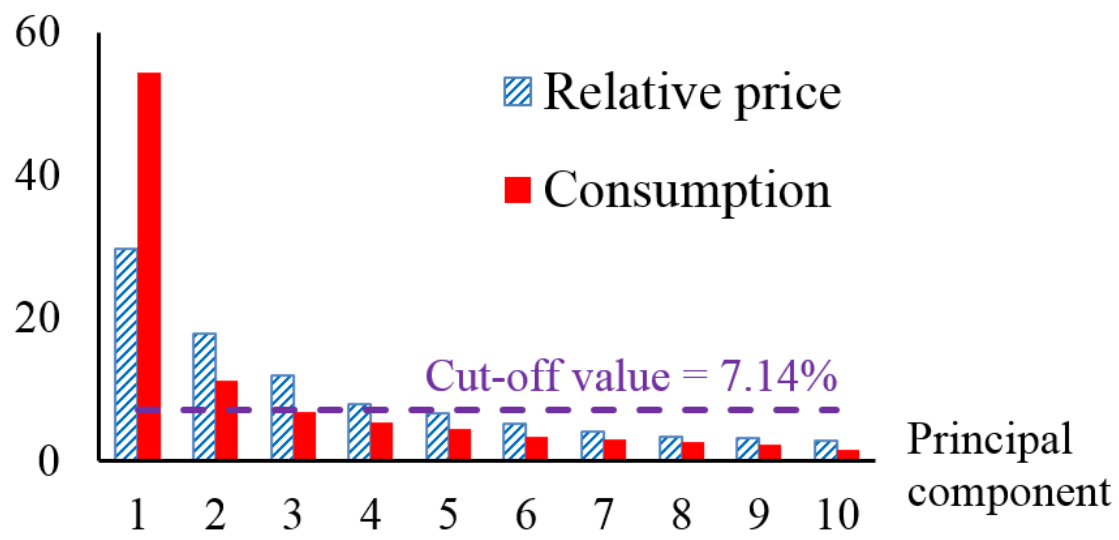

Notes: The cut-off value is based on the Kaiser-Guttman rule (Kaiser, 1960; Guttman, 1954) that a component (extracted from PCA on standardized data) is considered important when it explains at least $1 / \mathrm{n}$ of the total data variation (where $\mathrm{n}$ is the number of original variables).

We continue the above analysis by replacing relative price with consumption. The starting point here is the matrix $\mathbf{Q}$ from Section A4. The PCA is then performed on the matrix $\mathbf{Y}=\left[\mathbf{y}_{1}, \mathbf{y}_{2}, \ldots, \mathbf{y}_{14}\right]$ where $\mathbf{y}_{\mathrm{i}}$ is the standardized $\overline{\mathbf{q}}_{\mathbf{i}}$. We present the results in another Scree

Denote the eigenvalues of this matrix as $\gamma_{i}(i=1 \ldots, 14)$. It can be shown that $\gamma_{i}=\lambda_{i} /(m-1)$ and component contributions to total variance from the two approaches are the same: $\lambda_{i} / \Sigma_{i} \lambda_{i}=\gamma_{i} / \Sigma_{i} \gamma_{i}=\gamma_{i} / 14$. That is, PCA is a variance preservation transformation.

${ }^{22}$ Since the sum of the eigenvalues of the correlation matrix equals the number of original variables (14), this is equivalent to choosing PCs that correspond to eigenvalues (of a correlation matrix) that are greater than 1. This rule is also known as the "Kaiser-Guttman rule" (Kaiser, 1960 and Guttman, 1954). 
plot, which is shown by the red bars of Figure A4.6. The accompanied loadings are provided in columns (6) to (9) of Table A4.6. In this case, the first PC alone accounts for 54\% of the total data variation, and we can use just the first 2 PCs to represent our data. It seems that while the cross-country pricing is too heterogeneous for us to detect a common driving factor, the cross-country consumption behaviour exhibits a stronger common trend.

\section{Eigenvalues and correlations}

Given the above discussion, it is natural to ask: How do we interpret the explanatory power of the first PC? As mentioned, this consumption is also measured by the first eigenvalue of the correlation matrix. It indicates the maximum amount of variance of the variables which can be accounted for with a linear model by a single component. More importantly, according to Friedman and Weisberg (1981), the eigenvalues can be approximated by linear functions of $n(n-1)$ (off-diagonal) correlation coefficients of the $n$ variables, even when the correct specification is non-linear. Understanding the relationship between the first eigenvalue and the correlations is therefore crucial in relating the underlying data dynamics to the computed percentage of variance explained. Morrison (1967) shows that a linear relationship between the first eigenvalue of the correlation matrix (denoted as $\gamma_{1}$ ) and the average correlation (denoted as $\bar{\rho}$ ) would be: 23

$$
\gamma_{1} \approx 1+(n-1) \bar{\rho} \text { where } \bar{\rho}=\frac{1}{n^{2}-n} \sum_{j=1}^{n} \sum_{i=1}^{n} \rho_{i, j}(i \neq j) .
$$

The proportion of variance accounted for by the first PC is $\gamma_{1} / n=1 / n+(n-1) \bar{\rho} / n$. When $n$ is large, $1 / \mathrm{n}$ approaches zero and $\mathrm{n} /(\mathrm{n}-1)$ approaches one, so this proportion approaches $\bar{\rho}$, which is can also be expressed by any function of the central tendency of underlying off-diagonal correlation coefficients.

Let's see how well this approximation rule help explains our data. In the lower (upper) triangle of the matrix in Table A4.7 we present, in the upper triangle, the correlation matrix of the 14 relative price and consumption series. Since each standalone matrix is symmetric, the mean of the off-diagonal elements is equal to the mean of the upper (lower) triangle's elements. The mean correlation is 0.232 for price and 0.48 for consumption. In the following computations, we show only results for prices. The first eigenvalue of the price correlation

\footnotetext{
${ }^{23}$ This estimate is exact in the case of all positive correlations. It performs well when there are only a few, small, nonsystemic negative correlations. In a general case where there can be negative correlation, an increase in $\bar{\rho}$ will not necessarily lead to an increase in $\gamma_{1}$ We can use the general approximation, given as: $\gamma_{1} \approx 1+\max _{\mathrm{m}}\left[(\mathrm{m}-1) \bar{\rho}_{\max }\right]$ where $\bar{\rho}_{\max }$ is the maximum value of $\bar{\rho}$ among all possible sub-matrices of size $m$ and all possible reversals of the variables with negative correlations. Since the first eigenvalue exhibits the strength of co-movement among variables, its value only depends on the magnitudes of the correlation coefficients, not their signs. Therefore, in (A4.4), using $\bar{\rho}$ as the average of the absolute correlation, gives a reasonable approximation.
} 
matrix is 4.18 , while that estimated by approximation rule is $1+(14-1) \times 0.232=4.02$. This would yield an underestimation for the actual eigenvalue of $(4.18-4.02) / 4.18=4 \% .{ }^{24}$ The proportion of data variation accounted for by the first principal component can be computed as: ${ }^{25}$

$$
\Upsilon_{1} / 14=\gamma_{1} /\left(\sum_{i=1}^{14} \gamma_{i}\right)=1 / 14+(14-1) \bar{\rho} / 14=28.7 \%
$$

In this example, the actual proportion is $29.8 \%$ (Table A4.6). Thus, our approximation of $28.7 \%$ likewise underestimates the true value by $4 \%$.

Next, the sum of the elements in the correlation/covariance matrix is:

$$
\Sigma_{j=1}^{14} \Sigma_{i=1}^{14}\left|\rho_{i, j}\right|=14+\Sigma_{j=1}^{14} \Sigma_{i=1}^{14}\left|\rho_{i, j}\right|(i \neq j) .
$$

Recall from (A4.4) that $\bar{\rho}=\frac{1}{14^{2}-14} \sum_{j=1}^{14} \sum_{i=1}^{14} \rho_{i, j}(i \neq j) \approx \frac{\gamma_{1}-1}{14-1}$. Putting this expression into (A4.6) yields:

(A4.7) $\Sigma_{j=1}^{14} \Sigma_{i=1}^{14}\left|\rho_{i, j}\right|=14+\left(14^{2}-14\right) \bar{\rho} \approx 14+\left(14^{2}-14\right)\left(\frac{\Upsilon_{1}-1}{14-1}\right)=14 \Upsilon_{1}=14^{2}\left(\frac{\Upsilon_{1}}{14}\right)$.

Because of standardization, each variable's contribution to total variation is equal to one. Therefore, the incremental impact of individual variable is made solely through an increase of the absolute covariance. So long as a new variable has at least one non-zero correlation with old variables, the total data variation will increase. Applying (A4.7) gives an estimate of total data variation of $14 \gamma_{1}=14 \times 4.02=56.3$.

The above expositions are summarized in Table A4.8. This exercise has an important implication: The proportion of explained variance of the first PC is positively associated with the mean of absolute correlation of the variables. Since the estimate of the consumption eigenvalue is greater than that of the price's (Table A4.6), the former variable has a more homogeneous behaviour and it is easier to capture its dynamic with just the first PC.

\section{Notes on the decomposition of data variation}

Consider again the relative price matrix $\mathbf{K}$ :

$$
\mathbf{K}=\left[\begin{array}{cccc}
\overline{\mathrm{k}}_{1,1} & \overline{\mathrm{k}}_{1,2} & \ldots & \overline{\mathrm{k}}_{1,125} \\
\overline{\mathrm{k}}_{2,1} & \overline{\mathrm{k}}_{2,2} & \ldots & \overline{\mathrm{k}}_{2,125} \\
\vdots & \vdots & \ddots & \vdots \\
\overline{\mathrm{k}}_{155,1} & \overline{\mathrm{k}}_{155,2} & \ldots & \overline{\mathrm{k}}_{155,125}
\end{array}\right] \text { where } \overline{\mathrm{k}}_{\mathrm{c}, \mathrm{i}}=\frac{1}{155} \sum_{\mathrm{d}=1}^{155}\left[\log \left(\mathrm{p}_{\mathrm{i}, \mathrm{c}} / \mathrm{S}_{\mathrm{c}}\right)-\log \left(\mathrm{p}_{\mathrm{i}, \mathrm{d}} / \mathrm{S}_{\mathrm{d}}\right)\right]
$$

\footnotetext{
${ }^{24}$ The corresponding measures for the first eigenvalue of consumption correlation matrix are 7.62 and 7.25 . The resulting underestimation is thus $(7.62-7.25) / 14=2.6 \%$.

${ }^{25}$ When $\mathrm{n} \rightarrow \infty$, we have $1 / \mathrm{n} \rightarrow 0$ and $(\mathrm{n}-1) / \mathrm{n} \rightarrow 1$, so that $\gamma_{1} / \mathrm{n} \rightarrow \bar{\rho}$. By definition, we also have $0 \leq \gamma_{1} / \mathrm{n} \leq 1$ and $0 \leq \bar{\rho} \leq 1$. In words, when all items are perfectly correlated (uncorrelated), the first PC captures $100 \%$ $(0 \%)$ of data variation.
} 


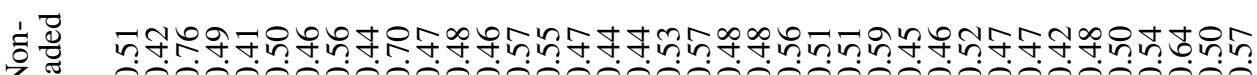
2 I 000000000000000000000000000000000

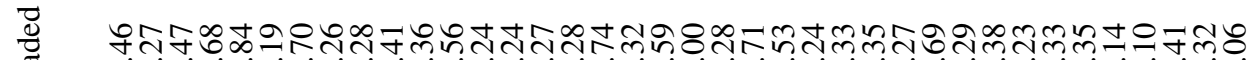
ت

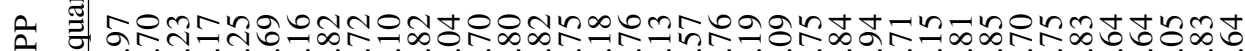

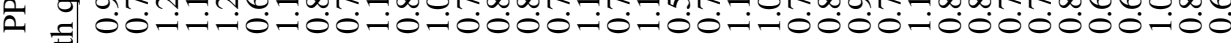

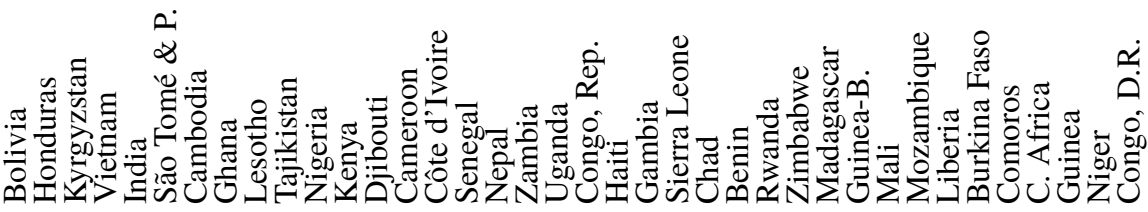
$\dot{0}$ ปニ

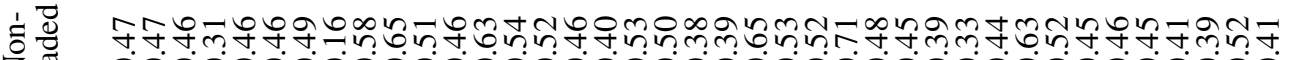
000000000000000000000000000000000000000

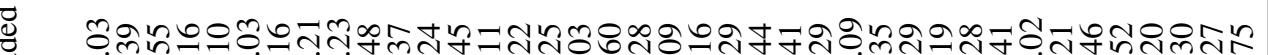
(4) m.

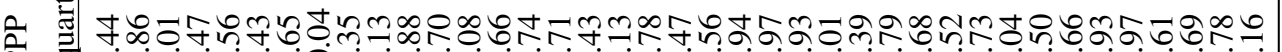

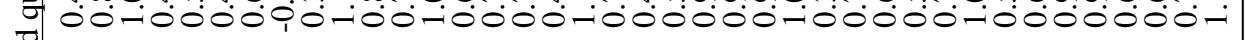

एं ڤ.

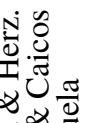

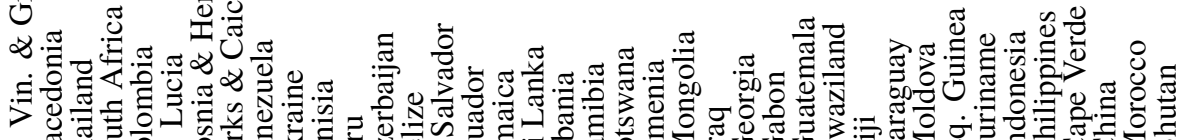

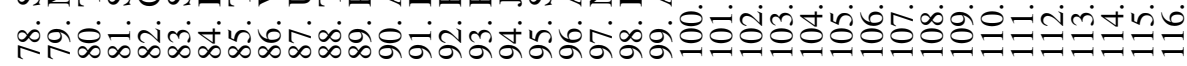

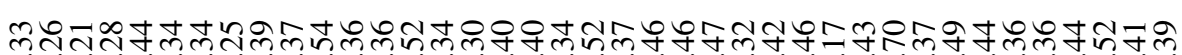
000000000000000000000000000000000000000

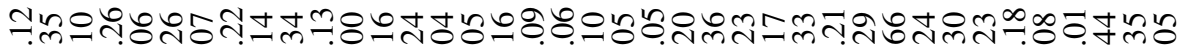

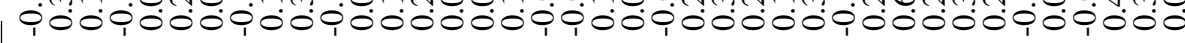

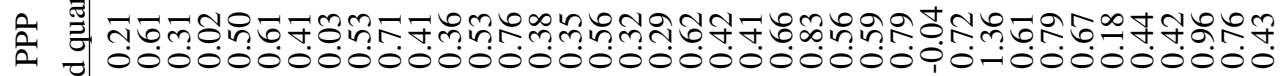

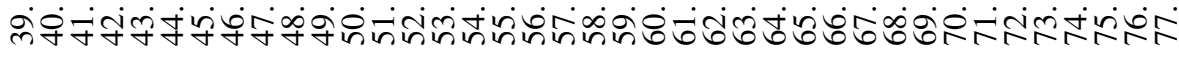

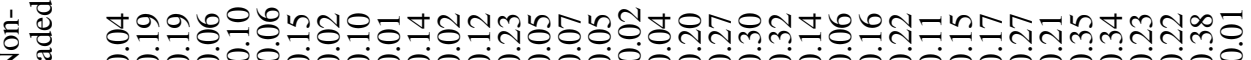
00009000000000000900000000000000000000

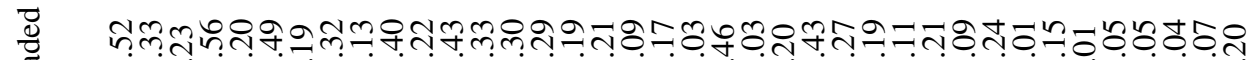

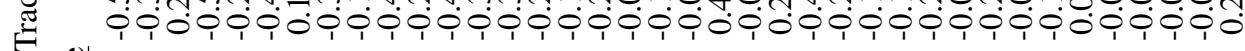
$\stackrel{2}{2}$

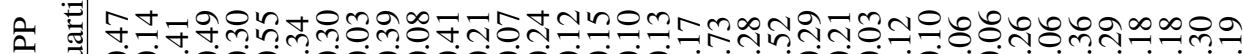

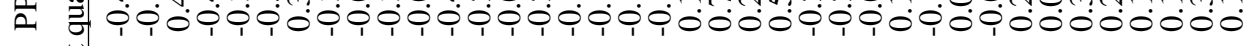
产

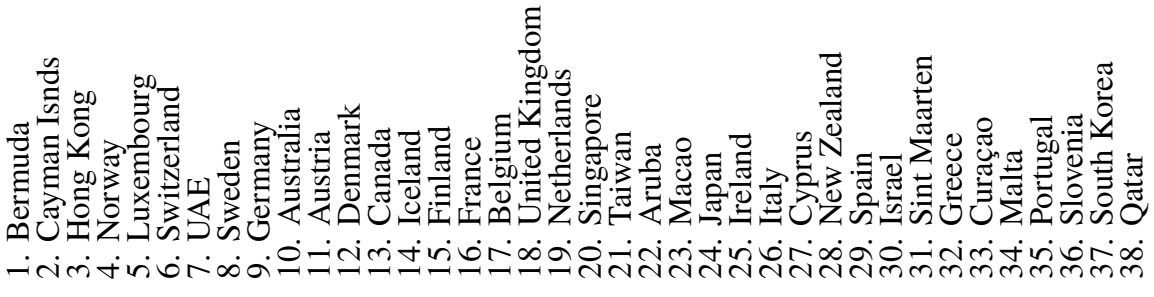




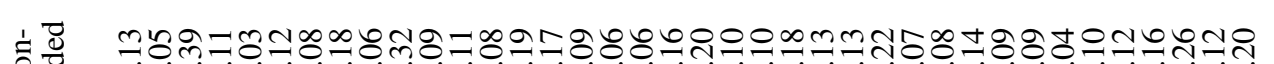

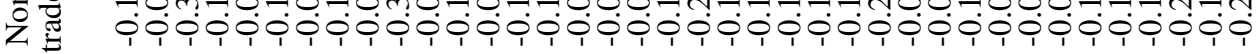

ఫ

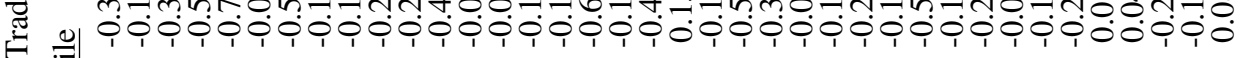

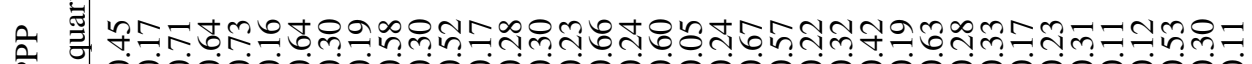

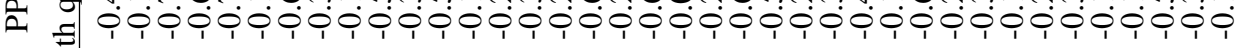
$=\stackrel{\infty}{\infty}$

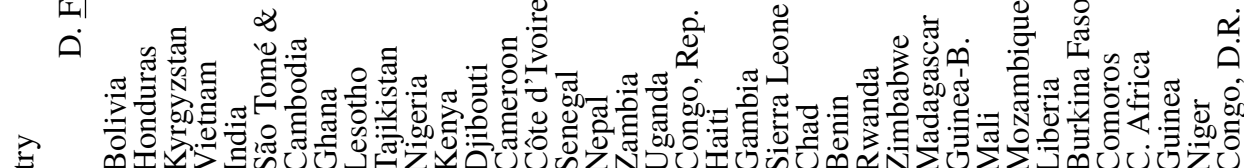

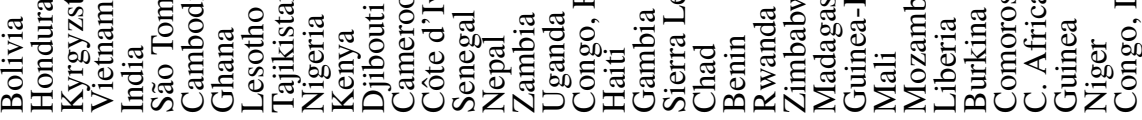
=

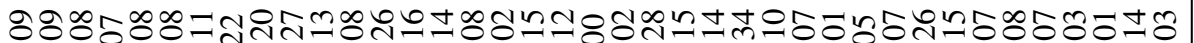

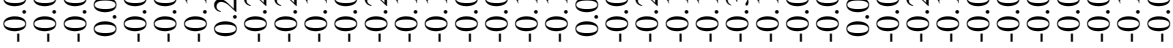

莡

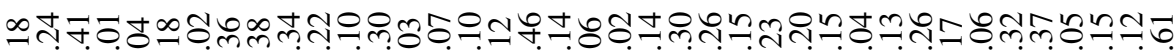
- J0

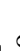

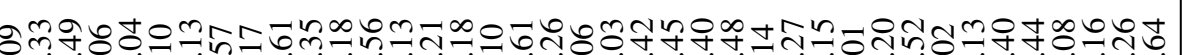

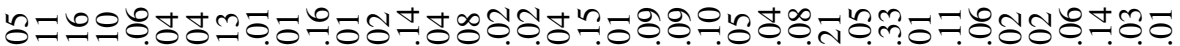

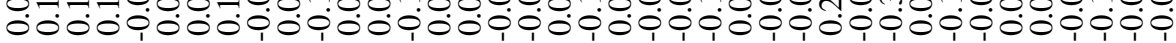

ㅅำ

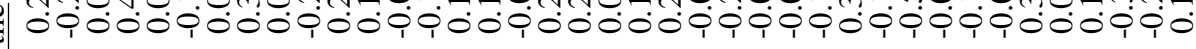

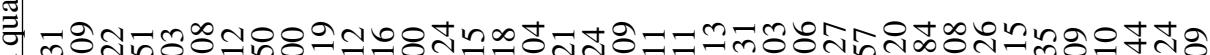
mo:iono ڤ్

ค่<smiles>C1CCCCC1</smiles>

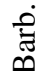

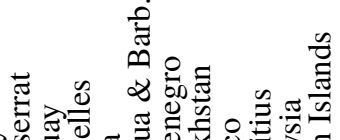<smiles>c1ccccc1</smiles>

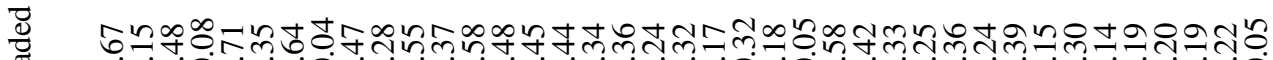

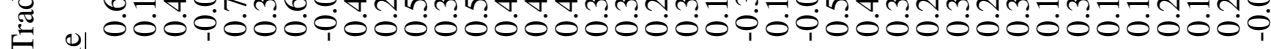

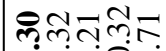
$0000^{\circ}$

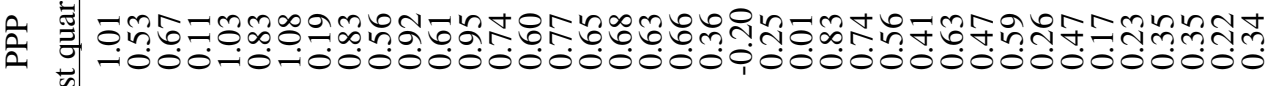
可 
Table A4.6: Loadings On the First Three Principal Dimensions

\begin{tabular}{|c|c|c|c|c|c|c|c|c|}
\hline \multirow[b]{2}{*}{$\begin{array}{c}\text { Basic heading } \\
\text { (1) }\end{array}$} & \multicolumn{4}{|c|}{ A. Relative price } & \multicolumn{4}{|c|}{ B. Consumption } \\
\hline & $\begin{array}{l}\text { PC1 } \\
\text { (2) }\end{array}$ & $\begin{array}{c}\text { PC2 } \\
(3)\end{array}$ & $\begin{array}{c}\text { PC3 } \\
\text { (4) }\end{array}$ & $\begin{array}{l}\text { Other } \\
\text { PCs } \\
(5)\end{array}$ & $\begin{array}{c}\text { PC1 } \\
(6)\end{array}$ & $\begin{array}{c}\text { PC2 } \\
(7)\end{array}$ & $\begin{array}{c}\text { PC3 } \\
(8)\end{array}$ & $\begin{array}{l}\text { Other } \\
\text { PCs } \\
(9)\end{array}$ \\
\hline 1. Fresh or chilled vegetables other than potatoes & 0.02 & 0.51 & 0.25 & & 0.26 & 0.08 & 0.41 & \\
\hline 2. Rice & 0 & -0.47 & -0.11 & & -0.11 & 0.65 & 0.13 & \\
\hline 3. Fresh, chilled or frozen fish and seafood & 0.13 & -0.27 & 0.02 & & 0.14 & 0.59 & -0.19 & \\
\hline 4. Food products nec & -0.42 & -0.15 & -0.08 & & 0.26 & 0.23 & -0.31 & \\
\hline 5. Fresh or chilled fruit & -0.04 & 0.3 & 0.43 & & 0.3 & 0.01 & 0.24 & \\
\hline 6. Mineral waters, soft drinks, fruit and juices & -0.42 & 0.1 & 0 & & 0.33 & 0.02 & -0.15 & \\
\hline 7. Bread & 0 & 0.14 & 0.36 & & 0.3 & -0.08 & 0.1 & \\
\hline 8. Pork + Lamb, mutton and goat & 0.16 & -0.21 & 0.48 & & 0.24 & 0.06 & 0.16 & \\
\hline 9. Other bakery products & -0.38 & -0.01 & 0.17 & & 0.34 & 0 & -0.07 & \\
\hline 10. Confectionery, chocolate and ice cream & -0.34 & 0.11 & -0.18 & & 0.32 & -0.03 & 0.01 & \\
\hline 11. Beer & -0.3 & 0.14 & 0.07 & & 0.23 & -0.28 & -0.46 & \\
\hline 12. Other meats and meat preparations & -0.34 & -0.27 & 0.18 & & 0.31 & -0.15 & -0.16 & \\
\hline 13. Beef and veal & 0.1 & -0.35 & 0.49 & & 0.18 & -0.16 & 0.56 & \\
\hline 14. Poultry & -0.36 & -0.18 & 0.17 & & 0.3 & 0.2 & 0.01 & \\
\hline Eigenvalues/Component variance $\left(\lambda_{i}\right)$ & 639 & 383 & 258 & & 1,166 & 242 & 148 & \\
\hline$\%$ of explained variance $\left(\lambda_{i} / \Sigma_{i=1}^{14} \lambda_{i}\right)$ & 29.8 & 18 & 12 & 40 & 54 & 11 & 7 & 28 \\
\hline Cumulative $\%$ of explained variance & 29.8 & 47.8 & 60 & 100 & 54 & 66 & 73 & 100 \\
\hline
\end{tabular}

Notes: Relative price of item $\mathrm{i}$ in country c is defined as $\mathrm{k}_{\mathrm{i}, \mathrm{c}}=(1 / 155) \Sigma_{\mathrm{d}=1}^{155} \mathrm{k}_{\mathrm{c}, \mathrm{d}}$ where $\mathrm{k}_{\mathrm{c}, \mathrm{d}}$ is the logarithmic difference between the Dollar prices of $i$ in $c$ and $d$. The corresponding relative consumption is $\mathrm{q}_{\mathrm{i}, \mathrm{c}}=(1 / 155) \Sigma_{\mathrm{d}=1}^{155} \mathrm{q}_{\mathrm{c}, \mathrm{d}}$ where $\mathrm{q}_{\mathrm{c}, \mathrm{d}}$ is the logarithmic difference between consumption of $\mathrm{i}$ in $\mathrm{c}$ and $\mathrm{d}$. Columns 2 to 4 of this Table present the values of the first 3 loading vectors (or eigenvectors, of the data matrix $\mathbf{X}^{\prime} \mathbf{X}$ ) for relative prices. Columns 5 to 7 show the loading vectors for consumption. These loadings are coefficients of a linear combination of the original variables to construct new variables (principal components). The last three rows show the corresponding eigenvalues, the contributions of the PCs to total data variation, and the cumulated PC variance contributions. 
SUPPLEMENTARY MATERIALS

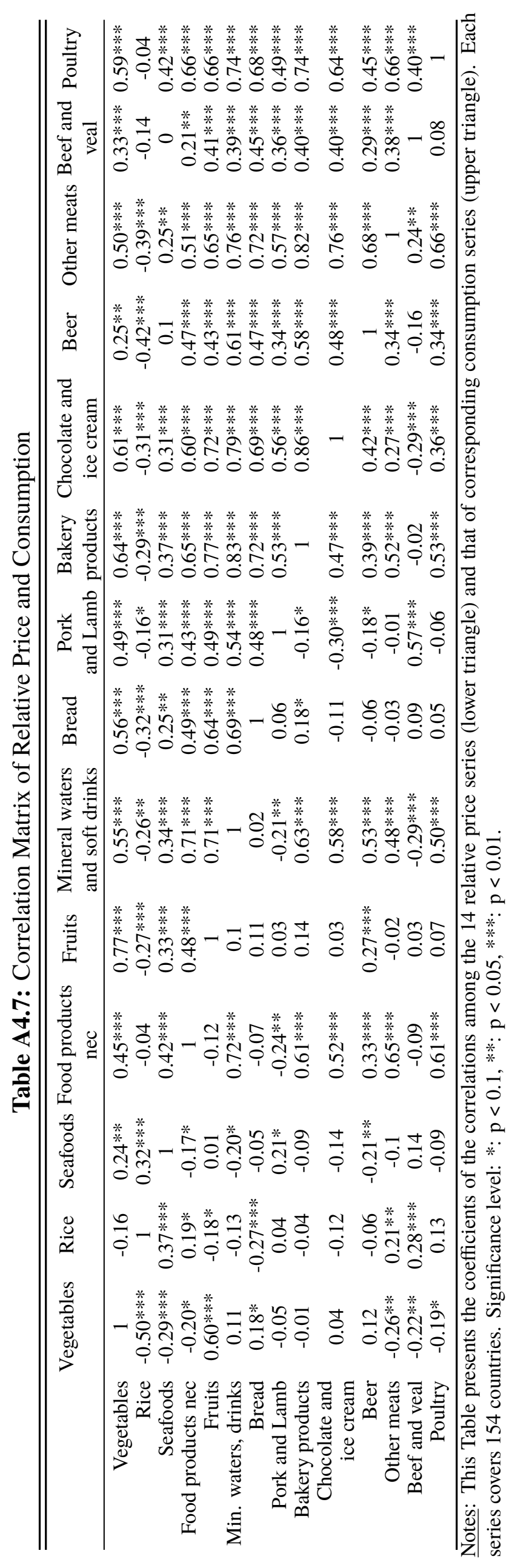




\section{SUPPLEMENTARY MATERIALS}

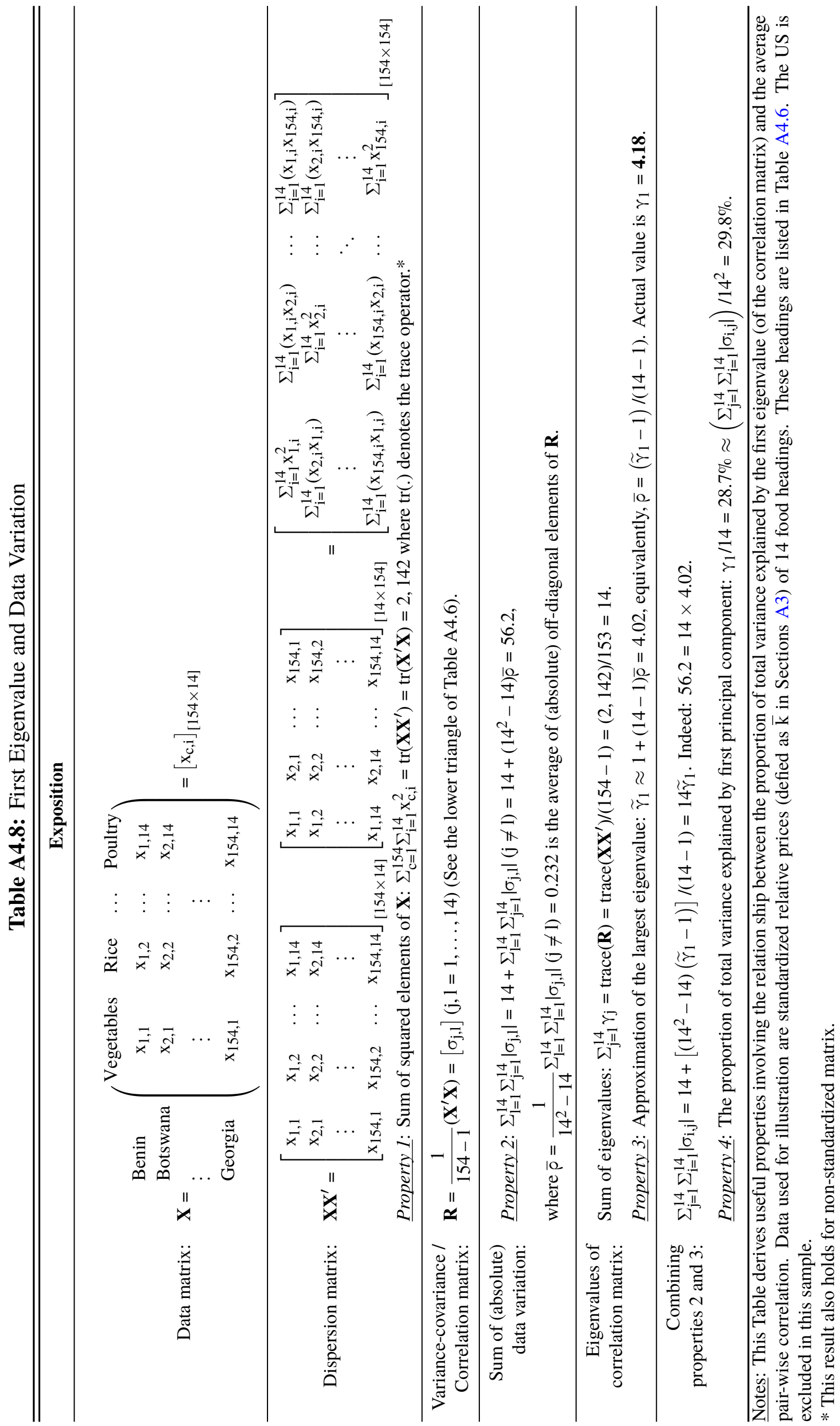


The mean and variance over all items and countries (referred to as "grand" mean and variance) are defined as:

$$
\mu_{\mathrm{k}}=\frac{1}{\mathrm{C} \times \mathrm{I}} \Sigma_{\mathrm{c}=1}^{\mathrm{C}} \Sigma_{\mathrm{i}=1}^{\mathrm{I}} \overline{\mathrm{k}}_{\mathrm{c}, \mathrm{i}} ; \sigma_{\mathrm{k}}^{2}=\frac{1}{\mathrm{C} \times \mathrm{I}} \Sigma_{\mathrm{c}=1}^{\mathrm{C}} \Sigma_{\mathrm{i}=1}^{\mathrm{I}}\left(\overline{\mathrm{k}}_{\mathrm{c}, \mathrm{i}}-\mu_{\mathrm{k}}\right)^{2}(\mathrm{C}=155, \mathrm{I}=125) .
$$

We can rewrite the grand mean as the mean of the column averages:

$$
\mu_{\mathrm{k}}=\frac{1}{\mathrm{I}} \Sigma_{\mathrm{i}=1}^{\mathrm{I}}\left(\frac{1}{\mathrm{C}} \Sigma_{\mathrm{c}=1}^{\mathrm{C}} \overline{\mathrm{k}}_{\mathrm{c}, 1}+\cdots+\frac{1}{\mathrm{C}} \Sigma_{\mathrm{c}=1}^{\mathrm{C}} \overline{\mathrm{k}}_{\mathrm{c}, \mathrm{I}}\right) \text {. }
$$

Since each of these averages equal zero, we have $\mu_{k}=0$. As a result, the grand variance equals the mean of the column variances, which are simply the average sums of squared column elements: $\sigma_{\mathrm{k}}^{2}=\frac{1}{\mathrm{I}} \Sigma_{\mathrm{i}=1}^{\mathrm{I}}\left(\frac{1}{\mathrm{C}} \Sigma_{\mathrm{c}=1}^{\mathrm{C}} \overline{\mathrm{k}}_{\mathrm{c}, 1}^{2}+\cdots+\frac{1}{\mathrm{C}} \Sigma_{\mathrm{c}=1}^{\mathrm{C}} \overline{\mathrm{k}}_{\mathrm{c}, \mathrm{I}}^{2}\right)$. Recall that the $\mathrm{i}^{\text {th }}$ column of $\mathbf{K}$ is the row averages of the price comparison matrix $\mathbf{K}_{\mathbf{i}}$. Clements et al. (2012) show that the variance the row averages of $K_{i}$ and that of each row and column of $\mathbf{K}_{\mathrm{i}}$ all takes the same value, denoted as $\sigma_{\dot{i}}^{2}$, which is also equal to the variance of the underlying price vector $\widetilde{\mathbf{p}}_{\dot{i}}$. Therefore, a more convenient way to express the grand variance is as the mean of the individual items' price variances:

$$
\sigma_{\mathrm{k}}^{2}=\frac{1}{\mathrm{I}} \Sigma_{\mathrm{i}=1}^{\mathrm{I}} \sigma_{\mathrm{i}}^{2}
$$

Now consider the commodity-based variance-covariance matrix of $\mathbf{K}$. The sum of $\mathbf{V}$ 's elements can be viewed as the total data variation and can be decomposed into two components:

$$
\Sigma_{\mathrm{c}=1}^{\mathrm{C}} \Sigma_{\mathrm{i}=1}^{\mathrm{I}} \sigma_{\mathrm{i}, \mathrm{j}}^{2}=\underbrace{\Sigma_{\mathrm{i}=1}^{\mathrm{I}} \sigma_{\mathrm{i}}^{2}}_{\text {Sum of diagonal elements/trace of } \mathbf{V}}+\underbrace{\Sigma_{\mathrm{c}=1}^{\mathrm{C}} \Sigma_{\mathrm{i}=1}^{\mathrm{I}} \sigma_{\mathrm{i}, \mathrm{j}}^{2}(\mathrm{i} \neq \mathbf{j})}_{\text {Sum of off-diagonal elements of } \mathbf{V}}
$$

$$
=\mathrm{I} \sigma_{\mathrm{k}}^{2}+\Sigma_{\mathrm{c}=1}^{\mathrm{C}} \Sigma_{\mathrm{i}=1}^{\mathrm{I}} \sigma_{\mathrm{i}, \mathrm{j}}^{2}(\mathrm{i} \neq \mathrm{j}) .
$$

The second line of the above follows from (A4.8). We can see that the first component is related to the degree of individual items' price dispersion: It is approximately twice the sum of the squared tradability indices derived in Section 3 of the main text. The second component, on the other hand, captures the patterns of price co-variability and can be examined via the PCA described in this section. A similar decomposition can be applied to the total variation of consumption.

\section{A5. Visualizing PCA results}

In Section A4 we show that the first principal component is constructed as the linear combination of the original variables $\mathbf{x}_{\mathbf{i}}$ with the weights (or loadings) given by $\mathbf{a}_{1}: \mathbf{p c}_{1}=\mathbf{X} \mathbf{a}_{1} \cdot{ }^{26}$

\footnotetext{
${ }^{26}$ Note that in Theil (1971)'s formulation, the relationship between $\mathbf{p}_{1}$ and $\mathbf{a}_{1}$ can be interchangeably expressed via two equations: $\mathbf{p} \mathbf{c}_{1}=\left(1 / \lambda_{1}\right) \mathbf{X} \mathbf{a}_{1}$ or $\mathbf{a}_{1}=\mathbf{X}^{\prime} \mathbf{p} \mathbf{c}_{1}$. Here we adopt the notations $\mathbf{p} \mathbf{c}_{1}=\mathbf{X} \mathbf{a}_{1}$ and $\mathbf{a}_{1}=\left(1 / \lambda_{1}\right) \mathbf{X}^{\prime} \mathbf{p} \mathbf{c}_{1}$ for a more straightforward interpretation of the eigenvector/loading vector $\mathbf{a}_{1}$. Note that this leaves the product of the two vectors unchanged. It can then be shown that the first principal component reduces the original sum
} 
We can see that $\mathbf{p c}_{1}$ is a projection of the original data points on the direction of a latent variable. By construction, $\lambda_{1}$ is the largest characteristic root and this projection therefore retains the most variation of the original data points. This also means $\mathbf{p c}_{1}$ would have the same number of observations (155) as our original variables. In a similar manner, if we redo our decomposition with the residual matrix $\left(\mathbf{X}-\mathbf{p c}_{1} \mathbf{a}_{1}^{\prime}\right)^{\prime}\left(\mathbf{X}-\mathbf{p} \mathbf{c}_{1} \mathbf{a}_{1}^{\prime}\right)$, instead of $\mathbf{X}^{\prime} \mathbf{X}$, we shall get a second component which will further reduce the residual variation by an amount of $\lambda_{2}$, and so on. Continuing with this decomposition gives us a total of 14 vectors $p_{i}$ and 14 values of $\lambda_{i}$. An important property of $\lambda_{i}$ is that it coincides with the variance of the $i$-th principal component $\left(\mathbf{p} \mathbf{c}_{\mathbf{i}}\right)$. Therefore, the ratio of $\lambda_{\mathrm{i}}$ and the total variance $\left(\operatorname{tr}\left(\mathbf{X}^{\prime} \mathbf{X}\right)\right)$ can be interpreted as the proportion of variation accounted for by the $\mathrm{i}$-th principal component. Here we further extend the discussions above and introduce a number of graphical tools to examine the output of our PCA. In particular, the workings of the "factor map", and how it helps to visualize the relative positions of the original variables/items and observations/countries with respect to the first two principal components is examined.

\section{PCA for relative prices}

Firstly, we would be interested in visualizing the contributions of original variables to the variation of our first two PCs from the PCA on relative prices. One way to do this is simply looking at the correlation between the first two PCs and these variables: $\rho_{\mathrm{i}, 1}=\operatorname{Corr}\left(\mathbf{x}_{\mathbf{i}}, \mathbf{p c}_{1}\right)$ and $\rho_{i, 2}=\operatorname{Corr}\left(\mathbf{x}_{\mathbf{i}}, \mathbf{p} \mathbf{c}_{2}\right)$. In Figure A5.7 we show an arrow map. Each arrow represents one of the 14 variables/items, and the coordinates of the arrow tips are $\rho_{i 1}$ and $\rho_{i 2}$, on the horizontal and vertical axes, respectively. Items of the same arrow colour belong to the same broad food group. The radius of the correlation circle is one: If variable $\mathrm{i}$ can be perfectly represented by PC1 and PC2, its arrow tip will be positioned exactly on the circle. ${ }^{27}$ In this scenario we have: $\rho_{i, j}^{2}=0(\forall j>2)$, which means all other PCs have no power in explaining the variation of variable i. However, in our case there is no such ideal situation. The variables that exhibit the strongest association with the first two PCs are "Mineral waters, soft drinks, fruit and vegetable juices", "Food products nec", and "Other bakery products", all have absolute correlation coefficients greater than 0.75. "Bread", "Rice" and "Vegetables" exhibit almost no correlation with the first PC. Along the second dimension, "Rice", "Beef and veal" and "Fresh, chilled or frozen fish and seafood" show the strongest association. Additionally, the closeness of the arrows indicates similar pricing behaviour of corresponding items. These arrows' direction also indicates the pair-wise correlation of the items, and indirectly implies item characteristic (dis)similarity. As

of squares by exactly $\lambda_{1}$, that is: $\operatorname{trace}\left[\left(\mathbf{X}-\mathbf{p c}_{1} \mathbf{a}_{1}^{\prime}\right)^{\prime}\left(\mathbf{X}-\mathbf{p c}_{1} \mathbf{a}_{1}^{\prime}\right)\right]=\operatorname{trace}\left(\mathbf{X}^{\prime} \mathbf{X}\right)-\lambda_{1}$.

${ }^{27}$ By construction, for each variable $i$, the sum of squared correlations equals one: $\Sigma_{j=1}^{14} \rho_{i, j}^{2}=1(i=1, \ldots, 14)$. 
can be seen in Figure A5.7, some of the items in the same broad food group exhibit markedly different behaviour. For example, while "Pork and lamb", "Seafood" and "Beef and veal" are quite similar in that they vary mostly with PC1, "Poultry" and "Other meats" seem to belong in a different meat subgroup that exhibits variation mostly along PC2. In the group "Staple", "Rice" shows strong negative correlation with PC2, while "Other bakery products" is strongly negatively correlated with PC1. This exercise points to the fact that grouping items based on broad definition might not be ideal, as their cross-country dynamics can be very different.

Alternatively, we can summarize this two-dimensional information by a "representation quality" measurement for each variable. This measure can be computed as: $\cos _{i}^{2}=\rho_{i, 1}^{2}+\rho_{i, 2}^{2}$, which is the squared length of the arrow. $\cos _{i}^{2}=1$ indicates that the variable can be perfectly represented by a combination of PC1 and PC2. From Figure A5.8 we can see that "Food products nec", "Mineral waters, soft drinks, fruit and vegetable juices" and "Other meats and meat preparations" are the items that seem to be the most appropriately represented by the combination of the first two PCs. In most cases, if an item is well represented by one dimension, it will not be by the other. Additionally, for some other variables, more than two components might be required to perfectly represent the data. These are items that have very low value of $\cos _{\mathrm{i}}^{2}$. In these cases the arrows are closer to the origin. The shortest arrows coincide with "Pork and Lamb" $\left(\rho_{i, 1}=0.32, \rho_{i, 2}=-0.33, \cos _{i}^{2}=0.22\right)$ and "Bread" ( $\left.\rho_{i, 1}=0.009, \rho_{i, 2}=0.22, \cos _{i}^{2}=0.05\right)$.

The second element of a "bi-plot" is the representation of the observations (here, countries) on the factor map, as illustrated in Figure A5.9. Here, the coordinates of each country are the corresponding "scores" of that country on the first two principal directions. In other words, they are the realizations of the two new variables: $\mathbf{p} \mathbf{c}_{1}=\mathbf{X} \mathbf{a}_{1}$ and $\mathbf{p} \mathbf{c}_{2}=\mathbf{X} \mathbf{a}_{2}$. For each country, the new "score" is a linear combination of its original prices for all items. Let's take the country with the highest income, "Bermuda", as an example. The new score of Bermuda along the first principal direction is: $\mathrm{pc}_{1,1}=\Sigma_{\mathrm{i}=1}^{14} \mathrm{x}_{\mathrm{i}, 1} \times \mathrm{a}_{\mathrm{i}, 1}$. Higher scores imply better representation by the first PC. Along the X-axis of Figure A5.9, we can see that the countries are generally arranged (from left to right) in an order of increasing income. This is expected, since the first PC is shown to be strongly and positively correlated with income. The countries are colour-coded by their income groups (or quartiles). The plot of 154 countries is perhaps too cluttered for identification, however. Cross-country behaviour may be heavily affected by determinants such as geographical and/or cultural "closeness". We examine this possibility by restricting the sample to only some of the highly developed countries, the OECD group. To be specific, these are the countries that are designated as "Eurostat-OECD" in the ICP data. We group these 
Figure A5.7: Correlation Circle of Relative Price, 14 Items, 154 Countries PCA - Relative prices (Food Items)

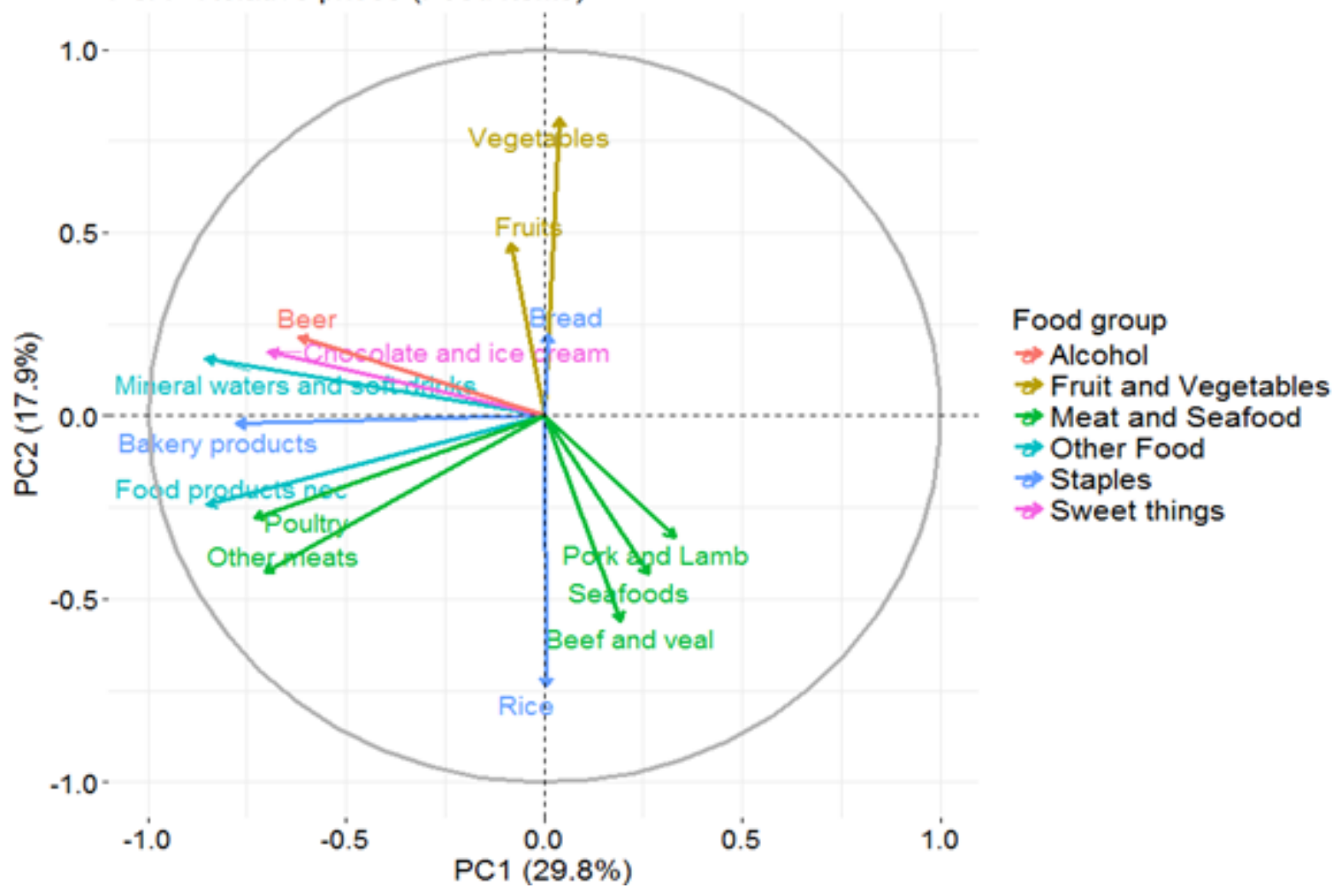

Notes: This Figure visualizes the correlation between each of the 14 original variables (14 food prices) and the first two principal components. The coordinates of the arrow on the two axes are the corresponding correlations. The length of the arrows represents the total explanatory power of the PCs for said variables. The percentages in the axes' titles indicate the proportion of variation explained by these PCs.

Figure A5.8: Quality of Relative Price Representation, 14 Items, 154 countries

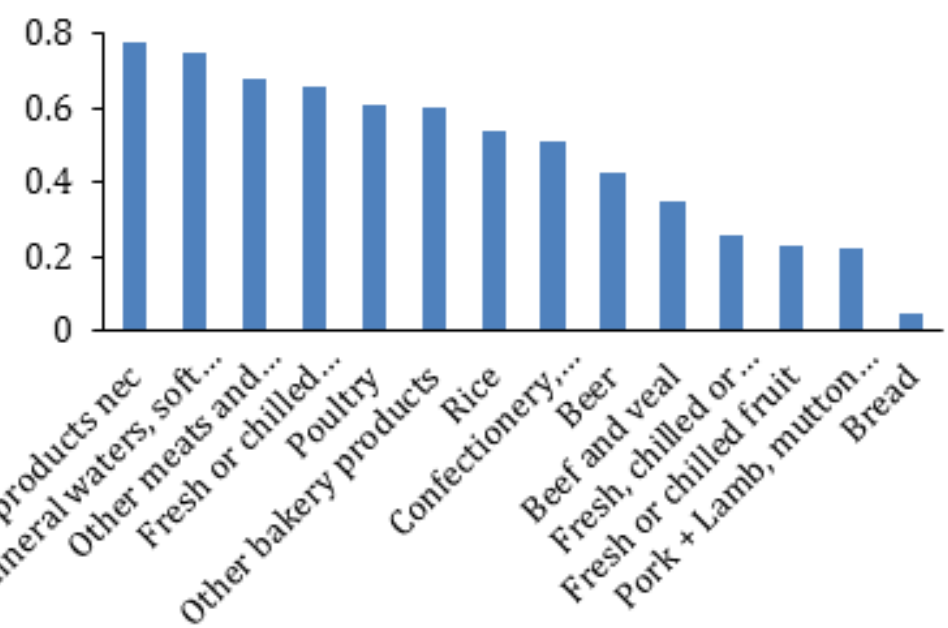

Notes: This Figure presents the quality of PC1 and PC2 in representing each original variable, constructed as $\cos _{i}^{2}=\rho_{i, 1}^{2}+\rho_{i, 2}^{2}$ where $\rho_{i, 1}$ and $\rho_{i, 1}$ are the correlations between the corresponding variable and PC1 and PC2, respectively. This measure of quality shows how well a variable can be represented by a combination of PC1 and PC2.

countries into 10 geographical areas, as indicated in Figure A5.10. Compared with the full sample analysis, here the explanatory power of PC1 and PC2 declines slightly - to $28 \%$ and $16 \%$, respectively. The points that lie close to each other, such as those of Luxembourg, France 
and Netherlands, or Austria and Germany, or Australia and New Zealand, can be identified as very similar in terms of their pricing pattern. That is, if an item is relative more expensive in one country, it is likely to be just as expensive in countries that are located close to it in the factor map. In this regard, East Asian countries (Japan and South Korea) are possible outliers of the OECD. The similarity of pricing seems to be driven mostly by geographical factors.

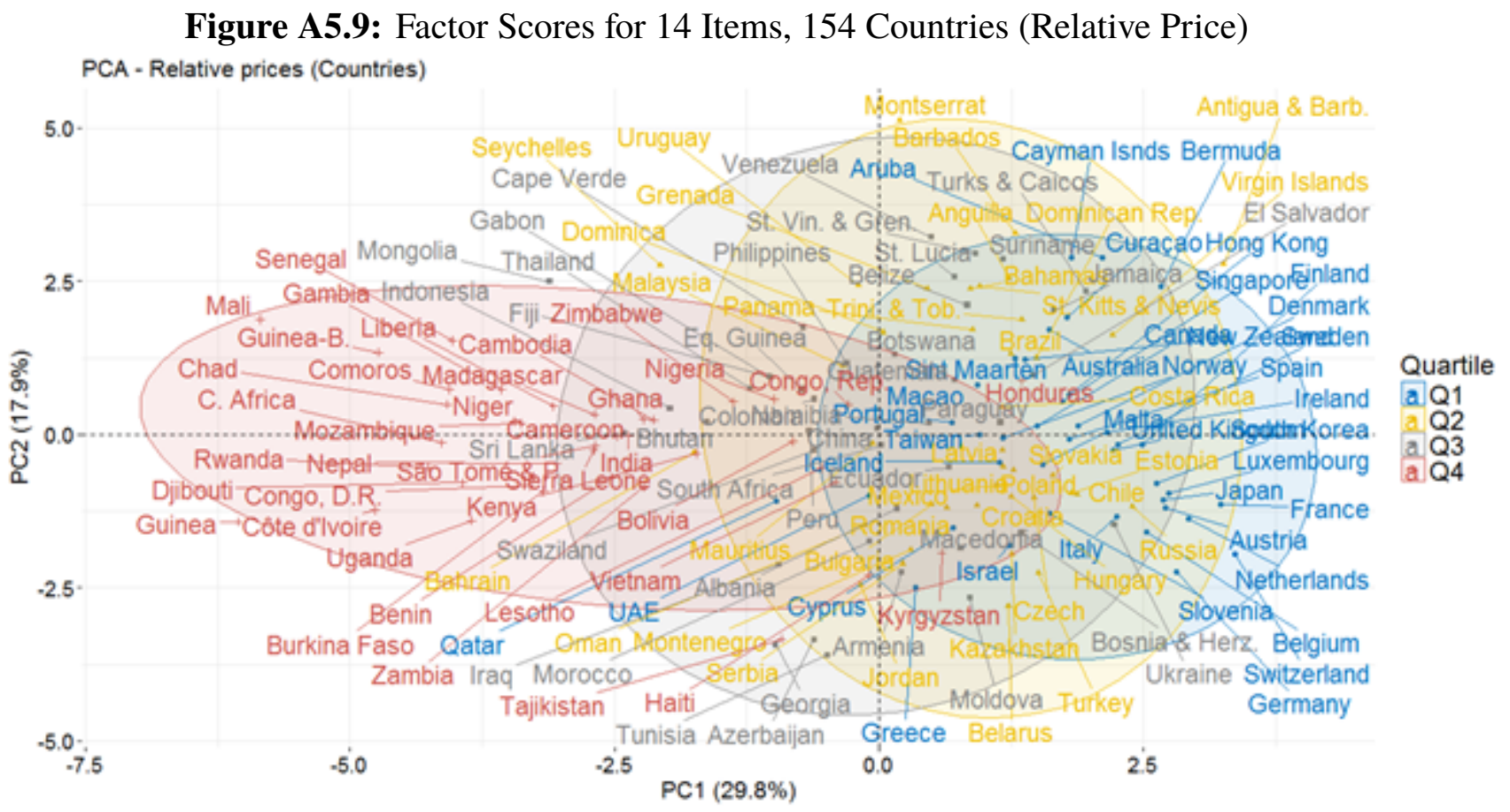

Notes: This figure presents the "scores" (positions) of all countries along the first and second principal directions. Countries are grouped and colour-coded by income quartiles (with Q1 is the richest). Concentration ellipses are added to further distinguish country by income clusters. The percentages in the axes' titles indicate the proportion of variation explained by these PCs.

\section{PCA for consumption}

We have shown that the bi-plots are powerful tools that offer interesting insights about the pattern of global food relative prices. Along the same line, we can explore similar characteristics in terms of consumption behaviour. The underlying variable of this analysis is $\log \mathrm{q}_{\mathrm{ic}}$. For the consumption/real per capita consumption, the correlations of PCs and the 14 variables are now markedly changed: In Figure A5.11 we can see the majority of the cross-country consumptions exhibit strong correlation with PC1, while "Rice" and "Fresh, chilled or frozen fish and seafood" tilt toward the second PC. Overall these variables are much better represented by the two PCs, as evidence in the arrows' length. In Figure A5.12, similar to the factor map of PCA on relative prices, here the countries arrange along the first principal direction quite well, especially for the poorest economies. The correlations of the first PC with relative income and food budget share are 0.93 and -0.72 , respectively. Examining the OECD sample reveals that compared with the full sample analysis, the consumption behaviour among these countries is more diverse, 
Figure A5.10: Factor Scores for 14 Items, 46 OECD-Eurostat Countries (Relative Price) PCA - Relative prices (OECD Countries)

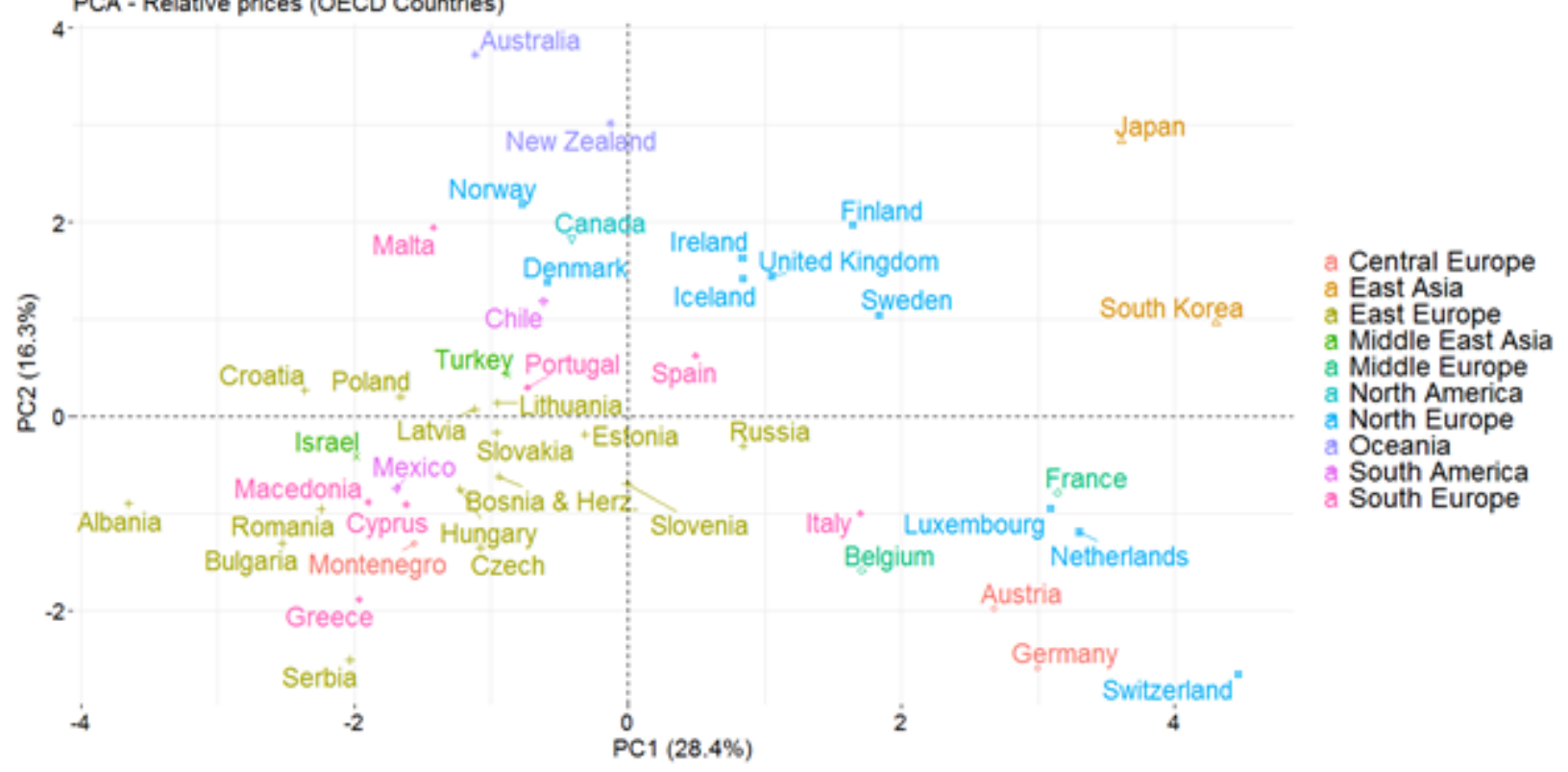

Notes: This figure presents the "scores" (positions) of all countries designated as "OECD-Eurostat" along the first and second principal directions. Countries are grouped and color-coded by geographical areas. The percentages in the axes' titles indicate the proportion of variation explained by these PCs.

resulting in a large drop of PC1 and PC2's explanatory power (from 54\% to $26 \%$ and from $18 \%$ to $15.6 \%$, respectively). Nevertheless, compared with the result of relative prices (as in Figure A5.9), the countries' scores now form more visible clusters, implying greater similarity among the grouped countries. Japan and South Korea still exhibit features of outliers, together with Albania and Romania.

\section{PCA for relative consumption}

In Section 5.2 we show that the explanatory power of income to $\mathrm{PC} 1$ of consumption is much higher than the corresponding impact to $\mathrm{PC} 1$ of prices. If the common factor driving the cross country dispersion of consumption is essentially income, then a similar analysis on the difference between consumption and income should yield lower adjusted $\mathrm{R}^{2}$. We construct two new measures of "relative consumption" as consumption deflated by (i): Income and (ii): Weighed average consumption. The corresponding measures are $\log \mathrm{q}_{\mathrm{ic}}-\log \left(\mathrm{Y}_{\mathrm{c}} / \overline{\mathrm{Y}}\right)$ and $\log \mathrm{q}_{\mathrm{ic}}-\Sigma_{\mathrm{i}=1}^{\mathrm{n}} \mathrm{w}_{\mathrm{ic}} \log \mathrm{q}_{\mathrm{ic}}=\log \mathrm{q}_{\mathrm{ic}}-\log \mathrm{Q}_{\mathrm{c}}$ where $\mathrm{w}_{\mathrm{ic}}$ denotes the expenditure share of $\mathrm{i}$ and $\mathrm{n}$ is the number of all items at each level. It can be seen that the second measure is analogous to the relative price variable used. Table A5.9 presents the results. As can be seen, the outputs of PCA for the two measures are almost identical, and the magnitudes of correlations between PC1 and income are significantly reduced. 
Figure A5.11: Correlation Circles of Consumption, 14 Items, 154 Countries PCA - Quantities (Food items)

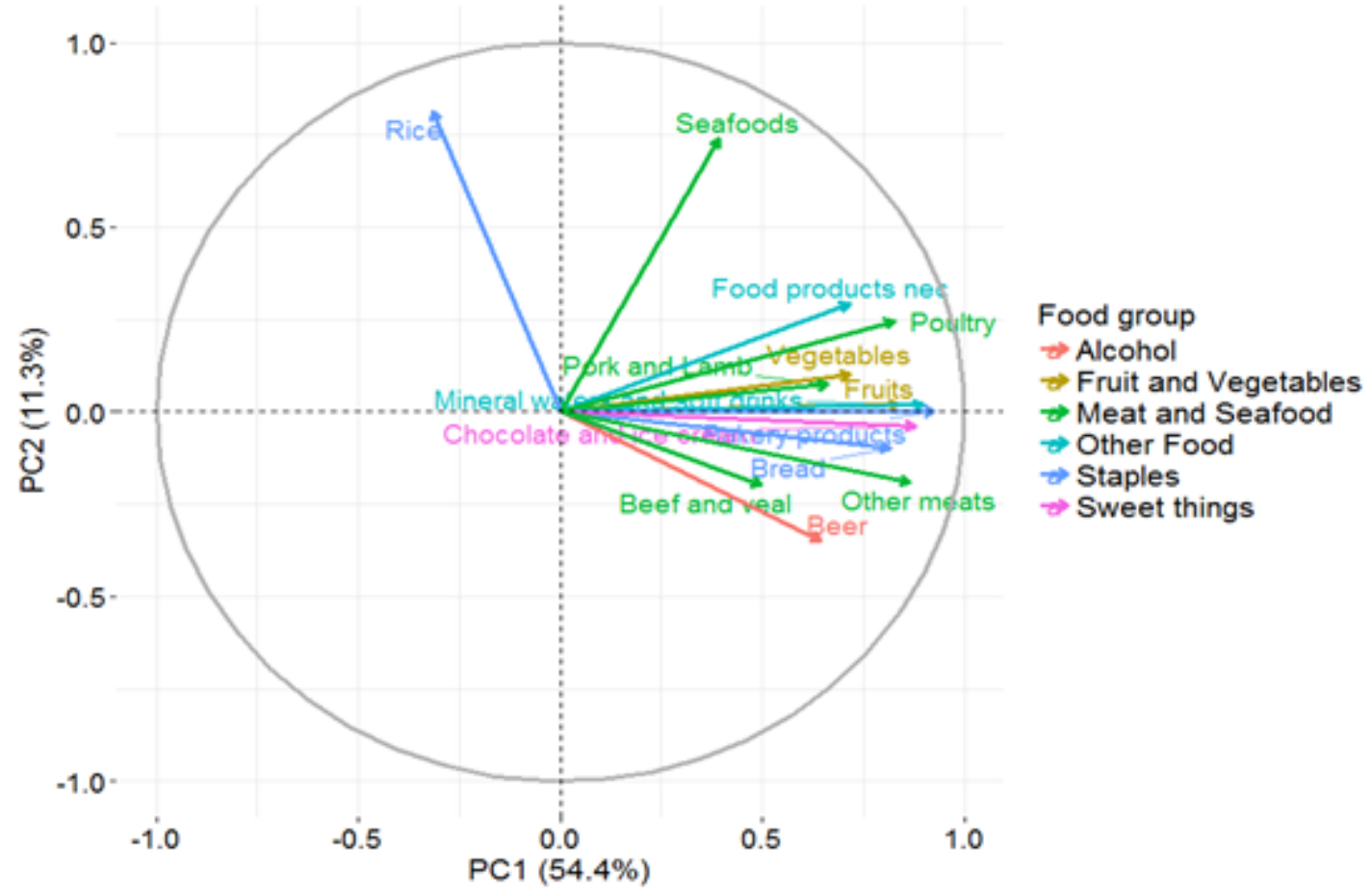

Notes: See notes to Figure A5.7.

Figure A5.12: Factor Scores for 14 Items, 154 Countries (Consumption)

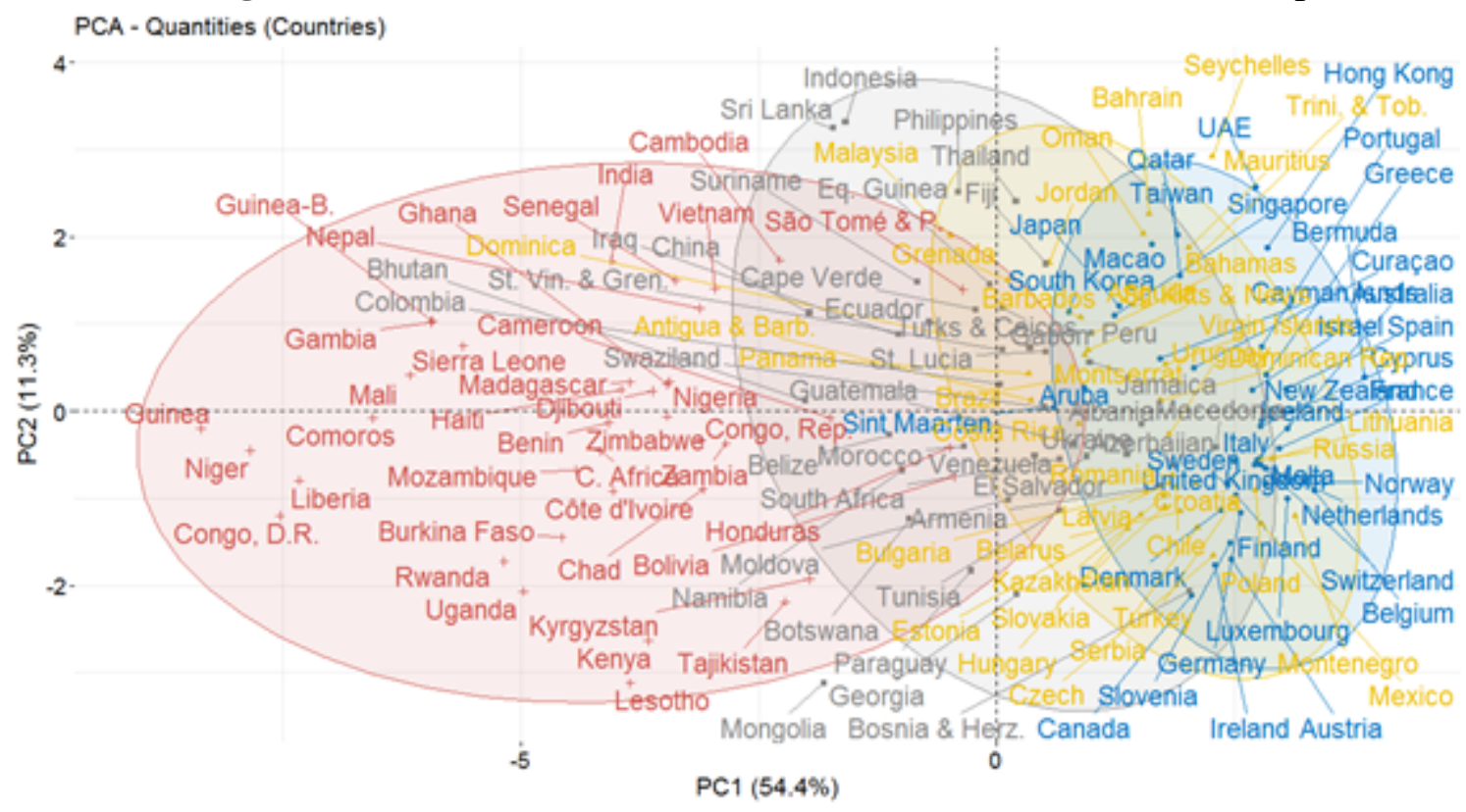

Notes: See notes to Figure A5.9. 
Figure A5.13: Factor Scores for 14 Items, 46 OECD-Eurostat Countries (Consumption) PCA - Quantity (OECD Countries)

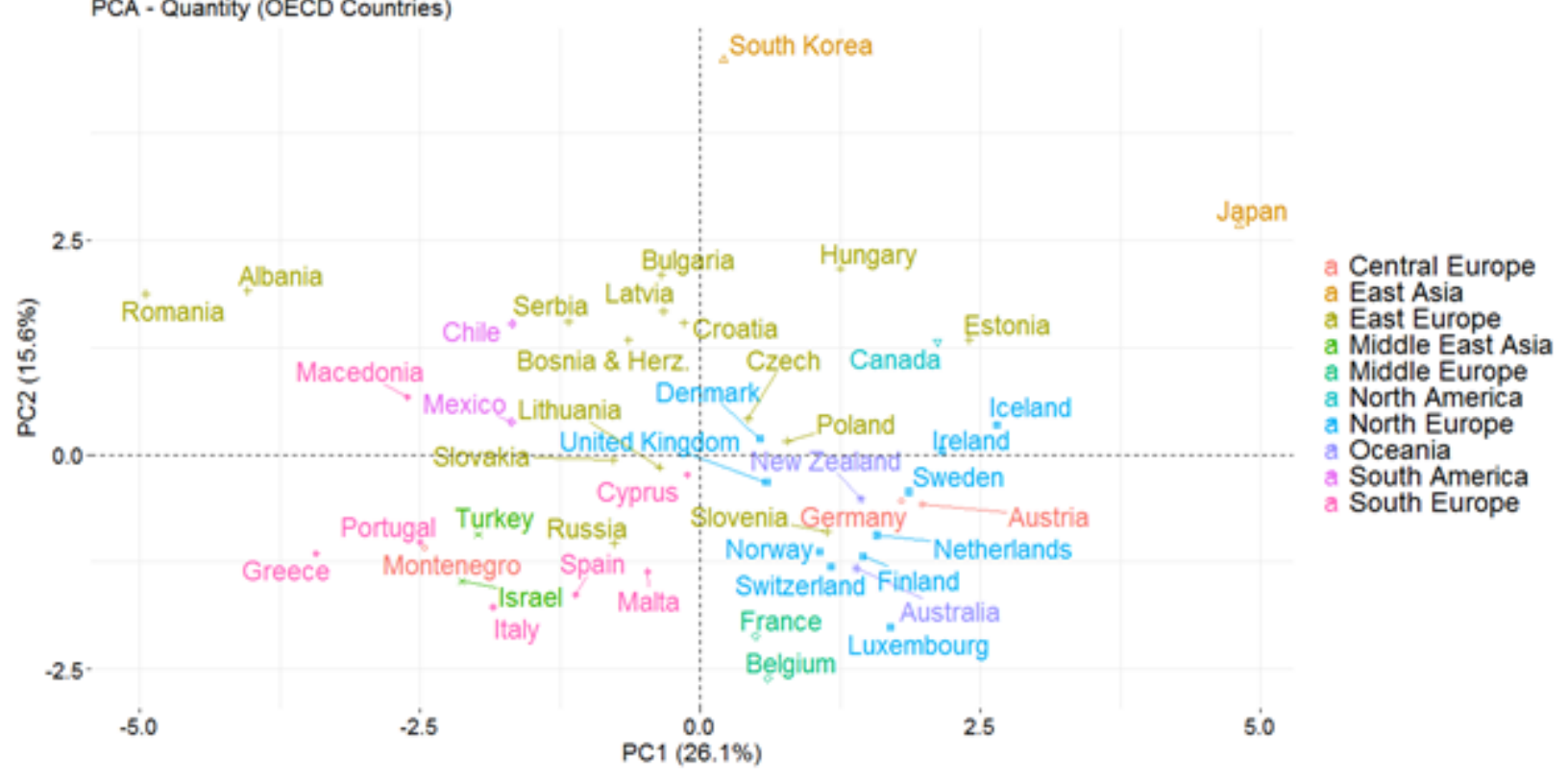

Notes: See notes to Figure A5.10.

Table A5.9: PCA Results for Relative Consumption

\begin{tabular}{|c|c|c|c|c|c|c|c|}
\hline Aggregation level & $\begin{array}{c}\text { No. of } \\
\text { variables/items }\end{array}$ & $\begin{array}{c}\text { PC1 } \\
\text { contribution }(\%)\end{array}$ & $\begin{array}{l}\text { No. of PCs required } \\
\text { for }>80 \% \text { contribution }\end{array}$ & \multicolumn{2}{|c|}{$\begin{array}{l}\text { Correlation between } \\
\text { PC1 and } \log \left(\mathrm{Y}_{\mathrm{c}} / \overline{\mathrm{Y}}\right)\end{array}$} & \multirow{2}{*}{$\begin{array}{l}\text { SD } \\
(7)\end{array}$} & \multirow{2}{*}{$\begin{array}{c}\text { SD } \\
\text { weighted } \\
\text { (8) }\end{array}$} \\
\hline (1) & (2) & (3) & (4) & $\frac{\text { Coefficient }}{(5)}$ & $\frac{t-s t a t}{(6)}$ & & \\
\hline \multicolumn{8}{|c|}{ A. Deflated consumption $\left[\log \mathrm{q}_{\mathrm{ic}}-\log \left(\mathrm{Y}_{\mathrm{c}} / \overline{\mathrm{Y}}\right)\right]$} \\
\hline Basic heading & 125 & 26.5 & 19 & 0.56 & 8.39 & 2.81 & \\
\hline Class & 101 & 30.9 & 17 & 0.55 & 8.2 & 2.83 & \\
\hline Group & 48 & 46.9 & 7 & 0.46 & 6.47 & 2.84 & \\
\hline Category & 16 & 71.8 & 2 & 0.32 & 4.22 & 2.58 & \\
\hline Main Aggregate & 2 & 98.2 & 1 & 0.53 & 7.67 & 0.93 & \\
\hline \multicolumn{8}{|c|}{ B. Relative consumption $\left(\log \mathrm{q}_{\mathrm{ic}}-\Sigma_{\mathrm{i}=1}^{\mathrm{n}} \mathrm{w}_{\mathrm{i}} \log \mathrm{q}_{\mathrm{ic}}\right)$} \\
\hline Basic heading & 125 & 25.5 & 19 & 0.57 & 8.45 & 2.83 & 1.4 \\
\hline Class & 101 & 29.8 & 17 & 0.56 & 8.26 & 2.85 & 1.32 \\
\hline Group & 48 & 44.5 & 7 & 0.48 & 6.66 & 2.87 & 1.26 \\
\hline Category & 16 & 69.2 & 2 & 0.31 & 4.03 & 2.6 & 0.82 \\
\hline Main Aggregate & 2 & 99.8 & 1 & 0.54 & 7.98 & 0.95 & 0.41 \\
\hline
\end{tabular}

Notes: This table reports the correlation between the first principal component and real income (at each aggregation level) for all consumption items. The underlying variables for PCA are: Deflated consumption (panel A), relative consumption (panel B). Column (2) indicates the number of headings that have positive expenditure (these are documented in Table A1.3). Column (7) shows the standard deviation of the variables (across items and

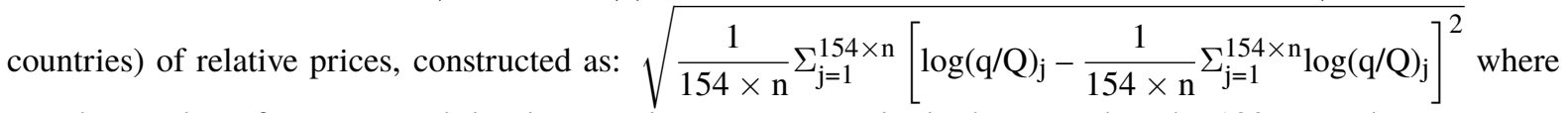
$\mathrm{n}$ is the number of items at each level. For relative prices, multiply these numbers by 100 gives the percentage difference. Column (8) shows the average of the square root of the weighted variance: $1 / 154 \Sigma_{\mathrm{c}=1}^{154} \sqrt{\Pi_{\mathrm{c}}}$ where $\Pi_{\mathrm{c}}=\Sigma_{\mathrm{i}=1}^{\mathrm{n}} \mathrm{w}_{\mathrm{ic}}\left(\log \mathrm{q}_{\mathrm{ic}}-\log \mathrm{Q}_{\mathrm{c}}\right)^{2} \cdot \log \left(\mathrm{Y}_{\mathrm{c}} / \overline{\mathrm{Y}}\right)$ is the per capita income of country c relative to the cross-country geometric mean. 


\section{APPENDIX REFERENCES}

Balk, B. (1996). A comparison of ten methods for multilateral international price and volume comparison. Journal of Official Statistics 12(2), 199 - 222.

Barnett, W. A., W. E. Diewert, and A. Zellner (2009). Introduction to Measurement with Theory. Macroeconomic Dynamics 13(S2), $151-68$.

Betts, C. M. and T. J. Kehoe (2017). Real exchange rate movements and the relative price of non-traded goods. USC-INET Research Paper No. 17-31. Working paper 14437, National Bureau of Economic Research.

Campbell, N. A. and W. R. Atchley (1981). The geometry of canonical variate analysis. Systematic Biology 30(3), 268 - 80.

Cattell, R. B. (1966). The scree test for the number of factors. Multivariate Behavioral Research 1(2), $245-76$.

Clements, K. W. and Y. Lan (2007). Exchange rates, productivity, poverty and inequality. Applied Economics 39(4), 471 - 76.

Clements, K. W., Y. Lan, and S. P. Seah (2012). The Big Mac Index two decades on: An evaluation of Burgernomics. International Journal of Finance and Economics 17(1), 31 -60 .

Clements, K. W. and J. Si (2017). Engel's law, diet diversity, and the quality of food consumption. American Journal of Agricultural Economics 100(1), 1 - 22.

Cuthbert, J. (2009). Implicit data structure and properties of selected additive indices. In P. Rao (Ed.), Purchasing Power Parity: Recent Advances in Methods and Applications, Volume 2, Chapter 7, pp. 160 - 80. Cheltenham: Edward Elgar.

Deaton, A. and B. Aten (2017). Trying to understand the PPPs in ICP 2011: Why are the results so different? American Economic Journal: Macroeconomics 9(1), 243 - 64.

Deaton, A. and A. Heston (2010). Understanding PPPs and PPP-based national accounts. American Economic Journal: Macroeconomics 2(4), 1 - 35.

Diewert, W. E. (1999). Axiomatic and economic approaches to international comparisons. In A. Heston and R. E. Lipsey (Eds.), International and Interarea Comparisons of Income, Output, and Prices, Volume 61 of Studies in Income and Wealth, pp. 13 - 107. Chicago: University of Chicago Press.

Diewert, W. E. (2013). Methods of aggregation above the basic heading level within regions. In The Real Size of the World Economy: The Framework, Methodology, and Results of the International Comparison Program, Chapter 5, pp. 121 - 68. Washington, DC: World Bank.

Dikhanov, Y. (1997). Sensitivity of PPP-based income estimates to choice of aggregation procedures. Development Data Group, International Economics Department, The World Bank, Washington DC, January.

Eltetö, O. and P. Köves (1964). On a problem of index number computation relating to international comparison. Statisztikai Szemle 42(10), 507 - 18.

Engel, C. (1999). Accounting for U.S. real exchange rate changes. Journal of Political Economy 107(3), $507-38$.

Feenstra, R. C., H. Ma, and D. P. Rao (2009). Consistent comparisons of real incomes across time and space. Macroeconomic Dynamics 13(S2), $169-93$.

Friedman, S. and H. F. Weisberg (1981). Interpreting the first eigenvalue of a correlation matrix. Educational and Psychological Measurement 41(1), 11 - 21.

Geary, R. C. (1958). A note on the comparison of exchange rates and purchasing power between countries. Journal of the Royal Statistical Society. Series A (General) 121(1), 97 - 9.

Gini, C. (1931). On the circular test of index numbers. International Review of Statistics 9(2), $3-25$. 
Guttman, L. (1954). Some necessary conditions for common-factor analysis. Psychometrika 19(2), $149-61$.

Iklé, D. M. (1972). A new approach to the index number problem. Quarterly Journal of Economics 86(2), 188 - 211.

International Comparison Program (2011). 2011 ICP Data Access and Archiving Policy. Stage I: Guilding Principles for Data Access. Retrieved from: http://pubdocs . worldbank. org/en/703631487200786325/110210-ICP-EB04-DataAccess.pdf.

Kaiser, H. F. (1960). The application of electronic computers to factor analysis. Educational and psychological measurement 20(1), $141-51$.

Khamis, S. H. (1972). A new system of index numbers for national and international purposes. Journal of the Royal Statistical Society 135(1), 96 - 121.

Morrison, D. R. (1967). Multivariate Statistical Methods. New York: McGraw-Hill.

Neary, J. P. (2004). Rationalizing the Penn World Table: True multilateral indices for international comparisons of real income. American Economic Review 94(5), 1411 28.

Ponomareva, N., J. Sheen, and B. Z. Wang (2019). The common component of bilateral US exchange rates: To what is it related? Empirical Economics 56(4), $1251-68$.

Rao, P. D. S. (2013). The framework of the international comparison program. In P. D. S. Rao (Ed.), Measuring the Real Size of the World Economy: The Framework, Methodology, and Results of the International Comparison Program -ICP, Chapter 1, pp. 13 - 45. Washington, DC: World Bank.

Stock, J. H. and M. W. Watson (2002a). Forecasting using principal components from a large number of predictors. American Statistical Association 97(460), 1167 - 79.

Stock, J. H. and M. W. Watson (2002b). Macroeconomic forecasting using diffusion indexes. Journal of Business and Economic Statistics 20(2), 147 - 62.

Szulc, B. (1964). Indices for multiregional comparisons. Przeglad Statystyczny 3, 239 - 54.

Theil, H. (1971). Principles of Econometrics. California: Wiley.

Vo, L. H. (2020). Exchange rates, Prices and Consumption. Ph.D thesis, Economics Department, Business School, the University of Western Australia. Avaialable at: https://research-repository.uwa.edu.au/en/publications/ exchange-rates-prices-and-consumption.

World Bank (2013a). 2011 International Comparison Program Data. Online database. [Accessed in Jun 2018]. Available at: http://siteresources.worldbank.org/ ICPEXT/Resources/ICP_2011.html.

World Bank (2013b). Measuring the Real Size of the World Economy: The Framework, Methodology, and Results of the International Comparison Program-ICP. Washington, DC: World Bank.

World Bank (2013c). 2011 International Comparison Program Data for Researchers. Unpublished. 